\title{
MODELOS EUROPEOS DE EUTANASIA Y SUICIDIO ASISTIDO EN HOLANDA, BÉLGICA, SUIZA, LUXEMBURGO Y FRANCIA ${ }^{1}$
}

\section{Maria Lourdes Labaca Zabala ${ }^{2}$}

\section{Resumen:}

Algunos países europeos, han reconocido la eutanasia y/o el suicido asistido. Procedemos a concretar las Leyes que se han promulgado en Holanda, Bélgica, Suiza y Luxemburgo, así como las Proposiciones que no han prosperado en Francia. Destacaremos, también, la posición que ha mantenido el Consejo de Europa en relación con la protección de la dignidad del paciente en la fase terminal y los cuidados paliativos. Concluiremos con el régimen de protección de los cuidados paliativos en España. Entendemos que estamos en presencia de un derecho que corresponde a todo paciente en la fase final de su vida.

Palabras clave: Eutanasia, Suicidio asistido, Enfermos terminales, Modelos europeos, Consejo de Europa

\section{INTRODUCCIÓN}

Durante los últimos años se han manifestado distintas posiciones en la sociedad española en relación con los tratamientos que reciben los pacientes en la fase final de su vida. Las personas que padecían estas situaciones y sus familias han recurrido, en algunas ocasiones, a los tribunales con la finalidad de poder concluir con los sufrimientos que padecían.

A pesar de que en España no se ha logrado el consenso suficiente para proceder a la regulación del derecho a la eutanasia o al suicidio asistido, hemos de indicar que, en algunos países de nuestro entorno, caso de Holanda, Bélgica, Suiza y Luxemburgo, sí lo han desarrollado, sin olvidar el caso de Francia, país en el que no han prosperado las distintas Proposiciones de Ley que se han presentado al Parlamento.

La disposición de la propia vida de un enfermo terminal, puede revestir la forma de eutanasia o de suicido médicamente asistido. Cabe distinguir ambas prácticas atendiendo al agente causal directo e inmediato de la muerte del paciente: alguien diferente al propio paciente en el caso de la eutanasia, o bien, en el caso del suicido médicamente asistido, la propia persona enferma es quien se auto administra él los fármacos

\footnotetext{
${ }^{1}$ Investigación realizada con el Proyecto de Investigación de la UPV/EHU (2013-2014), Código NUPV 13/01, sobre el tema: "Los derechos de los pacientes en el ámbito sanitario en España y Francia". Estancias realizadas en el Tribunal Europeo de Derecho Humanos de Estrasburgo en abril de 2014 y Tribunal de Justicia de la Unión Europea de Luxemburgo, en mayo de 2014.

${ }^{2}$ Profesora Agregada de la Facultad de Derecho de la UPV/EHU.E-mail: marialourdes.labaca@ehu.es
} vol.07, nº. 02, Rio de Janeiro, 2014.pp. 892-1009 
que pondrán fin a su vida de acuerdo con su voluntad. La expresión "médicamente asistido" precisa que para llevar a cabo su acción ha de contar con la colaboración expresa de un médico, por lo general mediante la prescripción de fármacos, o la puesta a punto de algún dispositivo, que permitirá al paciente causarse la muerte en el momento que éste desee. Este médico colaborador puede estar presente o no en el momento en el que el paciente tome la decisión de poner fin a su vida, cuestión que no debe considerarse esencial. En el caso de que la persona no requiera ayuda de otro para su suicidio, suele hablarse de "auto liberación".

Es por ello que, procederemos a desarrollar las distintas Leyes que se han pronunciado en los países en los en los que se reconoce la eutanasia o el auxilio al suicidio o suicidio asistido. Así también, nos ocuparemos de ver la posición que ha mantenido el Consejo de Europa en relación con la eutanasia, el suicidio asistido y los cuidados paliativos a través de distintas Recomendaciones. Finalmente, trataremos los cuidados paliativos en España.

\section{LA LEY HOLANDESA 26691/2001, "LEY DE TERMINACIÓN DE LA VIDA A PETICIÓN PROPIA Y DEL AUXILIO AL SUICIDIO”}

Se logra definitivamente legalizar la eutanasia en Holanda el año 2001 incluyendo una eximente en el Código penal, para que el médico que cumpla con las exigencias objetivas, subjetivas y administrativas cause la muerte de un paciente a petición del mismo o cuando hubiera prestado auxilio al suicido del moribundo. La Ley entró en vigor el día 1 de abril de 2002, despenalizándose tanto la eutanasia como el suicidio médicamente asistido $^{3}$.

Esta reforma modifica el art. 293 del Código penal que a partir de este momento contiene la siguiente redacción:

1. El que quitare la vida a otra persona, según el deseo expresado y serio de la misma, será castigado con la pena de prisión de hasta doce años o con una pena de multa de la categoría quinta.

2. El supuesto al que se refiere el párrafo 1 no será punible en el caso de que haya sido cometido por un médico que haya cumplido con los requisitos de cuidado recogidos en el artículo 2 de la Ley sobre comprobación de la terminación de la vida a petición propia del auxilio al suicido, y se lo haya comunicado al forense municipal conforme al artículo 7, párrafo segundo de la Ley reguladora de los funerales.

La Ley holandesa es una Ley que "goza de claridad, sintaxis, metodología y elaboración comprensiva que resulta ser altamente encomiable, siendo una pieza técnicamente recomendable"4.

La Ley consta de cuatro Capítulos y Disposiciones Finales desarrollándose a lo largo de 24 artículos en los que se contienen: a- Las Definiciones (art. 1), b- Los Requisitos de cuidado y esmero profesional (art.

\footnotetext{
${ }^{3}$ En Adelante, SMA.

${ }^{4}$ ARMANDO S. y ANDRUET H. "Ley holandesa de terminación de la vida a petición propia, nuestra consideración acerca de la eutanasia”, en Derecho y Salud, 2001, pp. 169 y ss.
} 
2), c- Las Comisiones regionales de comprobación de la terminación de la vida a petición propia y del auxilio al suicidio (art. 3 a 19), d- La Modificación de algunas Leyes de la legislación holandesa (art. 20 a 22), y finalmente, d- Las Disposiciones finales (art. 23 y 24$)^{5}$.

\section{Estudio de la Ley Holandesa de terminación de la vida a petición propia y del auxilio al suicidio}

\section{Definiciones contenidas en la Ley}

Destacar que es en el primer artículo de la Ley dónde el legislador holandés define de forma inequívoca algunas cuestiones fundamentales, como la determinación de los sujetos implicados en la terminación de la vida de un paciente y el auxilio al suicidio, así como las funciones que les corresponden.

Queremos señalar que, consideramos fundamental destacar las siguientes definiciones:

1. Auxilio al suicido: Ayudar deliberadamente a una persona a suicidarse o facilitarle los medios necesarios a tal fin, tal y como se recoge en el art. 293, párrafo segundo, del Código penal.

2. El médico: El médico que, según la notificación, ha llevado a cabo la terminación de la vida a petición del paciente o ha prestado auxilio al suicidio.

3. El Asesor. El médico al que se ha consultado sobre la intervención de un médico de llevar a cabo la terminación de la vida a petición del paciente o de prestar auxilio al suicidio.

4. Los asistentes sociales: Los asistentes sociales a los que se refiere el art. 446, párrafo primero, del Libro $7 \circ$ del Código civil.

5. La Comisión: Comisión de comprobación a la que se refiere el art. 3 de la presente Ley.

6. El Inspector regional: Inspector regional de la inspección de la Asistencia Sanitaria del Control estatal de la salud pública ${ }^{6}$.

\footnotetext{
${ }^{5}$ Para más información sobre la eutanasia en Holanda ver: JOCHENSEM, H. "Eutanasia: la situación en Holanda y una evaluación crítica", en Cuadernos de bioética, vol. 7, n 27, 1996. pp. 297 y ss. ROYES I QUI, A. "La eutanasia y el suicidio médicamente asistido”, Psicooncología: Investigación y clínica biopsicosocial en oncología, vol. 5, no 2-3, 2008, pp. 323 y ss. MARCOS DEL CANO, A. M. "La eutanasia en el ordenamiento jurídico holandés", en Cuadernos de bioética, volumen 7, n 27, 1996, pp. 319 y ss. TOMAS-VALIENTE LANUZA, C. "La regulación de la eutanasia en Holanda”, en Anuario de Derecho penal y Ciencias penales, Tomo 50, Fasc/mes 1-3, 1997, pp. 293 y ss. SEZZATINI, E. "Aspectos biojurídicos sobre la legalización de la eutanasia”, en Labor hospitalaria: organización y pastoral de la salud, no 291, 2009, pp 29 y ss. J. P. TAK, P. “La nueva Ley sobre eutanasia en Holanda, y sus precedentes”, en Revista penal, n 12, 2003, pp. 109 y ss. JÚDEZ GUTIÉRREZ, F. J. "Suicidio asistido y eutanasia: un debate clásico y trágico, con pronóstico reservado", en Anales del Sistema sanitario de Navarra, vol. 30, no extr. 3, 2007, pp. 137 y ss. STEVENS, J. "La eutanasia es un hecho una actividad impune en Holanda: declaraciones del Doctor J. Stevens, en Cuadernos de bioética, vol. 4, nº 14, 1993, pp. 64 y ss.
}

${ }^{6}$ Art. 1-b, c, d, e, f, yg. 
Requisitos de cuidado y esmero profesional que exige la Ley

Se dispone en el art. 2 de la Ley, en relación a los requisitos que deben concurrir en relación con el cuidado y esmero profesional:

1. Los requisitos de cuidado a los que se refiere el art. 293, párrafo 2º, del Código penal, lo que supone que el médico:

a) Ha llegado al convencimiento de que la petición del paciente es voluntaria y bien meditada.

b) Ha llegado al convencimiento de que el padecimiento del paciente es insoportable y sin esperanzas de mejora.

c) Ha informado al paciente de la situación en la que se encuentra y de sus perspectivas de futuro.

d) Ha llegado al convencimiento junto con el paciente de que no existe ninguna otra solución razonable para la situación en la que se encuentra éste último.

e) Ha consultado, por lo menos, con un médico independiente que ha visto al paciente y que ha emitido su dictamen por escrito sobre el cumplimiento de los requisitos a los que se refieren los apartados a), b) c), d) yf).

f) Ha llevado a cabo la terminación de la vida o el auxilio al suicido con el máximo cuidado y esmero profesional posible.

2. El médico podrá atender la petición de un paciente que cuente al menos con dieciséis años de edad, que ya no esté en condiciones de expresar su voluntad pero que estuvo en condiciones de realizar una valoración razonable de sus intereses al respecto antes de pasar a encontrarse en el citado estado de incapacidad y que redactó una declaración por escrito que contenga una petición de terminación de su vida. Se aplicará por analogía los requisitos de cuidado a los que se refiere el párrafo primero.

3. Si se trata de un paciente menor de edad, de entre dieciséis y dieciocho años, al que se le puede considerar en condiciones de realizar una valoración razonable de sus intereses en este asunto, el médico podrá atender una petición del paciente de terminación de su vida o una petición de auxilio al suicido, después de que los padres o el padre o la madre que ejercen la patria potestad o la persona que tenga la tutela sobre el menor, haya participado en la toma de decisiones.

4. en el supuesto de que el paciente menor de edad tenga una edad comprendida entre los doce y los dieciséis años y que se le pueda considerar en condiciones de realizar una valoración razonable de sus intereses en este asunto, el médico podrá atender una petición del paciente de terminación de su vida o a una petición de auxilio al suicido, en el caso de que los padres o el padre o la madre que ejercen la patria potestad o la persona que tenga la tutela sobre el menor esté de acuerdo con la terminación de la vida del paciente o con el auxilio al suicidio. Se aplicará por analogía el párrafo segundo. 
Comisiones regionales de comprobación de la terminación de la vida a petición propia y del Auxilio al suicidio

Creación, composición y nombramiento de las Comisiones

Las Comisiones regionales comprobaran las notificaciones de los casos en los que se ha llevado a la práctica la terminación de la vida a petición propia y el auxilio al suicido, según se establece en los artículos 293 y 294 del Código penal7.

Se señala los requisitos que deben cumplir las Comisiones en su constitución, la especialidad de los integrantes (médico, jurista.) y suplentes ${ }^{8}$ y se determina a quien corresponde nombrarlos, así como la vigencia del cargo y sus funciones?

Cese y Despido

Todos los miembros integrantes de la Comisión regional (Presidente, miembros titulares y suplentes) pueden solicitar su cese al Ministro. También pueden ser despedidos todos los miembros de la Comisión señalados anteriormente por el Ministro correspondiente como consecuencia de su ineptitud, incapacidad o por cualquier otra causa debidamente fundamentada ${ }^{10}$.

\section{Remuneración}

Los miembros de la Comisión, Presidente, miembros titulares y suplentes percibirán dietas y reembolsos de los gastos de viajes y alojamientos conforme al actual baremo oficial, en la medida en que no se conceda por otro concepto una remuneración del Tesoro Público en concepto de los citados gastos ${ }^{11}$.

Tareas y competencias

En relación con las tareas y competencias que corresponden a la Comisión, queremos destacar las siguientes, todas ellas recogidas en los artículos 8,9 y 10 de la Ley:

Partiendo del informe señalado en el art. $7^{\circ}$, párrafo $2^{\circ}$, de la Ley reguladora de los funerales, la Comisión juzgará si el médico que ha provocado la muerte asistida a petición del paciente o el auxilio al suicidio, ha actuado conforme a los requisitos de cuidado a los que se refiere el art. $2^{\circ}$.

\footnotetext{
${ }^{7}$ Art. 3.1 de la Ley.

${ }^{8}$ Art. 3.2 de la Ley.

${ }^{9}$ Art. 4. Apartados 1,2 y 3.

${ }^{10}$ Art. 5 y 6 de la Ley.

${ }^{11}$ Art- 7 de la Ley.
} 
La Comisión podrá solicitar al médico que complemente su informe por escrito u oralmente, en el caso de que esta medida se considera necesaria para poder juzgar convenientemente la actuación del médico.

La Comisión podrá pedir información al médico forense, al asesor o a los asistentes pertinentes, en el caso de que sea necesario para poder juzgar adecuadamente la actuación del médico ${ }^{12}$.

Así también, la Comisión comunicará al médico por escrito su dictamen motivado dentro del plazo de seis semanas contadas a partir de la recepción del informe al que se refiere el párrafo 1º del art. 8 .

La Comisión comunicará su dictamen a la Fiscalía General del Estado y al inspector regional para la asistencia sanitaria:

1. En el caso de que, en opinión de la Comisión, el médico no haya actuado conforme a los requisitos de cuidado establecidos en el art. 2.

2. En el caso de que se produzca una situación como la recogida en el art. 12, último parágrafo de la Ley reguladora de los funerales. La Comisión comunicará esta circunstancia al médico.

El plazo citado en el apartado $1^{\circ}$ podrá ser prolongado una sola vez por un máximo de seis semanas. La Comisión se lo comunicará al médico.

La Comisión tendrá competencia para dar una explicación oral al médico sobre su dictamen. Esta explicación oral podrá realizarse a petición de la Comisión o del propio médico ${ }^{13}$.

Se establece que la Comisión estará obligada a facilitar al fiscal toda la información que solicite y que sea necesaria: 1- Para poder juzgar la actuación del médico en un caso como el referido en el art. 9, párrafo segundo, o, 2.- Para una investigación criminal.

Si se ha facilitado información al fiscal, la Comisión se lo comunicará al médico ${ }^{14}$.

Método de trabajo

En relación con el Método de trabajo, se dispone en la presente Ley que:

1. La Comisión se encargará de llevar un registro de los casos de terminación de la vida a petición propia o de auxilio al suicidio que se le hayan notificado y hayan sido cometidos a su juicio. Los Ministros podrán establecer reglas más detalladas al respecto mediante Órdenes Ministeriales ${ }^{15}$.

2. El dictamen se aprobará por mayoría simple de votos.

3. Un dictamen sólo podrá ser aprobado por la Comisión en el caso de que todos los miembros de la misma tomen parte en su votación ${ }^{16}$.

\footnotetext{
${ }^{12}$ Art. 8 de la Ley, apartados 1 a 3.

${ }^{13}$ Art. 9 de la Ley, apartados 1 a 4.

${ }^{14}$ Art. 10 de la Ley.

${ }^{15}$ Art. 11 de la Ley.
} 
4. Los Presidentes de las Comisiones regionales de comprobación se reunirán por lo menos dos veces al año para tratar el método de trabajo y el funcionamiento de las Comisiones. A la reunión acudirán un representante de la Fiscalía General del Estado y un representante de la Inspección para a Asistencia Sanitaria de la Inspección del Estado de la Sanidad Pública ${ }^{17}$.

Secreto y Abstención

1. Los miembros o miembros suplentes de la Comisión estarán obligados a mantener en secreto los datos de los que dispongan en la realización de sus tareas, salvo que alguna disposición legal les obligue a comunicarlo ( $y$ con el alcance concreto de la obligación correspondiente) o que su tarea haga necesaria la realización de un comunicado ${ }^{18}$.

2. Un miembro de la Comisión que ocupe su puesto en la misma con el fin de tratar un asunto, deberá abstenerse y podrá ser escusado en el caso de que se produzcan hechos o circunstancias que pudieran afectar a la imparcialidad de su dictamen ${ }^{19}$.

3. Los miembros, los miembros suplentes y secretario de la Comisión se abstendrán de opinar acerca de la intención de un médico de llevar a cabo la terminación de la vida a petición del paciente o de prestar auxilio al suicidio ${ }^{20}$.

Presentación de informes

1. Una vez al año, antes del día 1 de abril, las Comisiones presentarán ante los Ministros un informe común del trabajo realizado en el año natural inmediatamente anterior. Los Ministros redactarán un modelo de informe siguiendo el modelo establecido que se aprobará mediante Orden Ministerial.

2. En el informe del trabajo realizado que se señala en el párrafo anterior se hará mención en cualquier caso de:

a) El número de casos de terminación de la vida a petición propia y de auxilio al suicidio que se les hayan notificado y sobre los cuales la Comisión ha emitido dictamen,

b) La naturaleza de estos casos,

c) Los dictámenes y las consideraciones que han llevado a los mismos ${ }^{21}$.

\footnotetext{
${ }^{16}$ Art. 12 de la Ley.

${ }^{17}$ Art. 13 de la Ley.

${ }^{18}$ Art. 14 de la Ley.

${ }^{19}$ Art. 15 de la Ley.

${ }^{20}$ Art. 16 de la Ley.

${ }^{21}$ Art. 17 de la Ley.
} 
3. Con ocasión de la presentación del presupuesto al Parlamento, los Ministros entregarán anualmente un informe sobre el funcionamiento de las Comisiones, partiendo del informe del trabajo realizado mencionado en al art. 17, párrafo primero ${ }^{22}$.

4. A propuesta de los Ministros y por medio de Decreto Legislativo, se establecerán reglas sobre las Comisiones con respecto a.

a) Su número y competencias relativas.

b) Su sede.

5. En virtud de o mediante Decreto Legislativo, los Ministros podrán establecer más reglas sobre las Comisiones en lo relativo a:

a) El número de miembros y la composición,

b) El método de trabajo y la presentación de informes ${ }^{23}$.

\section{Modificaciones de otras Leyes}

A partir de los artículos 20, 21 y 22 se procede a la modificación de distintos preceptos del ordenamiento.

Modificación del Código penal en lo que se refiere a los arts. 293, 294, 295 y 422.

El art. 293 pasará a tener la siguiente redacción:

1. "El que quitare la vida a otra persona, según el deseo expreso y serio de la misma, será castigado con la pena de prisión de hasta doce años o con una pena de multa de la categoría quinta.

2. El supuesto al que se refiere el párrafo $1^{\circ}$ no será punible en el caso de que haya sido cometido por un médico que haya cumplido con los requisitos de cuidados recogidos en el art. 2 de la Ley sobre comprobación de la terminación de la vida a petición propia y del auxilio al suicidio, y se lo haya comunicado al forense municipal conforme al art. 7, párrafo segundo de la Ley reguladora de los funerales ${ }^{24}$.

Por su parte, el art. 294.1 dispone: "El que de forma intencionada indujera a otro para que se suicide o le facilitara los medios necesarios para ese fin, será, en caso de que se produzca el suicidio, castigado con una pena de prisión de hasta tres años o con una pena de multa de la categoría cuarta. Se aplicará por analogía el art. 293, párrafo segundo".

3. En el art. 295 se añadirá después del art. 293, párrafo primero.

\footnotetext{
${ }^{22}$ Art. 18 de la Ley.

${ }^{23}$ Art. 19 de la Ley.

${ }^{24}$ Art. 20 de la Ley.
} 
4. En el art. 422 se añadirá después del art. 293, párrafo primero ${ }^{25}$.

Se procede a la modificación de la Ley Reguladora de los Funerales que pasará a tener la siguiente redacción:

La Ley Reguladora de los Funerales se modifica de la siguiente manera:

a) El artículo 7 pasa a tener la siguiente redacción:

"El que haya realizado la autopsia procederá a expedir una certificación de defunción si está convencido de que la muerte se ha producido por causas naturales.

i. En el caso de que el fallecimiento se haya producido como consecuencia de la aplicación de técnicas destinadas a la terminación de la vida a petición propia o al auxilio al suicidio, a los que se refiere el artículo 293, párrafo segundo y el artículo 294, párrafo segundo, segunda frase del Código Penal, el médico que trata el paciente no expedirá ningún certificado de defunción e informará inmediatamente, mediante la cumplimentación de un formulario, al forense municipal o a uno de los forenses municipales, de las causas de dicho fallecimiento. Además del formulario, el médico enviará un informe motivado sobre el cumplimiento de los requisitos de cuidado a los que se refiere el artículo 2 de la Ley de comprobación de la terminación de la vida a petición propia y del auxilio al suicidio.

ii. Si se producen otros casos distintos de los mencionados en el párrafo segundo y el médico que trata al paciente considera que no puede proceder a expedir un certificado de defunción, se lo comunicará (rellenando un formulario) inmediatamente al forense municipal o a uno de los forenses municipales"26.

b) El artículo 9 pasa a tener el siguiente texto:

"La forma y la composición de los modelos de certificado de defunción a presentar por el médico que trata al paciente y por el forense municipal, se regularán por medio de Decreto Legislativo.

i. La forma y la composición de los modelos para la notificación y el informe a los que se refiere el artículo 7, párrafo segundo, de la notificación a que se refiere el artículo 7, párrafo tercero y de los formularios a que se refiere el artículo 10, párrafos primero y segundo, serán regulados por medio de Decreto Legislativo a propuesta de los Ministro de Justicia y Nuestro Ministro de Bienestar, Sanidad y Deportes" ${ }^{27}$.

c) El artículo 10 pasa a tener la siguiente redacción:

\footnotetext{
${ }^{25}$ Art. 20 de la Ley.

${ }^{26}$ Art. 7, párrafo 1,2 y 3 .

${ }^{27}$ Art. 9, párrafo 1 y 2.
} 
"Si el forense municipal cree que no puede proceder a expedir una certificación de defunción, informará inmediatamente al fiscal a este respecto rellenando el formulario establecido por medio de Decreto Legislativo y avisará en el acto al funcionario del Registro Civil.

i. Sin perjuicio de lo estipulado en el párrafo primero y en caso de que se produzca una notificación como las mencionadas en el artículo 7, párrafo segundo, el forense municipal se lo comunicará (rellenando un formulario) inmediatamente a la Comisión Regional de comprobación a la que se refiere el artículo 3 de la Ley de comprobación de la terminación de la vida a petición propia y de auxilio al suicidio. Asimismo, adjuntará el informe motivado al que se refiere el artículo 7, párrafo segundo 28 .

d) $\mathrm{Al}$ artículo 12 se le añade una frase con la siguiente redacción: En caso de que el fiscal, en los casos referidos en el artículo 7, párrafo segundo, considere que no puede proceder a expedir una certificación de no objeción al entierro o a la incineración, se lo comunicará inmediatamente al forense municipal y a la Comisión Regional de comprobación a la que se refiere el artículo 3 de la Ley de comprobación de la terminación de la vida a petición propia y de auxilio al suicidio.

e) En el artículo 81, parte primera, se sustituye "7, párrafo primero" por: 7, párrafos primero y segundo.

Se procederá a la Modificación de la Ley General de Derecho Administrativo:

La Ley General de Derecho Administrativo se modificada de la siguiente manera: En el artículo 1:6, al final de la parte d), se sustituye el punto por un punto y coma y se añade una parte quinta que dispone: e) decisiones y actuaciones en ejecución de la Ley de la comprobación de la terminación de la vida a petición propia y del auxilio al suicidio.

\section{Disposiciones finales}

La Ley de la Terminación de la vida a petición propia y del auxilio al suicidio entrará en vigor en la fecha establecida en el Real Decreto ${ }^{29}$. Se contiene así también la denominación de la Ley que acabamos de señalar anteriormente y se ordena su publicación en el Boletín Oficial del Estado de los Países Bajos y que todos los Ministros, Autoridades, Colegios y funcionarios relacionados con ella la lleven a la práctica ${ }^{30}$.

\footnotetext{
${ }^{28}$ Art. 10, párrafo 1 y 2.

${ }^{29}$ Art. 23 de la Ley.

${ }^{30}$ Art. 24 de la Ley, Publicada por parte del Ministro de Justicia, de Sanidad, de Bienestar y Deportes, Senado, año 2000-2001, Ley $26691, \mathrm{n}^{\circ} 137$.
} 


\section{Cuestiones más relevantes de la Ley de la Terminación de la vida a petición propia y del auxilio al suicidio: especial referencia al contenido de los artículos 1 y 2 de la Ley holandesa 26691/2001}

El legislador se ha encargado de definir de forma inequívoca, quienes son y concretar la función que se le asigna a cada uno de los operadores que intervienen en la terminación de la vida o en el auxilio al suicidio $^{31}$.

Desarrollaremos seguidamente el contenido que consideramos más destacado de la Ley en relación con: a- el médico y las actuaciones terapéuticas destinadas a causar la muerte del paciente ${ }^{32}$, y, b- los requisitos de cuidado y esmero que se exigen a los profesionales sanitarios ${ }^{33}$.

\section{El médico y las actuaciones terapéuticas destinadas a causar la muerte del paciente}

El médico es el sujeto encargado de ejecutar el acto eutanásico (actuación terapéutica dirigida a causar la muerte del paciente), es decir, quien termina con la vida del enfermo a petición propia, o por el contrario en una categoría más leve, colaborará prestando el auxilio para que el paciente pueda en definitiva provocarse la muerte por sí mismo; actividad toda ella que es explicitada sintéticamente en los apartados a) "Auxilio al suicidio"34.

Las atenciones básicas que además debe prestar el médico en esta fase de la enfermedad suponen que sean aplicadas: a- terapias contra el dolor, b- una adecuada atención psicológica, afectiva y emocional al paciente, que en ocasiones, no está suficientemente atendido e incorporar la totalidad de cuidados paliativos que la ciencia médica tiene a su alcance.

Estaremos siempre en presencia de enfermos que han llegado al fin de su vida, o de enfermos incurables, terminales, los que se encuentran in extremis o los que están ya condenados a morir.

En esta fase de la vida del paciente, el médico es quien colabora en la terminación de la misma, cuando ello significa que no asumirá actitudes que aparecen claramente desmesuradas y obsesivas a los efectos de mantener a la misma, favoreciendo con esa actuación la muerte digna de cada uno de los enfermos, no parece en modo alguno reprochable. Una cosa es respetar la voluntad del enfermo y no poder aplicarle una terapia o técnica que él rechaza, y otra cosa muy distinta quitarle directamente la vida. El primero de los actos

\footnotetext{
${ }^{31}$ Para más información, ver: ROYES A. "La eutanasia y el suicidio médicamente asistido", en Psicooncología, vol. 5, n 2-3, 2008 , p. 330.

${ }^{32}$ Art. 1 de la Ley.

${ }^{33}$ Art. 2 de la Ley.

${ }^{34}$ ARMANDO S. y ANDREUT, "Ley holandesa de terminación de la vida a petición propia ...”, ob. cit. p. 173. vol.07, nº. 02, Rio de Janeiro, 2014.pp. 892-1009 
es un acto médico, en tanto que el segundo es del médico ${ }^{35}$. Este aspecto en verdad no se diferencia de la misma observación que desde el punto de vista confesional se ha brindado a este tratamiento.

Los médicos deben ser suficientemente cuidadosos y no por ello, tomar actitudes militantes y fundamentalistas en defensa de la vida del paciente a cualquier precio. La vida digna del hombre impone en igual sentido una muerte digna, esto es "ortotanasia”, la muerte del ser humano en el momento oportuno.

Por todo lo que se ha señalado hasta este momento, ARMANDO y ANDREUT consideran que al médico le corresponde actuar positivamente provocando la muerte del paciente a pesar de que estemos ante un comportamiento que está en contradicción con la función asignada a la ciencia médica que es la de curar a los enfermos ${ }^{36}$.

\section{Los requisitos de cuidado y esmero que se exigen a los profesionales sanitarios}

El médico puede cumplir con su cometido a través de dos vías: a)- a través del auxilio al suicidio del paciente, es decir, ayudándole deliberada y directamente a ello o facilitarle los medios para que se produzca la muerte, o, b)-produciendo la muerte del paciente por sí mismo (el médico) a petición del propio paciente. En ambos supuestos, se estaría ante una intervención activa y positiva por parte del médico que provocaría la muerte.

La actuación del médico en estos supuestos no es ni de curar, ni de aliviar o consolar al paciente, es claramente tanática y ello en verdad que parece ser, una categoría epistemológica que dista todavía bastante de poder ser admitida dentro de la ortodoxia médica.

En la Ley holandesa es el médico quien ejecuta materialmente los procedimientos de muerte o colabora para que el paciente los pueda como tal efectuar, previo cumplimiento de un conjunto de extremos dispuestos por la propia Ley, para que el nombrado procedimiento no merezca reproche jurídico, puesto que el descrédito social -aunque se intente de alguna manera silenciar- obviamente que existe. Y si bien puede sostenerse que la vida es una cuestión acerca de la cual existe una clara autonomía, para mantenernos dentro de una esfera propiamente racional del problema -sin perjuicio de que nos resulte de extrema dificultad quitar también de ella su perspectiva transcendente y de ser siempre donación divina- y por lo tanto, todo individuo personalmente con muchas o pocas razones, podrá terminar disponiendo de ella, mas lo que no parece posible, es que pueda efectuar esa enajenación del poder dispositivo sobre su propia vida a un tercero, con independencia que sea médico o no.

\footnotetext{
${ }^{35}$ GARCÍA D. "Ética de los confines de la vida”, en Ética y Vida. Estudios de biología, Bogotá, 1998, Tomo III, p. 302.

${ }^{36}$ ARMANDO S. y ANDREUT, "Ley holandesa de terminación de la vida a petición propia ...”, ob. cit. p. 177. vol.07, nº. 02, Rio de Janeiro, 2014.pp. 892-1009
} 
La autonomía del sujeto enfermo no parece posible que pueda dispensar a que definitivamente, sea un tercero el que juzgue si su propia decisión resulta adecuada o no a un determinado estado médico-clínicopsicológico y luego ejecutar o colaborar en el acto mismo de producir la muerte, pues tan pronto como ese otro tercero médico, interviene en el proceso evaluando las condiciones externas del acto autonómico del paciente, asume una transitividad dicha autonomía que por eso mismo, hace que ella para el paciente deje de ser autonomía y se convierta directamente en una petición sometida a un control externo y ajeno y por lo cual: parece que tal decisión no es autónoma sino heterónoma. Definitivamente depende de otro que se puede o no cumplir, se trata entonces de un acto claramente transitivo y está claro que -y siempre desde el nivel puramente racional del problema- no existe otro posible, que no sea uno mismo, quien pueda disponer de su propia vida. Toda disposición que se hace de la vida ajena en tales condiciones resulta civilmente cuestionable.

No existe en manera alguna autonomía en la elección por el paciente, puesto que en verdad se está tratando la misma dimensión autonómica, a que sea otro quien defina en nombre del enfermo y que como tal, no está en modo alguno bajo la misma condición ni física ni psicológica que le permitan hacer una evaluación semejante a la que realiza quien sí tiene la autonomía para la decisión y disposición de su propia vida.

Esta fuera de duda de que existen muchas actividades, ejecuciones y actuaciones, en que la dimensión de la autonomía del sujeto puede trasladarse y aquél que aparece como receptor de la misma, la puede ejecutar, realizar o actuar como si fuera el cedente de la autonomía, más cuando se trata de trasladar la misma facultad de disponer de la vida, no siendo el cesionario-médico en las condiciones semejantes en las que se encuentra el cedente-paciente, el cesionario deja la autonomía y será el médico que en el presente caso quien deberá llevar adelante la gestión seudo-médica y claramente tanática, no están en condiciones de equiparación que permitan que puede cumplir adecuadamente con la cesión autonómica que defectuosamente se le intenta realizar y como tal, resulta extraño que esta actividad se pueda legalizar ${ }^{37}$.

Queremos destacar los requisitos que exige la Ley en relación con el "cuidado y esmero profesional" y que son los siguientes:

Los requisitos que deberán concurrir en relación con el cuidado y esmero profesional que deben prestar los médicos en esta fase final de la vida del paciente son los que a continuación señalamos: Que el médico:

1. Ha llegado al convencimiento de que la petición del paciente es voluntaria y bien meditada.

2. Ha llegado al convencimiento de que el padecimiento del paciente es insoportable y sin esperanza de mejora.

3. Ha informado al paciente de la situación en la que se encuentra y de sus perspectivas de futuro.

${ }^{37}$ ARMANDO S. y ANDREUT, "Ley holandesa de terminación de la vida a petición propia ...”, ob. cit. p. 183. vol.07, nº. 02, Rio de Janeiro, 2014.pp. 892-1009 
4. Ha llegado al convencimiento junto con el paciente de que no existe ninguna otra solución razonable para la situación en la que se encuentra el paciente.

5. Ha consultado, por lo menos, con un médico independiente que ha visto al paciente y que ha emitido su dictamen por escrito sobre el cumplimiento de los requisitos de cuidado a los que se refiere en los apartados anteriores, $y$,

6. Ha llevado a cabo la actuación médica encaminada a provocar la muerte o el auxilio al suicidio con el máximo cuidado y esmero profesional.

Así también, el médico podrá atender la petición de un paciente cuando al menos tenga dieciséis años de edad, que ya no esté en condiciones de expresar su voluntad pero que estuvo en condiciones de realizar una valoración razonable de sus intereses al respecto antes de pasar a encontrarse en el citado estado de incapacidad y que redactó una declaración por escrito que contenga una petición de terminación de su vida.

En el presente caso ser realizaran por analogía los requisitos de cuidado a los que se refiere el párrafo anterior.

Si se trata de un paciente menor de edad, cuya edad esté comprendida entre los dieciséis y los dieciocho años, al que se le pueda considera en condiciones de realizar una valoración razonable de sus intereses en este asunto, el médico podrá atender una petición del paciente de terminar con su vida o de auxilio al suicidio, después de que los padres o el padre o la madre que ejerzan la patria potestad o la persona que tenga la tutela sobre el menor, hayan participado en la toma de decisión.

En caso de que el paciente menor de edad tenga una edad comprendida entre los doce y los dieciséis años y que se le pueda considerar en condiciones de realizar valoraciones razonables de sus intereses en este asunto, el médico podrá atender a su petición de auxilio al suicidio o de terminación de su vida, en el caso de que los padres, el padre o la madre que ejerzan la patria potestad o la persona que tenga la tutela sobre el menor, estén de acuerdo con la terminación de la vida del paciente o con el auxilio al suicidio. Se aplicará por analogía el párrafo anterior ${ }^{38}$.

Una vez cumplidos los requisitos que se contienen en el art. 2 de la Ley se podrá dispensar la punición penal al médico interviniente. Todos los requisitos deben cumplirse cumulativamente ${ }^{39}$.

\footnotetext{
${ }^{38}$ Art. 293 de la Ley holandesa.

${ }^{39}$ ARMANDO S. y ANDREUT, "Ley holandesa de terminación de la vida a petición propia ...”, ob. cit. p. 184.
} vol.07, nº. 02, Rio de Janeiro, 2014.pp. 892-1009 
Petición voluntaria y meditada del enfermo

El primer requisito que nos exige la Ley es que el médico tenga la firme convicción de que la petición realizada por parte del paciente haya sido emitida de forma voluntaria y debidamente meditada.

En esta afirmación que acabamos de realizar no se debe ver ninguna vuelta a la actitud paternalista del médico que se mantenía en épocas pasadas, en el que el enfermo además de padecer una situación clínica penosa, tenía también una notoria incapacidad para pensar y por lo cual el paternalismo del médico pensaba por él.

Por el contrario, pensamos que el paciente que siente próxima su muerte, debe valorar el momento que está viviendo. En esta fase de la enfermedad, también tendrá que tenerse en consideración la capacidad psicológica que tiene el paciente para tomar una decisión de esta transcendencia y que algún grado de objetividad se exigirá a la hora de adoptar esta decisión, destacando que el estado de depresión del paciente puede afectar a su toma de decisión.

Además, se exige que el paciente actúe sin ningún tipo de coacción externa cuando está adoptando esta decisión, cuestión que es difícil que se produzca realmente, siempre existirá algún miembro de la familia que puede llevarle a adoptar esta decisión.

El médico deberá cumplimentar el formulario pre-impreso que establece la Ley, en el que se deberán adoptar medidas que afecten a la decisión final. Este médico que cumplimenta el formulario es quien ha llevado adelante la atención anterior del paciente, y por lo tanto, es muy posible que su misma especialidad puede estar muy alejada de aquellas otras, que le han permitido reconocer con mayor cuota de éxito el funcionamiento mismos de los llamados mecanismos de defensa, o de falsas estrategias mentales que el propio enfermo puede generar consciente o inconscientemente para producir el mismo acto de información acerca de la adecuada ponderación de la decisión que ha sido obtenida del paciente.

Por ello, entienden ARMANDO y ANDREUT que el convencimiento que el médico tenga será siempre relativo y que este dato supone que estamos en presencia de un hecho de suma gravedad, puesto que no se puede perder de vista ni siquiera por un instante, que su situación le otorga las facultades para la realización del acto transitivo de producir la muerte a su paciente. Además, se tendrá que tener en consideración el tiempo que el profesional puede dedicarle al paciente, así como la asignación de recursos que destina la administración al ámbito sanitario, y el desgaste profesional, todo ello afectará a la decisión adoptada por el enfermo que está en la fase terminal de su enfermedad ${ }^{40}$.

${ }^{40}$ ARMANDO S. y ANDREUT, "Ley holandesa de terminación de la vida a petición propia ...”, ob. cit. p. 185. vol.07, n. 02, Rio de Janeiro, 2014. pp. 892-1009 
Dolor insoportable sin mejora ulterior

Al igual que ocurría con el requisito señalado anteriormente, en el presente caso, también podemos estar en presencia de algunos vicios que afectan al cumplimiento de éste requisito. Aquí nos enfrentamos a dos temas de gran transcendencia:

1. que el padecimiento del enfermo resulte insoportable, $y$;

La Ley exige que el padecimiento sea “insoportable”, pero, en realidad ¡la Ley se está refiriendo a los padecimientos físicos, espirituales o también a los morales? Si bien una adecuada hermenéutica de la Ley, permitiría afirmar que no habiéndose efectuado la diferenciación entre todas ellas, se pensase que se cumpliría con el requisito exigido cuando se padeciera cualquiera de ellas, pero entendemos que habría que ponerlo en relación con cada uno de los pacientes en concreto.

Parece que la Ley holandesa arrebata al individuo el tiempo necesario para reflexionar, ofreciéndole a cambio la posibilidad de tomar un camino relativamente inmediato y que como tal, aunque sea ponderado y meditado, lo será siempre en una temporalidad tan breve que como tal, desvirtúa la meditación que puede exigirse de la toma de decisión.

Otra de las cuestiones que resultan altamente discutible es cuando la Ley hace referencia a que el padecimiento debe ser "insoportable". Si bien existen un conjunto de parámetros que permiten efectuar una especie de medición respecto a los distintos grados que puede tener el dolor, no es menos cierto que esas mediciones han sido realizadas sobre la base de elementos objetivos externos, tales como, movilidad, comunicabilidad y otros que son reflejos clínicos. Pero, en ningún caso puede existir una posibilidad de tratar de forma uniforme la cuantificación del dolor.

El dolor es una experiencia somato psíquica en la que el componente físico sólo juega un papel del $35 \%$ de la experiencia del dolor, de forma que los elementos psicológicos, espirituales y sociales conforman la expresión o acción evocada individual de la sensación psíquica-dolorosa, de lo que podemos concluir que el nivel de dolor viene matizado en cada enfermo según su nivel cultural, sus creencias religiosas y su grado de conocimiento de la enfermedad.

La objetividad del dolor que se pretende lograr a través de la caracterización de que el dolor es insoportable, en modo alguno existe. Atendiendo a la incidencia de los aspectos psicoemocionales en su configuración, pues el dolor siempre es individual y propio de cada uno de los enfermos, es a ellos y no a los demás a quienes duele, y con independencia de que pueda medirse, lo cierto es que en esas mediciones nunca podrán tenerse en consideración algunas variables no fisiológicas y por lo tanto tampoco, conseguir establecer alguna pauta objetiva de cuándo el dolor es insoportable o soportable. 
Por ello, se entiende que será suficiente con denunciar que se padece un dolor insoportable por parte del paciente, para que el mismo habilite la condición necesaria para poder reclamar el acto eutanásico. En este punto es importante destacar que la norma general que es la Ley, viola una de las características generales que hace a la misma esencia de ella, como es que sea general. En realidad, no estamos ante el supuesto típico de dolor insoportable, sino que se remite a una condición subjetiva y claramente discriminatoria y arbitraria ${ }^{41}$.

El supuesto de hecho que plantea la Ley holandesa pasa a ser entonces particular y no general porque está fuera de duda, que existen individuos que están dispuesto a sacrificios y dolores que otros en modo alguno podrían sobrellevar, y ello en manera alguna puede ser cuantificado externamente, cada uno conoce aquello que le duele y cuánto le duele, por lo que el dolor entendemos que es individual y específico de la interrelación entre los siguientes componentes:

a) Sensación física transmitida por un sistema nociceptivo;

b) Estado psicoemocional del paciente, y;

c) Creencias, influencias y fantasías que actúen sobre el enfermo. Por todo ello, aparece como un severo despropósito el intentar cuantificar el dolor individual, como igualmente sería inútil tratar de medir la alegría espiritual que los individuos poseen, y ello se ve multiplicado en la complejidad de la construcción normativa, cuando además es una tercera persona la que tiene que evaluar el grado de insoportabilidad que tiene el dolor.

Además de esta deficiencia que se puede considerar que es sustancial y ordenada respecto a la cuantificación objetiva del padecimiento y sólo admitiendo que por ello comprendemos dolor físico, puesto que como tendremos oportunidad de destacar posteriormente, resulta obvio que existen otros tipos de padecimientos no físicos y que también pueden ser insoportables y que pueden ser cuantificados a través de parámetros externos y objetivos, en estos actos también quedará habilitada la posibilidad de aplicar la eutanasia o el acto eutanásico.

Queremos señalar que, entendemos que el paciente que solicita su propia muerte se encuentra, en muchas ocasiones, en un estado de depresión importante y que complica o hace difícil que se puede considerar que la decisión que adopta sea verdaderamente libre. El paciente terminal sigue su propio proceso psicológico ante la enfermedad y el mismo se va mostrando a lo largo del distintas fases, iniciándose con una que es la negación de la enfermedad, la ira, la depresión, seguida de una segunda fase de aceptación, con lo cual bien puede acontecer que la solicitud de la eutanasia por parte del paciente, sea coincidente con dicha fase de severa angustia y que tal como, en términos generales la misma ciencia médica tiene acreditado, resulta ser el

${ }^{41}$ ARMANDO S. y ANDREUT, “Ley holandesa de terminación de la vida a petición propia ...”, ob. cit. p. 186. vol.07, nº. 02, Rio de Janeiro, 2014.pp. 892-1009 
primer estadio del difícil proceso del paciente en su estado terminal y que también en muchas ocasiones, es superada posteriormente ${ }^{42}$.

En este punto queremos destacar que algunos autores, entre los que queremos citar a Robert TWYCROSS, profesor de medicina paliativa en la Clínica MacMillan de la Universidad de Oxford ha concluido, tras veinte años de trabajo en medicina paliativa que: "Cuando se tienen en cuenta todos los factores físicos, psíquicos, sociales y espirituales, la eutanasia no es una respuesta” ${ }^{\text {*3 }}$. Destacar además que, hoy en día la medicina paliativa se ve acompañada en algunos países bajo un modelo de Unidades Hospices ${ }^{44} \mathrm{o}$ Albergues que rigurosamente se han convertido en un verdadero símbolo de la mejor medicina que se puede ofrecer para este tipo de pacientes ${ }^{45}$.

Lo cierto es que en relación con el dolor físico, se puede afirmar sin riesgo de cometer falacia alguna que, en estos momentos existen medicamentos que pueden controlar de forma eficaz el dolor en un 99\% de los casos, además no podemos olvidar que uno de los deberes positivos que se exigen a la comunidad médica en relación con la dignidad como derecho del paciente es que los médicos han declarado y conocen el derecho que tiene todo paciente a aliviar su sufrimiento teniendo como base los conocimientos médicos vigentes ${ }^{46}$.

El uso de analgésicos para aliviar los sufrimientos de los enfermos terminales, incluso con riesgo de abreviar sus días de vida, puede ser moralmente conforme a la dignidad humana si la muerte no es pretendida directamente, ni como fin ni como medio, sino solamente prevista y tolerada como inevitable. Los cuidados paliativos constituyen una forma privilegiada de caridad desinteresada, por ello, debe ser alentada esta opción ${ }^{47}$.

Para que la ingesta de analgésicos sea la correcta, deben cumplir con ciertas condiciones, con el fin de evitar que en realidad estén encubriendo claramente acciones eutanásicas:

a) Que no exista otra alternativa mejor para el paciente,

b) Que no se pueden utilizar otras terapéuticas o utilizadas sean fútiles,

c) Se advierte la existencia evidente de dolor físico en el paciente,

\footnotetext{
${ }^{42}$ ARMANDO S. y ANDREUT, “Ley holandesa de terminación de la vida a petición propia ...”, ob. cit. p. 187.

${ }^{43}$ FERNÁNDEZ CREHUET, J. "Eutanasia, atención a pacientes terminales y profesionales de la salud. Intervención en la Comisión del Senado sobre Eutanasia”, en Cuadernos de Bioética, no 44, 2001, pp. 55 y ss.

${ }^{44}$ El movimiento de "Hospices" se inició en Gran Bretaña el año 1948 bajo los indicaciones de la Dra. Cicely Saunders en St. Thoms Hospital, habiéndose ya consolidado como estructura compleja a partir de la década de los setenta.

${ }^{45}$ ARMANDO S. y ANDREUT, "Ley holandesa de terminación de la vida a petición propia ...”, ob. cit. p. 187.

${ }^{46}$ Declaración de Lisboa de la Asociación Médica mundial sobre los Derechos de los Pacientes, adoptada por la 34 Asamblea Médica Mundial de 1981, enmendada por la 47 Asamblea General de Bali en 1995.

${ }^{47}$ Posición de la Conferencia Episcopal Argentina, Catecismo de la Iglesia Católica, nº 2279.
} 
d) El enfermo cumplió o puede razonablemente hacerlo después, con sus deberes religiosos, personales, familiares y civiles respectivos.

No debe existir entonces sobredosis alguna de analgésicos, el propósito debe ser aliviar el dolor del paciente y no provocarle la muerte ${ }^{48}$.

A pesar de poder aplicarse todas estas terapias contra el dolor, la realidad ha mostrado que muchos pacientes que han sido atendidos a través de esta medicina paliativa han expresado su deseo de morir de forma clara y meditada.

2. que no existe esperanza de mejorar la salud del paciente.

Respecto al segundo de los condicionantes, que "no exista esperanza acerca de la mejoría del paciente", nos encontramos nuevamente ante un concepto de difícil delimitación.

Todos los médicos han tenido experiencias personales o conocen de otros que las han tenido, de situaciones médicamente terminales y que sin embargo factores que resultan propiamente extraños y poco explicables desde el ámbito médico, han logrado el restablecimiento del paciente.

El hecho de que existan casos en los que se ha demostrado que una enfermedad terminal no implica necesariamente la muerte del paciente, pone en severa tela de juicio la existencia clara, definitiva y permanente de la ausencia de esperanza de mejora en la salud del enfermo. Nada supone además que en un futuro esas enfermedades puedan ser tratadas y curadas.

En realidad, la Ley supone un reconocimiento mediático de la incapacidad de la medicina actual para resolver ciertas enfermedades. El hecho de que no existe esperanza para que mejore la enfermedad del paciente no supone que este hecho sea irreversible ${ }^{49}$.

Informar al paciente de la situación en la que se encuentra su salud

Este requisito es de carácter objetivo y también de cumplimiento obligatorio por parte del médico. Se debe asegurar no sólo la verosimilitud de la información que ha sido facilitada al paciente de tener debidamente documentado el llamado consentimiento por el médico, como así también, de haber destacado cuales son las perspectivas futuras de la enfermedad.

Se trata del consentimiento informado que el médico obtendrá del paciente que está requiriendo el acto eutanásico. Se presupone en el presente caso que al menos una parte ha brindado la información y la otra la ha comprendido y en consecuencia asiente o no acerca de lo que se le está informando y solicitando al paciente.

\footnotetext{
${ }^{48}$ Pontificio Consejo para la Pastoral de los Agentes de la Salud, Carta de los Agentes de la Salud, no 123.

${ }^{49}$ ARMANDO S. y ANDREUT, "Ley holandesa de terminación de la vida a petición propia ... ”, ob. cit. p. 190. vol.07, nº. 02, Rio de Janeiro, 2014. pp. 892-1009
} 
Al médico objetivamente la Ley no le impone que constate una recepción de la información que ha sido facilitada, esto es, no debe generarle preocupación que el paciente no comprenda definitivamente lo que el médico indica. Al médico tampoco le preocupa que el paciente haya comprendido o no la información que le ha facilitado acerca de su estado de salud y las soluciones posibles de la misma, será suficiente con que esté convencido de la petición que ha realizado el paciente, aunque definitivamente pueda tener un desconocimiento menor o mayor de lo que el mismo médico se encargo de explicar.

Además, en ningún momento señala la Ley la situación de deficiencia psicológica en la que se encuentra el paciente que se enfrenta al proceso de la muerte. Lo único que busca la Ley es que exista un convencimiento por parte del médico de la solicitud que ha expresado el paciente de concluir con su vida. No se requiere al médico otra cosa que no sea la de poner de manifiesto cuál es la razón médica que como tal acarree la muerte del paciente ${ }^{50}$.

Inexistencia de otra solución razonable

Debemos destacar que en el presente requisito existe una relación evidente y notoria de cooperación entre el paciente y el enfermo, puesto que, como exige la Ley, el médico debe estar convencido junto con el paciente que no existe otra solución razonable que no sea provocar la muerte del paciente. No se trata de una apreciación técnica la que al médico se le requiero por parte de la Ley, sino una participación volitiva semejante a la que el mismo paciente tiene, así pues, no se puede dejar de declarar una preocupación por la forma en la que puede influir dentro de la apreciación del propio médico el querer acabar con la vida del paciente.

La inviabilidad de otra solución razonable para la situación en la que se encuentra el paciente presenta cierta ambigüedad en la norma, ya que la situación en la que se encuentra el paciente debió quedar debidamente explicitada en la Ley y no lo está ${ }^{51}$.

Consulta y visita por un médico ajeno

Estamos en presencia de una "comprobación cruzada" y por la cual, otro médico acredita en el mismo sentido que aquel que llevará a cabo el cumplimiento de la solicitud de conclusión de la vida del paciente, de que la totalidad de extremos anteriores se encuentran debidamente acreditados.

\footnotetext{
${ }^{50}$ ARMANDO S. y ANDREUT, “Ley holandesa de terminación de la vida a petición propia ...”, ob. cit. p. 191.

${ }^{51}$ ARMANDO S. y ANDREUT, "Ley holandesa de terminación de la vida a petición propia ...”, ob. cit. p. 192. vol.07, nº. 02, Rio de Janeiro, 2014.pp. 892-1009
} 
La Ley ha omitido cualquier consideración en la que se concrete la especialidad que debe tener el médico ajeno consultado, por lo que, cualquier otra opinión que pueda confirmar la situación que expresa el primer médico es suficiente para cumplir con este requisito ${ }^{52}$.

Producir la muerte del enfermo con el máximo cuidado y esmero profesional

Se refiere este requisito la acción directa del médico en el cumplimiento de la terminación de la vida o del auxilio al suicidio de su paciente, pues se solicita al mismo que coloque el máximo cuidado y esmero profesional en la actuación médica solicitada.

Se requiere por lo tanto que sea un acto rápido, eficaz y en manera alguna cruento, requisitos que deberá cumplir el médico en el momento de provocar la muerte de su paciente. Tras estas exigencia lo que podemos destacar es que se trata de evitar el temor al dolor $y$ al sufrimiento por lo cruento que el proceso de la muerte puede generar para algunas enfermedades, es por ello que, entienden algunos autores que en esta fase es fundamental aplicar cuidados paliativos integrales que la medicina tiene hoy día a su alcance ${ }^{53}$.

\section{LA LEY RELATIVA A LA EUTANASIA DE BÉLGICA DE 28 DE MAYO DE 2002}

La Ley relativa a la eutanasia de 28 de mayo de $2002^{54}$, tuvo su origen en una Propuesta presentada en el Senado el año 1999. Dos años antes, se había producido en el Senado belga un amplio debate sobre el tema de la eutanasia. El origen de la misma fue una Recomendación del Comité Consultivo de Bioética emitida el día 12 de mayo del mismo año, en la que se hacía referencia a la oportunidad de regular la eutanasia. En la citada Recomendación, la Comisión dio su voto favorable a la liberación de dicha práctica, a pesar de que varios miembros se opusieron. El 22 de diciembre el Comité de Bioética emitió una segunda Recomendación relativa a la detención activa de la vida de las personas incapaces de expresar su voluntad ${ }^{55}$.

El 20 de octubre de 1999, las Comisiones de Justicia y de Asuntos Sociales del Senado de Bélgica comenzaron a debatir las Propuestas de Leyes de eutanasia y de otros problemas relacionados con el final de la

\footnotetext{
${ }^{52}$ ARMANDO S. y ANDREUT, “Ley holandesa de terminación de la vida a petición propia ...”, ob. cit. p. 193.

${ }^{53}$ ARMANDO S. y ANDREUT, "Ley holandesa de terminación de la vida a petición propia ...”, ob. cit. p. 194.

${ }^{54}$ Ley relativa a la eutanasia de 28 de mayo de 2002, publicada el día 22 de junio de 2002, Ministerio de Justicia, y que entró en vigor el día 20 de septiembre de 2002, tal y como se establece en el art. 16 de la citada Ley. Para más información sobre la eutanasia en Bélgica ver: GONZÁLEZ HERRANZ, "La metamorfosis del activismo pro eutanasia", en Persona y bioética, vol. 8, no 22-23, 2004, pp 1 y ss. ROYES I QUI, A. "La eutanasia y el suicido médicamente asistido", en Psicooncología: investigación y clínica biopsicosocial en oncología, vol. 5, n. 2-3, pp. 323 y ss. La eutanasia infantil en Bélgica, avergüenza y ha de espolearnos, en Ecclesia, no 3715, 2014, p. 5 y ss. VEGA GUTIÉRREZ, J. "La práctica de la eutanasia en Bélgica y la "pendiente resbaladiza", en Cuadernos de bioética, vol. 18, n 62, 2007, pp. 25 y ss.

${ }^{55}$ VEGA GUTIÉRREZ J., "La práctica de la eutanasia en Bélgica y la Pendiente resbaladiza", en Cuadernos de Bioética, XVIII, $2007 / 1$, p. 72 .
} 
vida de las personas, intentando que de alguna forma se siguiera el modelo holandés. Se dedicaron distintas reuniones y sesiones de trabajo que finalizaron el día 9 de julio de $2001^{56}$.

En la Ley no se menciona de forma explícita el suicidio asistido, la Ley habla siempre de eutanasia. Sin embargo, el primer informe elaborado por la Comisión Federal de Control y Evaluación de la eutanasia, precisaba que algunos supuestos de eutanasia fueron en realidad casos de suicidio médicamente asistido puesto que, el propio paciente ingirió por su propia mano el producto letal o activó el mecanismo instaurado con este fin ${ }^{57}$.

La Comisión de control señaló que, puesto que la Ley no exigía un procedimiento concreto para la práctica de la eutanasia, no procedía modificar el título de la citada Ley para introducir en la misma el supuesto de suicidio médicamente asistido, aunque esa misma Ley sí exige que el médico controle el proceso de morir en todo momento y en todos sus aspectos. De ello concluye ROYES que el suicidio médicamente asistido se interpreta como una acción eutanásica que debe cumplir con los requisitos que la Ley establece a tal efecto ${ }^{58}$.

La Ley belga no exige que sólo puedan acogerse a la misma los ciudadanos belgas, si bien en la práctica entre el solicitante y el médico que accede a una petición de eutanasia o de suicidio médicamente asistido debe mediar una relación asistencial suficientemente estrecha como para que el médico pueda verificar que el paciente cumple todas las condiciones exigidas por la Ley.

La Ley Relativa a la Eutanasia ${ }^{59}$ consta de dieciséis artículos en los que se incluyen: Disposiciones generales, Los requisitos y el procedimiento, La Declaración anticipada, La Declaración, La Comisión Federal de control y evaluación y Disposiciones particulares.

Según se establece en la LRE: Se entiende por eutanasia "el acto practicado por parte de una tercera persona, que pone intencionadamente fin a la vida de una persona a solicitud de ésta última" ${ }^{\text {. }}$.

Se dispone dentro de los Requisitos y el Procedimiento que se debe seguir para poder practicar la eutanasia que:

1. La práctica de la eutanasia debe ser solicitada por parte del paciente mayor de edad con capacidad suficiente y consciente en el momento en el que lo solicita. La petición debe ser voluntaria, meditada y reiterada, y no debe surgir como resultado de presiones externas.

2. El paciente debe encontrarse en una situación médica en la que no tiene solución y con sufrimientos físicos y psíquicos insoportables y constantes que no pueden ser subsanados y que deriven de una afección patológica grave e incurable o cómo consecuencia de un accidente.

\footnotetext{
${ }^{56}$ Para ver la evolución de la aprobación de la Ley en el Senado, ver obra de la autora, p. 74.

${ }^{57}$ ROYES, A. “La eutanasia y el suicidio ....”, ob. cit. p. 330.

${ }^{58}$ ROYES, A. "La eutanasia y el suicidio ....”, ob. cit. p. 331.

${ }^{59}$ La Ley Relativa a la Eutanasia, en adelante, LRE.

${ }^{60}$ Disposiciones Generales de la LRE, art. 2, Concepto de eutanasia.
} 
De todo ello, podemos concluir que la Ley autoriza la eutanasia cuando concurren los tres siguientes requisitos:

1. Que exista plena y libre voluntad del paciente de que se practique.

2. Que tenemos que estar en presencia de un enfermo terminal e incurable, que padece sufrimientos insoportables e incurables. La enfermedad debe ser terminal o debe estar en situación irreversible. También cuando estamos en presencia de un enfermo que tiene grave sufrimiento psicológico, con pérdida de autonomía, escasa calidad de vida, sentimiento de ser una carga para sus allegados, etc.

3. Que el enfermo padece dolores insoportables.

A pesar de que se cumplen todos los requisitos señalados anteriormente, es necesario que se cumplan las condiciones establecidas en la presente $L e y^{61}$.

El médico, antes de aplicar la eutanasia deberá tener en consideración determinadas cuestiones y cumplir con los siguientes requisitos:

1. Debe informar al paciente de su estado de salud y de su esperanza de vida, plantear las posibilidades terapéuticas que pueden existir, así como ofrecer los cuidados paliativos que tiene a su disposición.

2. Tras cumplir con los requisitos señalados anteriormente, médico y paciente tienen que llegar a la convicción de que la eutanasia es la única solución razonable en su situación médica y que la petición de eutanasia del paciente es completamente voluntaria.

3. La petición deberá realizarse por escrito, y puede haber sido redactada y autentificada antes, en previsión de condiciones futuras de incompatibilidad. Si el paciente se encuentra en una fase en la que no puede realizarlo por sí mismo, la solicitud se realizará por parte de una persona mayor de edad a su elección que no tendrá interés en la muerte del paciente. En la solicitud, ésta última persona deberá hacer constar que el paciente no puede formular personalmente la solicitud de eutanasia y deberá indicar las razones de su imposibilidad. En éste caso, la solicitud deberá realizarse por escrito y será presentada al médico, señalando el nombre del médico concreto. Este documento se conservará en el informe médico del paciente. El paciente puede revocar su solicitud en cualquier momento, en este caso, la solicitud será retirada del dossier del paciente y se le entregará personalmente a él ${ }^{62}$.

4. La Ley prevé además que se consulte con otro médico, independiente y con competencia en la enfermedad del paciente, así como a todo el equipo sanitario que atiende al enfermo, si existe el citado equipo ${ }^{63}$.

\footnotetext{
${ }^{61}$ Art. 3.1 de la LRE, Capítulo II, De las Condiciones y el Procedimientos.

${ }^{62}$ Art. 3.4 de la LRE:

${ }^{63}$ Art. 3.2 de la LRE.
} 
Además, si el médico pronostica que la muerte no ocurrirá en un periodo de tiempo breve, ha de consultar a un segundo médico, psiquiatra o especialista de la patología en cuestión, y deberá transcurrir al menos un mes de reflexión entre el momento de la petición de la eutanasia y su ejecución efectiva ${ }^{64}$.

Seguidamente la Ley recoge la Declaración anticipada que puede realizar toda persona mayor de edad o menor emancipada y capacitada para ello, por escrito, señalando su voluntad de que el médico le practique la eutanasia en determinados supuestos:

a) Que tenga un accidente o patología grave e incurable.

b) Que no esté consciente.

Esta declaración puede designar a una o varias personas de confianza, mayores de edad y señaladas por orden de preferencia, con los que el médico debe consultar para determinar la voluntad del paciente ${ }^{65}$.

La Ley establece que el médico que ha practicado la eutanasia, debe, en un plazo de 4 días remitir el documento en el que se contienen los requisitos que señala el art. $7^{\circ}$ a la Comisión Federal de Control y Evaluación que se señala en el art. $6^{66}$.

Se ha creado la Comisión Federal de Control y Evaluación de la aplicación de la Eutanasia cuya función es emitir informes en relación con la práctica de la eutanasia ${ }^{67}$. Estos informes se presentan en la Cámara Legislativa y el primer Informe fue presentado el día 23 de septiembre de $2004^{68}$.

Señalaremos seguidamente algunos requisitos que la Ley recoge y que consideramos que son fundamentales, como son: a- la voluntad del paciente, b- que la enfermedad esté en fase terminal, c- que el dolor sea insoportable, d- el retraso en el desarrollo de la medicina paliativa y la ampliación de la Ley, y e- la no punición de las transgresiones.

\section{La plena voluntad del paciente}

Este requisito es determinante a la hora de proceder a la aplicación de la eutanasia aunque se señala por parte de algún autor que en ocasiones, en el procedimiento que se sigue por parte del médico no se respeta. En el art. 14 de la Ley no se menciona expresamente la petición escrita por parte del paciente, es más en ocasiones, esta petición no existió. Señalan los médicos que en muchos casos el paciente estaba agónico, o padecía sufrimientos extremos, o tenía paralizados sus miembros.

\footnotetext{
${ }^{64}$ Art. 3.3 de la LRE.

${ }^{65}$ Art. 4.1 de la LRE: Se dispone en la Ley que se deberán cumplir otros requisitos. En el apartado 2o se dispone cuando el médico que práctica la eutanasia como consecuencia de la existencia de una declaración anticipada de voluntad del paciente no incurre en infracción,

${ }^{66}$ Capítulo IV: De la Declaración: art. 5o de la LRE.

${ }^{67}$ Capítulo V: De la Comisión Federal de Control y Evaluación, art. 6 de la LRE.

${ }^{68}$ VEGA GUTIÉRREZ J., "La práctica de la eutanasia en Bélgica y la Pendiente resbaladiza", Cada dos años se presenta un Informe, para ver los informes que se han emitido, ver: pp. 75 y ss del autor, ob. cit.
} 
En los distintos Informes emitidos por parte de la Comisión Federal de Control y Evaluación de la aplicación de la eutanasia ${ }^{69}$, cuando se estaba en presencia de la inexistencia de solicitud escrita del paciente, ha señalado que este hecho podía explicarse por la urgencia y el dramatismo de la situación en la que se encontraba el enfermo, y que el resto de datos permitían asegurar que se cumplía con las exigencia legales (petición de eutanasia reflexiva, voluntaria y repetida, sin presiones externas).

En algunos casos en los que no se ha emitido el acto voluntario del paciente, se interrogó a los médicos, y éstos declararon que: cuando la muerte era inminente, consideraban superflua una petición escrita o se conformaban con que una tercera persona pusiese por escrito la petición del paciente por no poder haberlo él mismo.

Debemos destacar que varios miembros de la Comisión mostraron sus reservas en la aceptación de las declaraciones realizadas por parte de los médicos, pero la Comisión respaldo estas decisiones, concluyeron afirmando que habían cumplido con las condiciones legales que señala la Ley.

Señala VEGA GUTÍERREZ que es evidente que en muchos casos no existe solicitud voluntaria, reflexiva y repetida del paciente, aunque la opinión de los familiares y allegados ha podido influir en la solicitud no escrita de los pacientes.

Destacar también que, varios médicos confundieron una petición escrita de eutanasia con la declaración anticipada. En este caso, efectivamente la previsión realizada de forma anticipada cuando el paciente tiene capacidad para ello, vemos que tampoco se cumple el requisito de la voluntariedad actual, porque en el tiempo que transcurre entre la elaboración de la declaración anticipada y el momento en el que se hace necesaria la voluntad actual del paciente (momento en el que se debe aplicar al eutanasia) el enfermo ha podido cambiar de opinión y no existe una nueva consulta sobre su parecer en el momento en el que se aplicará la eutanasia.

En relación a los médicos que señala la Ley que deben ser consultados, se ha detectado que los informes que debían emitir de forma preceptiva, en ocasiones no concluían señalando que efectivamente procedía aplicar la eutanasia, a pesar de ello, fueron dados por válidos. Además, para algunos miembros de la Comisión estos médicos que eran consultados no tenían la competencia profesional exigida por la Ley, a pesar de lo cual, la Comisión consideró que cualquier médico era suficiente, con independencia de su cualificación profesional. Con ello se detecto que, efectivamente cualquier médico, fuera cual fuera su especialidad podía asegurar que la afección que padecía el enfermo era incurable, grave, que el sufrimiento era insoportable, constante e irremediable, que es lo que exige la Ley $^{70}$.

\footnotetext{
${ }^{69}$ En adelante, La Comisión.

${ }^{70}$ VEGA GUTIÉRREZ J., "La práctica de la eutanasia en Bélgica y la Pendiente resbaladiza”, ob. cit. p. 81.
} 
En cuanto a eutanasia no voluntaria y los hospitales en los que se practica, señala VEGA GUTIÉRREZ el caso de una paciente a la que se le aplicó la eutanasia sin haberla solicitado por escrito, requisito éste último que exige la Ley para asegurar la plena voluntariedad. Este caso que se produjo el año 2003 fue muy comentado por los medios de comunicación, ya que, al tener conocimiento del hecho acaecido, el director del centro sanitario despidió al médico. A partir de este caso se ha cuestionado el papel que tiene la dirección del centro sanitario en el que se aplica la eutanasia en relación con el cumplimiento de los requisitos del procedimiento que establece la Ley. Destacar que generalmente estos casos se producen en la mayoría de los supuestos en centros católicos, lo que ha supuesto que muchos médicos se niegan a aplicar la eutanasia cuando así se lo solicitan sus pacientes para no tener problemas con el centro hospitalario en el que trabajan ${ }^{71}$.

Respecto a la eutanasia involuntaria se conocen dos casos desde que entró en vigor la Ley, el primero, el de una enfermera que había sido acusada de asesinato de tres ancianos, el segundo, el de un médico y una enfermera que provocaron la muerte de una anciana en un hospital.

Todos ellos están acusados de asesinato por parte del fiscal, que asegura que los casos en los que no concurren los requisitos que establece la Ley siguen considerándose delito de asesinato. En opinión de uno de los padres de la Ley, el Diputado Monfils, el médico que no respeta los requisitos que establece la Ley debe ser perseguido penalmente. Sin embargo los abogados señalan que se trató en todos los casos de un acto de caridad en el que se acompaño a la moribunda suavizando sus dolores.

Teniendo en consideración los Informes que se han emitido por parte de la Comisión durante los últimos años, VEGA GUTIÉRREZ entiende que no se han cumplido los requisitos de plena voluntariedad que exige la Ley, se admite la eutanasia sin petición escrita del enfermo, no se asegura que la voluntariedad sea actual, la función de control del médico consultor prevista por la Ley ha quedado desdibujada y la Comisión se preocupa poco de que se cumplan los requisitos legales, como son la plena voluntariedad del enfermo y los plazos previstos en la Ley $^{72}$.

\section{La enfermedad está en fase terminal}

En principio, la Ley no está limitada a los pacientes terminales. La primera eutanasia legal se aplicó a un paciente con una enfermedad degenerativa que no estaba en fase terminal.

La Comisión ha debatido sobre el pronóstico que debe tener el paciente para que se le aplique la eutanasia, uno de los miembros de la Comisión, médico de profesión, dudaba de los pronósticos de muerte

\footnotetext{
${ }^{71}$ VEGA GUTIÉRREZ J., “La práctica de la eutanasia en Bélgica y la Pendiente resbaladiza”, ob. cit. p. 81.

${ }^{72}$ VEGA GUTIÉRREZ J., "La práctica de la eutanasia en Bélgica y la Pendiente resbaladiza”, ob. cit. pp. 82-83.
} 
precoz de algunas de las declaraciones, aunque la Comisión consideró que era una estimación personal que corresponde exclusivamente al médico que trata al enfermo ${ }^{73}$.

\section{El dolor sea insoportable}

De los datos disponibles se puede señalar que el requisito legal del padecimiento de dolores insoportables no se cumple en la práctica, al no poder ser valorado, es más, debemos recordar que también se incluye el padecimiento psíquico dentro de los casos en los que se puede aplicar la eutanasia.

Se señala en los Informes que se han emitido por parte de la Comisión, que en todos los casos en los que se ha aplicado la eutanasia el dolor era insoportable, constante e intratable.

En algunos casos, los datos emitidos por parte del médico en relación con que el sufrimiento era insoportable o insoportables han sido juzgados por algún miembro de la Comisión como insuficientes, aunque la mayoría de los mismos han entendido que eran suficientes y además, no era de su competencia erigirse en jueces de los tratamientos utilizados. Además, se consideró en muchas ocasiones por parte de los miembros de la Comisión que el dolor insoportable es en buena parte algo subjetivo, que depende del propio paciente y de sus valores.

Por lo que respecta a que el sufrimiento sea intratable, la Comisión señaló que el paciente tiene derecho a rechazar el tratamiento. Afirma la Comisión que, en estos supuestos debe existir una relación entre médico y paciente, pero que esto no supone que necesariamente hay que aplicarle al paciente tratamientos paliativos, como proponía algún miembro de la Comisión. Sería suficiente con estar en presencia de "desesperanza del paciente, de la pérdida de dignidad y autonomía" como sufrimientos psicológicos que permitirían aplicar la eutanasia.

Podemos por ello concluir señalando que "no existe distinción entre eutanasia solicitada como consecuencia de dolor físico y por motivos de sufrimiento psicológico" y que se aplica la muerte al paciente con dolor controlado pero que la solicitan por otros motivos: pérdida de autonomía, poca calidad de vida ... etc. ${ }^{74}$.

\section{El retraso en el desarrollo de la medicina paliativa}

Por los datos que se tienen hasta este momento, la verdad es que en Bélgica se ha incrementado, durante los últimos años, el número de atenciones paliativas a pacientes. Tras aprobarse la Ley de eutanasia, poco después, se aprobó la Ley de cuidados paliativos, concretamente el mes de julio de 2002. Estos cuidados

\footnotetext{
${ }^{73}$ VEGA GUTIÉRREZ J., "La práctica de la eutanasia en Bélgica y la Pendiente resbaladiza”, ob. cit. p. 83.

${ }^{74}$ VEGA GUTIÉRREZ J., "La práctica de la eutanasia en Bélgica y la Pendiente resbaladiza”, ob. cit. p. 84.
} 
pueden ser prestados en centros sanitarios o en los domicilios de los propios pacientes, y no se paga la asistencia por visitas médicas.

\section{El retraso en el desarrollo de la medicina paliativa}

Las Leyes de eutanasia se van ampliando y haciéndose más permisivas, suprimiendo los mecanismos de control. Existe poca voluntad para que se cumpla la Ley y se mantenga en los términos adoptados inicialmente. No se ha transmitido ningún expediente a los Tribunales y la Comisión considera adecuada la aplicación que se está haciendo de la Ley, silenciando las posiciones discrepantes de algunos de sus miembros.

Existen algunas voces, incluso del propio Presidente de la Comisión que considera que debe incluirse, también la eutanasia en el caso de los menores. Dos Senadores del partido liberal presentaron una Proposición de Ley el año 2002 en relación con el tema. En el texto propuesto, no figuraba la edad mínima e introducía la noción de "capacidad de discernimiento", teniendo en cuanta, que los niños enfermos crónicos tienen una madurez mucho mayor que la de sus compañeros de su misma edad.

En el caso de que se aprobara esta Ley, los médicos deberán evaluar si el niño es capaz de comprender su estado, y, aunque se consulte a los padres y familiares próximos, éstos no podrán oponerse a la petición de eutanasia del menor si los médicos lo consideran legítimo ${ }^{75}$. Esta Proposición de Ley fue aprobada en Sesión Plenaria del Senado y enviada a la Comisión de Justicia el día 15 de julio de 2004.

Esta Proposición de Ley incluye también el "suicidio asistido" en la legislación para los que deseen realizar ellos mismos este último acto. En el mismo, se cambian y precisan los conceptos de "ser consciente" y de "no ser ya consciente", por "ser consciente de su propia personalidad" y "no ser consciente de su propia personalidad", que las declaraciones anticipadas tengan un carácter de ilimitado, y que el médico que rechace realizar una eutanasia tenga la obligación de enviar al paciente a otro médico.

Al suprimirse estas restricciones, podrán darse respuestas claras a las peticiones justificadas de muerte dulce y humana, concluye la Propuesta de ampliación y cambio de la Ley ahora vigente.

Es evidente que, a pesar de que la Ley lleva pocos años vigente, tanto la Comisión como otras instancias recomiendan su reforma y ampliación a los casos de eutanasia no voluntaria e involuntaria, como es sin duda el caso de los niños y los enfermos mentales ${ }^{76}$.

Esta reforma se ha producido el día 3 de marzo de 2014 tras la firma del Rey de la citada Ley. Se permite a través de la misma a los niños y adolescentes optar por la eutanasia en casos muy restringidos,

\footnotetext{
${ }^{75}$ VEGA GUTIÉRREZ J., "La práctica de la eutanasia en Bélgica y la Pendiente resbaladiza”, ob. cit. p. 85. HOVINE A. “L'EUTHANASIE, AUSSI POUR LES ENFANTS”, en Diario La Libre Belgique, 7-IX-2004, p. 85.

${ }^{76}$ VEGA GUTIÉRREZ J., "La práctica de la eutanasia en Bélgica y la Pendiente resbaladiza”, ob. cit. p. 86. 
cuando padezca un sufrimiento físico insoportable y su muerte a corto plazo sea inevitable. Destacar que, según se señala en las últimas encuestas, el 75\% de los ciudadanos están a favor de la eutanasia siempre que exista un control médico estricto.

\section{LA LEY SUIZA SOBRE LA ASISTENCIA AL SUICIDIO}

La eutanasia está castigada penalmente en Suiza, sin embargo no lo está la ayuda al suicidio a condición de que dicha ayuda se efectúe por motivos desinteresados. El art. 115 del Código penal suizo aparece como una solución intermedia, a medio camino entre la impunidad absoluta y la represión indiscriminada. Se trata de una fórmula de compromiso que, aunque penaliza la asistencia al suicidio en general, limita el carácter punible la acción a las actuaciones "egoístas", es decir, cuando el que ayuda al suicidio obtendría en caso de consumarse algún beneficio aunque cuando este no fuese únicamente de tipo material, lo cual incluiría la satisfacción de necesidades afectivas como el odio, el desprecio o el deseo de venganza ${ }^{77}$.

En Suiza la ayuda al suicidio no tiene que contar necesariamente con la asistencia de un médico. El Departamento Federal de Justicia del país precisa que la asistencia al suicidio consiste en facilitar al paciente la sustancia moral que éste ingerirá por si mismo, sin intervención externa por si mismo, sin intervención externa, a fin de acabar con su vida.

A partir del año 2004 la Academia de Ciencias Médicas de Suiza ha reconocido al médico que mantiene una relación personal con su paciente el derecho de proporcionarle su ayuda al suicido en base a una decisión moral personal y en el marco del respeto al principio de autonomía del paciente. La Academia ha reconocido que el derecho a ejercer la autonomía o la autodeterminación personal es el eje moral sobre el que gira la libertad de decisión acerca de la propia vida y de la propia muerte, lo que implica la posibilidad de que otros puedan intervenir en la realización de nuestra propia libertad. Si ésta capacidad de autonomía personal se viera afectada de forma importante por alguna circunstancia, en este caso la ayuda al suicidio debería considerarse punible. Sin embargo, la interpretación que este Comité presenta del citado artículo del Código penal suizo excluye que quepa hablar de un derecho de los pacientes residentes en el país a exigir de otros ciudadanos, médicos o no, ayuda al suicidio, lo que constituye, la razón de ser de diversas organizaciones no gubernamentales de ayuda al suicidio ${ }^{78}$.

\footnotetext{
${ }^{77}$ ROYES, A. “La eutanasia y el suicidio ...”, ob. Cit. P. 331.

${ }^{78}$ ROYES, A. “La eutanasia y el suicidio ...”, ob. cit. p. 331.
} 
La Ley Suiza sobre "Directivas de aplicación de la Ley de la salud pública y de asistencia al suicidio en centro sanitarios de interés público", que entró en vigor en enero de 2013, Ley del Cantón de Vaud tuvo su origen en el art. 27-d) de la Ley de la salud pública ${ }^{79}$.

El art. 27.d de la Ley de la Salud pública ${ }^{80}$, base legal de la Ley de Asistencia al Suicidio ${ }^{81}$ según se señala en el apartado $1^{\circ}$, dispone, en relación con la asistencia al suicido en establecimientos sanitarios reconocidos como de interés público que:

1. Los establecimientos sanitarios reconocidos de interés público no pueden rechazar la asistencia al suicidio cuando sea solicitado por un paciente o un residente, siempre que se cumplan las siguientes condiciones:

a) El médico responsable del tratamiento o del establecimiento médico, en concurrencia con el equipo que aplica los cuidados, el médico que atiende y los familiares o personas próximas al paciente o residente, verifiquen que:

i. es capaz de discernir su decisión de suicidarse y que persiste con su intenciónvoluntad de suicidarse.

ii. padece una enfermedad o secuelas graves e incurables.

b) Las alternativas, en particular las que hacen referencia a los cuidados paliativos, han sido evaluados con el paciente o con el residente.

2. Tras verificar las condiciones establecidas en el apartado a), párrafo $1^{\circ}$, el médico responsable puede solicitar la opinión de otro médico autorizado a ejercer la medicina en el Cantón de Vaud o de una Comisión de evaluación interna del centro sanitario o establecimiento médico-social.

3. El médico responsable solicitará por escrito la asistencia al suicidio en un plazo de tiempo razonable.

4. Si el paciente dispone de una vivienda exterior y el establecimiento sanitario no dispone de una sección específica para este fin, el médico puede rechazar la asistencia al suicidio en el citado establecimiento, a pesar de que el regreso del paciente a su vivienda habitual sea razonablemente exigible.

5. El personal del establecimiento sanitario y el médico responsable que están implicados en la aplicación de la asistencia al suicidio, no pueden intervenir, a título profesional, en el proceso de asistencia al suicido.

6. Cuando la asistencia al suicidio se va a aplicar en el establecimiento sanitario, el médico responsable debe asegurarse que los medios empleados están en consonancia con las prescripciones médicas.

7. El Departamento concreta las condiciones en las que debe aplicarse este artículo, tras consultar con las personas implicadas en la misma.

Vigente el art. 27.d) de la LSP, el auxilio al suicidio se aplicaba en Suiza en las condiciones señaladas anteriormente. Destacar que, antes de entrar en vigor la Ley de asistencia al suicidio y como consecuencia de la aplicación del suicidio asistido que permitía la LSP a través de su art. 27.d), se emitieron dos Recomendaciones de la Comisión Nacional de ética para la medicina los años 2005 y 2006. La citada Comisión recomendó al legislador que los poderes públicos supervisaran las organizaciones de ayuda al

\footnotetext{
${ }^{79}$ Para más información sobre la Ley de asistencia al suicidio y la Ley de la salud pública, ver: Página del Cantón de Vaud, http://www.vd.ch/themes/sante-social/services-de-soins/assistance-au-suicide/. Consultado el 12-08-2013.

${ }^{80}$ Ley de la Salud pública, de 29 de mayo de 1985 y que entró en vigor el 1 de enero de 1986. Gran Consejo del Cantón de VAUD. En adelante, LSP.

${ }^{81}$ En adelante, LAS.
} 
suicidio que actuaban en Suiza al amparo del art. 115 del Código penal ${ }^{82}$. Así también, la Recomendación 13/2006 consideró que la práctica del suicidio asistido debía regirse por un acuerdo de mínimos que garantizase, la protección de quienes se plantean inicialmente poner fin a la vida con la asistencia de estas organizaciones ${ }^{83}$.

Esta Comisión considera que, desde la perspectiva ética, la asistencia al suicidio se fundamenta en dos ejes: a- el apoyo y la atención a las personas que se plantean el suicidio, y, b- el respeto a su derecho a la autodeterminación ${ }^{84}$.

Existe desde el año 1982 en Suiza la organización EXIT ${ }^{85}$, miembro de la Federación de Asociaciones del Derecho a morir dignamente, con dos sedes independientes: EXIT-Suisse Romande, con sede en Ginebra, y EXIT-Deutsche Schweiz, con sede en Zurich, admitiendo ambas como asociados exclusivamente a ciudadanos suizos. Estas organizaciones auxilian al paciente que desea poner fin a su vida y que cumple ciertos requisitos, facilitándole las correspondientes prescripciones médicas del producto letal, para lo que utilizan los servicios de un médico de la organización, acompañando al paciente en el proceso de decisión de suicidarse y en todo el proceso posterior a la muerte.

Los miembros asociados a EXIT que deciden suicidarse disponen de tres posibilidades: a- solicitar la intervención de un representante de la asociación, si el solicitante cumple los requisitos establecidos por la organización, este representante le proporcionará el producto letal. b- el solicitante formula su petición de asistencia al suicidio directamente a su médico habitual, que decidirá en conciencia. c- si el paciente decide actuar por si mismo, sin ayuda de nadie, se trata de un acto de auto liberación, en cuyo caso el papel de la organización se limita a facilitar a sus asociados, con tres meses de antelación mínimo, una guía para facilitar esta tercera opción.

Cuando el paciente suizo solicita la asistencia al suicidio mediante las organizaciones que hemos señalado, se pone en marcha un procedimiento que en líneas generales, es el siguiente: El paciente debe ser legalmente capaz, debe manifestar de forma reiterada su deseo de morir y debe experimentar sufrimiento a su parecer insoportable, o estar severamente incapacitado para las actividades cotidianas.

Los voluntarios de EXIT siguen un protocolo extremadamente preciso con el fin de diferenciar a los pacientes que pueden ser efectivamente ayudados en esta fase del auxilio al suicidio, de los que no reúnen alguna o algunas de las condiciones exigidas para ello.

\footnotetext{
${ }^{82}$ Recomendación 9/2005 de la comisión.

${ }^{83}$ Recomendación 13/2006, Criterios de diligencia relativos a la asistencia al suicidio.

${ }^{84}$ ROYES Albert, "La eutanasia y el suicidio médicamente asistido", en Psicooncología, Volumen 5, no 2-3, 2008, p. 335.

${ }^{85}$ http://www.exist.ch. Consultado el 12-08-2013. 
A pesar de ayudar al enfermo en esta última fase, las organizaciones recomiendan sistemáticamente que recurran a cuidados paliativos y que informen a sus allegados de su petición de asistencia al suicidio.

En una segunda fase, el paciente es examinado por parte de un médico de la organización, éste no prescribirá el fármaco letal a menos que esté convencido de que el paciente cumple los requisitos señalados anteriormente y si el médico que le atiende de forma habitual no desea participar en la asistencia al suicidio, físicamente, un voluntario de EXIT le facilitará al paciente el producto letal para que él mismo lo ingiera o active el dispositivo implementado a tal fin. En este supuesto, será el propio voluntario quien informara a la policía y al forense de la causa del fallecimiento del paciente ${ }^{86}$.

Existe otra organización EXIT, EXIT-Dignitas, con sede en Forch-Zurich ${ }^{87}$. Es una organización fundada el año 1998 que facilita la asistencia al suicidio a pacientes que no son ciudadanos suizos y que son socios de su organización. Entienden y afirman que es inaceptable, por razones éticas, que el suicidio asistido en Suiza sea una posibilidad únicamente al alcance de las personas que casualmente son ciudadanos suizos.

El procedimiento que se sigue por parte de esta organización es bastante similar al que hemos señalado anteriormente, con la diferencia de que los socios que no son suizos deben desplazarse necesariamente a Suiza con el fin de que un médico suizo confirme que cumple los requisitos exigidos: en caso afirmativo, el médico suizo puede extender la prescripción que será posteriormente facilitada al paciente con la ayuda y el acompañamiento de los miembros de Dignitas ${ }^{88}$.

La Ley del Cantón de Vaud y sus Directivas de aplicación entró en vigor el día 1 de enero de 2013. En la misma, se señala el procedimiento que debe seguir un paciente o residente en Suiza que quiere acceder al suicidio asistido. Se debe asegurar que se respetan los Derechos Fundamentales, las libertades individuales y la autodeterminación de la persona que quiere poner fin a su vida ${ }^{89}$. Así también, trata de proteger de una decisión de poner fin a la vida adoptada de forma precipitada, establece el acompañamiento que va a recibir el paciente y el procedimiento garantista de que la solicitud de asistencia al suicidio se corresponde, bien con la voluntad libre y reflexiva adoptada por parte de un residente o de un paciente. Asegura, así mismo, todas las alternativas posibles, especialmente las que hacen referencia a los cuidados paliativos, con el fin de que la asistencia al suicidio se constituya en una verdadera solución, el último recurso que desea el paciente.

La Ley se compone de 9 apartados que vamos a señalar seguidamente, destacando las cuestiones que consideramos más relevantes.

\footnotetext{
${ }^{86}$ ROYES Albert, “La eutanasia y el suicidio médicamente asistido”, ob cit. p. 333.

${ }^{87}$ http://dignitas.ch, esta organización no pertenece a la Federación de Asociaciones por el Derecho a la muerte digna. Consultado el 12-08-2013.

${ }^{88}$ ROYES Albert, “La eutanasia y el suicidio médicamente asistido”, ob cit. p. 334.

${ }^{89} \mathrm{http}: / /$ www.vd.ch/themes/sante-social/services-de-soins/assistance-au-suicide/. Consultado el 12-08-2013.
} vol.07, n. 02, Rio de Janeiro, 2014.pp. 892-1009 
1. Señala que el fundamento legal de la Ley, que tal y como hemos señalado anteriormente deriva del art. 27.d) de la Ley de 25 de mayo de 1985 de la Salud pública.

2. Señala la forma en la que debe realizarse la solicitud: La solicitud de asistencia al suicidio debe realizarse por escrito por parte del residente $\mathrm{e}^{90} /$ paciente a la dirección del establecimiento o a la dirección del centro de cuidados en el que se encuentra, quienes deberán informar a la dirección del establecimiento.

La dirección del establecimiento dirige-transmite rápidamente la solicitud al médico responsable del establecimiento hospitalario o del establecimiento médico-social.

Cuando la solicitud se ha presentado en el establecimiento sanitario por parte de la tercera persona que quiere que se le practique la asistencia al suicidio, la dirección del establecimiento sanitario o de cuidados paliativos, éstos pedirán al paciente o al residente que lo realice por escrito.

La dirección del centro sanitario puede solicitar que se realice una reunión entre el médico responsable, la tercera persona y el paciente o residente.

3. El médico responsable procederá al estudio de la solicitud presentada. Tras cumplir con las prescripciones señaladas en el punto anterior. El médico responsable, junto con el equipo de tratamiento del paciente, el médico que atiende al enfermo, el representante de cuidados, con el acuerdo del paciente/residente, sus familiares, verificará que las condiciones legales que señalaremos seguidamente se han cumplido:

a) El paciente/residente:

i. es capaz de entender lo que supone su decisión de suicidarse.

ii. su voluntad de suicidarse persiste.

iii. sufre de una enfermedad o de las secuelas de un accidente grave e incurable.

b) Las alternativas de tratamiento, en particular las relativas a los cuidados paliativos, han sido evaluadas con el paciente o residente.

El médico responsable puede solicitar en estos casos la opinión de otro médico, que autorice la aplicación de la eutanasia, o de la Comisión interna que existe en cada centro sanitario, tal y como está previsto en el art. 27.d) de la LSP. Si el médico responsable sospecha que la solicitud de la eutanasia por parte del paciente está afectada por padecimientos psíquicos del paciente/residente, o de influencias externas, debe solicitar la intervención de un psiquiatra.

\footnotetext{
${ }^{90}$ Recordar que cuando se hace referencia a RESIDENTE se menciona al posible enfermo que en principio se exige que sea residente en Suiza.
} 
4. La resolución del médico sobre la aplicación o no de la eutanasia: Corresponde al médico responsable de concretar por escrito, en un plazo máximo de cuatro semanas, teniendo en consideración la complejidad del caso la resolución adoptada. Si el paciente o residente cuenta con un representante en el ámbito de los cuidados, éste también deberá ser informado de la conclusión a la que llega el médico. Así también, el médico deberá informar a la dirección del centro y/o a la administración médica.

El médico responsable deberá motivar su decisión y señalar claramente las siguientes cuestiones: Que:

a) Los requisitos que exige la Ley se han cumplido,

b) Si es posible que el paciente vuelva a su domicilio, siempre que el paciente se encuentre en un centro sanitario,

c) La posibilidad de que el paciente o residente acuda a la mediación o a la Comisión en los supuestos en los que no exista acuerdo.

Si no se respeta el plazo de las cuatro semanas que hemos señalado anteriormente, el médico regional puede ser investigado.

5. La Información personal: El médico responsable, junto con los responsables del centro, deben informar a las personas señaladas en la Ley de las intervenciones de asistencia al suicidio que se han realizado.

6. Información al médico regional ${ }^{91}$ : Los responsables del centro sanitario, en colaboración con el médico responsable, deben informar anónimamente al médico regional y transmitir a través de fax o correo electrónico, la edad, el sexo y la patología que ha justificado la asistencia al suicidio que se ha aplicado.

7. La Comisión de seguimiento de la aplicación de la Ley y sus Directivas: El Departamento de salud y de Acción social ha creado una Comisión que deberá vigilar-verificar el cumplimiento de lo que se establece en el art. 27.d) de la Ley de 29 de mayo de 1985 de la Salud Pública. La Comisión no es un órgano de evaluación de los casos en los que se ha aplicado la asistencia al suicidio, pero puede dar recomendaciones a los responsables del Departamento.

Esta Comisión está integrada por representantes de distintas Instituciones, tales como, 1 Representantes del servicio de salud pública: médico de la región como presidente, 2 representantes de la asociación de asistencia al suicidio, 2 representantes de establecimientos médico-sociales, 1 representante de Comisión, 1 representante de la Federación de hospitales de la región, 1 representante de la asociación de

\footnotetext{
${ }^{91}$ Cuando se hace referencia a la Región, queremos referirnos al Cantón de Vaud.
} 
médicos en EMS de la Sociedad regional de médicos (GMEMS), 1 representante de clínicas privadas inscritas en la lista de clínicas privadas de la región y 1 representante de la asociación de pacientes.

8. Las sanciones: Si no se respetan las directivas-indicaciones, sobre todo la que hace referencia a las cuatro semanas, puede suponer sanciones que se contienen en la LSP.

9. Entrada en vigor: La Ley entrará en vigor el día 1 de enero de 2013.

Antes de entrar en vigor la Ley, concretamente el día 17 de junio de 2012, los ciudadanos de la región fueron llamados a posicionarse en relación con la iniciativa legislativa popular -contra-proyecto- presentada por EXIT. El Consejo de Estado y el Gran Consejo se opusieron a la citada iniciativa con el fin de evitar los posibles abusos y de garantizar la protección de las personas vulnerables respetando su libertad individual. Los ciudadanos-as aceptaron el contra-proyecto con una mayoría del 61,6\%.

Los ciudadanos y ciudadanas respondieron a tres cuestiones en relación con el contra-proyecto presentado por el Gran Consejo que proponía la modificación del art. 27.d) de la LSP.

a) ¿Aceptan la iniciativa popular de asistencia al suicido que modifica la Ley de 29 de mayo de 1985 de la salud pública?

b) ¿Aceptan el contra-proyecto del Gran Consejo que propone modificar la Ley de 29 de mayo de 1985 de la salud pública?

c) Si la iniciativa popular y el contra-proyecto se aceptan por parte de los ciudadanos, ¿Es la iniciativa legislativa del Gobierno o el contra-proyecto el que debe entrar en vigor?

El contra-proyecto ${ }^{92}$ o iniciativa legislativa de asistencia al suicidio en los centros médico-sociales (EMS) fue presentado por parte de EXIT en febrero de 2009.

El contenido de esta iniciativa legislativa establecía las normas por las que, un establecimiento sanitario (hospital o establecimiento médico-social) reconocido de interés público, no pueden rechazar la asistencia al suicidio. Estas normas vienen a garantizar que la decisión del paciente adoptada voluntaria y libremente y tras la reflexión correspondiente y sin injerencias ajenas o de terceras personas debe ser respetada y ejecutada.

La iniciativa legislativa señala los tres criterios que deben cumplirse necesariamente en estos casos:

1. La persona-paciente debe tener capacidad suficiente para conocer el alcance de la decisión que adopta, solicitar el suicido asistido. Para ello, es importante que el equipo médico, sus allegados y el médico responsable puedan llegar a la decisión de que el paciente cumple con este requisito.

\footnotetext{
${ }^{92}$ Contra-proyecto: en adelante “iniciativa legislativa”.
} 
2. La persona-paciente debe persistir en su voluntad de suicidarse. El miedo al dolor puede, efectivamente, mermar la capacidad de discernir del paciente, por ello es indispensable que los cuidadores se aseguren de que es consciente de que persiste con su voluntad de poner fin a su vida.

3. Finalmente, el paciente o residente debe padecer una enfermedad o las secuelas de un accidente grave e incurable. Efectivamente, el Consejo de Estado destaca la importancia de que se aplique la asistencia al suicidio a este tipo de pacientes.

El procedimiento previsto por parte de esta iniciativa legislativa se encamina a asegurar los mecanismos alternativos, concretamente los cuidados paliativos, que se han propuesto al paciente.

En el Gran Consejo se produjo un debate en el que, la gran mayoría de los Diputados rechazaban la iniciativa de mantener la iniciativa legislativa. Una minoría se declaraba hostil a la iniciativa, rechazando sobre todo que la ayuda al suicidio pudiera ser impuesto a los centros sanitarios en los que su ética rechazaba la aplicación de este tratamiento.

El Tribunal Federal en su Resolución de 3 de noviembre de 2006 confirmó que, cada persona capaz de discernir el derecho garantizado por parte de la Constitución y la Convención Europea de Derechos Humanos de decidir sobre el momento y la forma en la que debe darse por concluida su vida. Este derecho a decidir sobre la propia vida-muerte pertenece al derecho a la autodeterminación que se contiene en el art. 8.1 del Convenio Europeo de Derechos Humanos y que cada persona que se encuentra en esta situación, es libre de elegir y de actuar de acuerdo a lo que considera oportuno.

En la habitación del establecimiento médico-social, el residente puede disponer de un lugar privado en el que puede hacer valer libremente su derecho y su decisión.

La iniciativa desea hacer valer el derecho a la autodeterminación sin ningún tipo de trabas al residente del establecimiento médico-social, que con plenitud de facultades puede solicitar la asistencia al suicidio. El paciente-residente puede estar debilitado en sus capacidades físicas, pero esto no supone automáticamente que tenga perdida su capacidad de comprender la solicitud que está realizando. Sus derechos no pueden reducirse por estar en el centro médico-social y porque el equipo que le atiende estime irrevocable la solicitud presentada. La evaluación de la solicitud del paciente-residente por parte del equipo que le cuida será problemática al cuestionarse la imparcialidad y los objetivos, ya que éstos pueden ser contrapuestos.

El contra-proyecto que rechazamos es una vía que favorece el ensañamiento a través de los cuidados paliativos y el paternalismo médico. Somete al paciente a la tutela institucional.

Queremos que los pacientes-internos que residen en un establecimiento médico-social puedan expresar su voluntad, elegir y actuar como si estuviesen en sus domicilios. 
La Propuesta realizada por parte del Consejo de Estado en relación a la determinación de las condiciones en materia de asistencia al suicidio en los hospitales y establecimientos médico-sanitarios fueron los siguientes:

a) El contra-proyecto sometido a la consideración del Consejo de Estado trata de concretar claramente las condiciones en las que los establecimientos sanitarios (hospitales y establecimientos médicossanitarios ${ }^{93}$ de interés público) no pueden rechazar la asistencia al suicidio.

Queremos destacar que el contra-proyecto:

b) Respeta la libertad individual y el derecho a la autodeterminación del paciente-residente.

c) Protege de la adopción de decisiones precipitadas y establece el acompañamiento y el procedimiento garantista, que la solicitud de asistencia al suicidio se corresponde con la solicitud de la voluntad libre, sin presiones de terceros, $\mathrm{y}$ reflexiva del residente o del paciente.

d) Asegura, así mismo, que todas las posibles alternativas que pueden emplearse en el presente caso, incluidos los cuidados paliativos, han sido propuestos, con el fin de garantizar que el suicidio asistido se constituye verdaderamente en la última solución o recurso al que acude la persona.

El Consejo de Estado estima que no es apropiado reducir la preocupación de respetar la integridad de los residentes, los pacientes y las personas que aplican los distintos cuidados a los problemas administrativos que pueden deducirse de la aplicación de este procedimiento. Consideran que debe garantizarse la protección de las personas enfermas o mayores que son especialmente vulnerables.

Contrariamente a lo que se pensaba inicialmente, el Consejo de Estado propone introducir un marco legal claro en los hospitales a los que se reconoce que son de interés público.

Es por ello que, el Consejo de Estado y el Gran Consejo propone rechazar la iniciativa popular de asistencia al suicidio en los establecimientos médico-sociales y a votar a favor del contra-proyecto ${ }^{94}$.

\section{LA LEYES DE LUXEMBURGO SOBRE "LA EUTANASIA Y LA ASISTENCIA AL SUICIDIO” Y “LOS CUIDADOS PALIATIVOS”}

El Diario Oficial del Gran Ducado de Luxemburgo ${ }^{95}$ publicó el día 16 de marzo de 2009 dos Leyes importantes: a) la "Ley de 16 de marzo de 2009 sobre la eutanasia y la asistencia al suicidio" ${ }^{\circ}$, y, b) La "Ley de 16 de marzo de 2009 relativa a los cuidados paliativos, a la directiva-testamento anticipada y al

\footnotetext{
${ }^{93}$ Establecimientos médico-sanitarios: en adelante "EMS".

${ }^{94}$ Para más información sobre la Ley de asistencia al suicidio de Suiza, ver: ROYES Albert, "La eutanasia y el suicidio médicamente asistido", ob. cit. pp. 331 y ss.

${ }^{95}$ Journal Officiel du Grand-Duque de Luxembourg, A- no- 46, de 16 mars 2009, pp. 609 a $619 .$.

${ }^{96}$ En adelante LEAS.
} 
acompañamiento al final de la vida" que modificó: 1.- El Código de la Seguridad Social, 2.- La Ley de 16 de abril de 1979 que establece el estatus general de los funcionarios del Estado, 3.- La Ley de 24 de diciembre de 1985 que establece el estatus general de los funcionarios municipales, y, 4.- El Código laboral.

\section{La Ley de 16 de marzo de 2009 sobre la eutanasia y la asistencia al suicidio}

La primera de las Leyes, la LEAS consta de ocho Capítulos y dieciséis artículos, que tras la decisión adoptada por parte de la Cámara de Diputados el día 18 de diciembre de 2008 y del Consejo de Estado de 19 de diciembre de 2008, se aprueba la citada Ley.

En el Capítulo primero se contienen las Disposiciones Generales y se afirma que en aplicación de la presente Ley, deberá entenderse por eutanasia "el acto que practicado por un médico pone intencionadamente fin a la vida de una persona, que lo solicitud de forma expresa y voluntaria" ${ }^{\prime 2}$.

Debemos entender por asistencia al suicidio cuando el médico ayuda intencionadamente a otra persona a suicidarse o facilita a una tercera persona los medios necesarios para ello, siempre que lo solicité el paciente de forma expresa y voluntaria

En el Capítulo segundo se incluye las condiciones y el procedimiento que debe seguirse para solicitar la eutanasia ${ }^{98}$.

Señala el art. $2^{\circ}$ en sus distintos apartados que: No se sancionará penalmente y no puede dar lugar a una acción civil de daños y perjuicios contra un médico, cuando éste actúe en respuesta a una solicitud de eutanasia o de asistencia al suicidio, siempre que se cumplan las siguientes condiciones:

1. Que el paciente sea mayor de edad y esté capacitado y consciente en el momento en el que realiza la citada solicitud.

2. La solicitud se presente de forma voluntaria, reflexiva, reiterada y que no haya existido presión exterior.

3. Que el paciente se encuentre en una situación en la que no tiene posibilidad de curación, que padezca sufrimientos físicos y psicológicos constantes e insufribles, no existiendo posibilidad de mejorar su estado de salud, y todo ello derive de una afección accidental o patología.

4. La solicitud del paciente de que se le aplique la eutanasia o la asistencia al suicidio debe realizarse por escrito.

El médico deberá en todos los casos, antes de proceder a aplicar la eutanasia o la ayuda al suicidio, respetar las condiciones formales y procedimentales siguientes:

\footnotetext{
${ }^{97}$ Art. 1 de la LEAS.

${ }^{98}$ Art. 2 y 3.
} 
5. Informar al paciente de su estado de salud y su esperanza de vida, informar al paciente de las alternativas terapéuticas que tiene todavía, teniendo en consideración su estado de salud, así como, los cuidados paliativos que procedan y sus consecuencias.

El médico debe llegar a la convicción de que la solicitud del paciente es voluntaria, y que, desde el punto de vista del paciente no existe ninguna otra solución en su situación concreta.

La información se recogerá en el expediente médico del paciente en el que se indicará que se ha informado debidamente.

1. Debe asegurarse de la persistencia del sufrimiento físico o psicológico del paciente, y de la voluntad mostrada por éste de la persistencia de su solicitud. Para ello, mantendrá distintas conversaciones con el paciente en un tiempo prudente, teniendo en consideración la situación sanitaria concreta del paciente.

2. Deberá consultar con otro médico cuando, como consecuencia del estado grave e incurable en el que se encuentra el paciente así se requiera. El médico al que se consulta deberá informarse del estado del paciente. Para ello, deberá ver el expediente médico del mismo, examinar al paciente, y asegurarse del carácter constante, insoportable y sin perspectivas de mejora del sufrimiento físico o psíquico.

Tras cumplir con todo ello, emitirá un informe en el que se contendrán todas las circunstancias descritas anteriormente y que se cumplen en el presente caso.

El médico consultado debe ser imparcial, tanto en relación con el paciente como con el médico que le trata, y ser experto en la enfermedad que tiene el paciente.

El médico que atiende al paciente informará a éste de las conclusiones a las que ha llegado el médico consultado.

1. A no ser que el paciente se oponga, se mantendrá informado al equipo que le atiende y a los familiares de la solicitud del paciente.

2. Se mantendrá informado de la solicitud presentada por el paciente a las personas de su confianza (del paciente) que haya designado éste en su declaración de solicitud de eutanasia o de auxilio al suicidio, a no ser que el paciente se oponga.

3. Debe asegurarse que el paciente ha manifestado su solicitud a las personas que él quiere.

4. Informar a la Comisión Nacional de Control y Evaluación el nombre de la persona que ha muerto y su registro.

La solicitud del paciente debe realizarse por escrito. En el documento constará la fecha y la firma del paciente. Si éste está impedido físicamente y de forma permanente para cumplimentar la solicitud, se realizará este trámite por parte de una persona designada por el paciente personalmente. 
La persona que firma el documento en nombre del paciente debe indicar las razones por las que actúa en este sentido.

En este caso, la solicitud debe realizarse por escrito y estar firmada por el paciente o por la persona que actúa en su nombre, realizando la solicitud ante el médico que trata al paciente, indicando su nombre en el documento. Este documento se incluirá en el expediente del paciente.

El paciente puede revocar su solicitud en cualquier momento, en este caso, la solicitud se retirará del expediente médico del paciente y le será devuelto.

Todas las solicitudes presentadas por el paciente, así como la designación del médico y los informes de éste y del resto de médicos consultados se incluirán en el expediente médico del paciente.

El médico que atiende al paciente, si lo considera oportuno, podrá solicitar la opinión de un experto que él elija, posteriormente incluirá el informe del experto en el expediente del paciente ${ }^{99}$.

El Capítulo tercero recoge las condiciones en las que se va a desarrollar el procedimiento de la eutanasia o la asistencia al suicidio ${ }^{100}$.

Comienza señalando que: "Toda persona mayor de edad y capacitada para ello, puede, en los casos en los que no pueda manifestar su voluntad, designar por escrito su solicitud de poner fin a su vida, las condiciones y circunstancias en las que desearía someterse a la eutanasia, siempre que el médico certifique la concurrencia de las siguientes circunstancias:

a) Que sufre una enfermedad o patología grave e incurable,

b) Que está inconsciente,

c) Que la situación en la que se encuentra es irreversible, teniendo en consideración el estado de la ciencia médica en ese momento.

Las voluntades señaladas para poner fin a la vida pueden incluir disposiciones en las que muestra o declara su voluntad en relación con el tipo de entierro que desea y la ceremonia funeraria.

En la declaración anticipada que realiza una persona se puede designar a una persona de confianza, que debe ser mayor de edad y que puede manifestar al médico la voluntad de dicha persona en relación con lo que hubiera deseado.

Si la persona que desea realizar la declaración de voluntad anticipada en relación con el final de la vida, está imposibilitada físicamente y no puede realizar la declaración y firmarla, estas voluntades anticipadas, éstas podrán ser realizadas por parte de una persona mayor de edad de la confianza de la persona que no puede realizarlas por sí misma. Este documento deberá ser firmado por dos testigos mayores de edad.

\footnotetext{
${ }^{99}$ Art. 3 LEAS.

${ }^{100}$ Art. 4 LEAS.
} 
En esta declaración deberán constar que el declarante no puede formalizar por sí mismo el documento ni firmarlo, justificando las causas que le impiden hacerlo.

Estas declaraciones anticipadas deberán estar fechadas y firmadas por: la persona que ha realizado la solicitud, los testigos y por la persona de confianza señalada por parte del paciente.

Esta imposibilidad del paciente para presentar por sí mismo la solicitud deberá ser certificada por el médico.

Las solicitudes del paciente de poner fin a su vida o de solicitar el auxilio al suicidio serán registradas en un registro automático bajo la vigilancia del Consejo Nacional de Control y de Evaluación.

Estas solicitudes pueden ser reiteradas, retiradas o adaptadas en cualquier momento. La Comisión Nacional deberá solicitar cada cinco años, a partir del momento en el que se procedió al Registro la confirmación de la persona que realizó la solicitud. Todos los cambios deben ser registrados. No se podrá realizar ninguna eutanasia, si se cumple el requisito que se contiene en el parágrafo $3^{\circ}$ que señala: "Si el médico tiene conocimiento de que el paciente ha manifestado su intención posterior a haber declarado su intención de poner fin a la vida, indicando que no desea que se le aplique la eutanasia”.

Si el médico detecta que alguno de sus paciente, o una persona se encuentra en la fase final de su vida, debe informarse en la Comisión Nacional si existe alguna solicitud en relación con esa persona en la que solicitaba que se le aplicase la eutanasia y si la misma está registrada.

El acceso a la información relativa a si existen disposiciones de los pacientes en los que muestra su voluntad de que se le aplique la eutanasia llegado el momento que señala la Ley y el régimen de registro de esas voluntades se desarrollaran reglamentariamente.

No se sancionará penalmente y no se podrá iniciar una acción de responsabilidad civil al médico que respondiendo a una solicitud de eutanasia o de suicidio asistido de las previstas en los párrafos 1 y 2, siempre que el médico verifique que:

1. Que el paciente padece una enfermedad o patología grave e incurable,

2. Que está inconsciente,

3. Que la situación en la que está el paciente es irreversible, si se tiene en consideración el estado actual de la ciencia médica ${ }^{101}$.

Los médicos deberán en todos los caso y antes de proceder a aplicar la eutanasia, respetar las condiciones formales y de procedimiento que señalaremos seguidamente:

1. Consultar a otro médico cuando la situación irreversible del paciente así lo requiera. El médico a quien se consulta deberá revisar el expediente médico y examinar al paciente. Redactará un informe

${ }^{101}$ Art. 4.3 LEAS. 
de sus impresiones. Si hay designada una persona de confianza en las disposiciones-voluntades finales del paciente, el médico que atiende al paciente deberá informarle de la situación en la que se encuentra y del resultado de la consulta realizada a otro médico. El médico a quien se consulta debe ser imparcial en relación, tanto con el paciente como con el médico que atiende al enfermo, debiendo ser también, especialista en la patología que padece el paciente.

2. Si existe un equipo de cuidados que atiende al enfermo deberá continuar manteniendo el tratamiento con los equipos que traten al enfermo en la fase final de su vida.

3. Si las voluntades-disposiciones anticipadas de una persona señalan a una persona de confianza, se deberá mantener con la misma una relación fluida para que pueda expresar lo que hubiese sido la voluntad del paciente en esos momentos.

4. Si las voluntades-disposiciones anticipadas señalaron a una persona de confianza, ésta participará a la hora de determinar la voluntad del paciente, junto con los familiares y allegados del paciente.

Las voluntades-disposiciones anticipadas, así como el conjunto de decisiones adoptadas por parte del médico que le trata al paciente y sus resultados, así como los informes del médico que fue consultado deberán completar el informe médico del paciente ${ }^{102}$.

El médico que practica la eutanasia o la asistencia al suicidio debe, en un plazo de ocho días, remitir un documento debidamente cumplimentado y Registrado, tal y como se señala en el art. 7 de la presente Ley, a la Comisión de Control y evaluación señalado en el art. 6 de la presente Ley ${ }^{103}$.

Se Constituye la Comisión Nacional de Control y Evaluación ${ }^{104}$ de la Ley ${ }^{105}$ que se encargará de controlar y evaluar la aplicación de la Ley. Estará compuesta por siete miembros que serán designados teniendo en consideración su especialidad y experiencia que considera importante la Comisión. Tres miembros serán expertos en medicina, uno de ellos será propuesta por parte del Colegio de médicos, la organización más representativa de médicos y dentistas propondrán dos miembros, en el que uno de ellos tendrá experiencia y cualificación específica que guarde relación con los cuidados paliativos. Otros tres miembros serán juristas, uno de ellos será abogado, otro magistrado, y el último, profesor de Derecho de la Universidad de Luxemburgo. Así también, habrá otro que pertenecerá a la función sanitaria y será propuesto por el Consejo Superior de algunas profesiones sanitarias, no concretándose a cuál de ellas pertenecerá. Otros dos miembros serán representantes de organismos que tienen como misión la de defender los derechos de los pacientes. Todos los miembros de la Comisión serán nombrados por el Gran Duque por un tiempo de tres

\footnotetext{
${ }^{102}$ Art. 4.3.3 LEAS.

${ }^{103}$ Capítulo IV, La Declaración Oficial, Art. 5 LEAS:

${ }^{104}$ La Comisión Nacional de Control y Evaluación, en adelante, "La Comisión”.

${ }^{105}$ Capítulo V: La Comisión Nacional de Control y de Evaluación, artículos 6 a 13.
} 
años, siendo renovable el nombramiento en tres ocasiones. Ser miembro de la Comisión es incompatible con la función de Diputado o del Gobierno o del Consejo de Estado. Los miembros de la Comisión elegirán entre ellos al presidente. La Comisión no podrá deliberar válidamente si no hay al menos siete miembros presentes. Las decisiones se adoptarán por mayoría. La Comisión establecerá su propio Reglamento de orden interno ${ }^{106}$.

La Comisión ha elaborado un documento de declaración oficial que deberá completar el médico y enviarlo a la Comisión cada vez que practique una eutanasia. El documento se compone de dos ejemplares, el primero debe ser firmado por el médico y deberá contener los siguientes elementos: nombre, apellidos y domicilio del paciente, nombre, apellido, código colegial del médico-médicos que le han tratado, que han sido consultados, que guarden relación con la eutanasia o con la asistencia al suicidio, el nombre, apellido y calificación profesional de todas las personas que han sido consultadas por el médico que ha tratado al paciente, así como las fechas de las consultas, y finalmente, si existen voluntades anticipadas en las que el paciente ha designado a la persona de confianza, deberá constar también, su nombre, apellido.

Este primer ejemplar del documento es confidencial y será remitido por el médico a la Comisión. No podrá ser consultado a no ser que así se decida por parte de quienes se señala en el siguiente artículo. Además, no podrá servir de base para la evaluación que va a realizar la Comisión en ningún caso.

El segundo ejemplar es también confidencial y contendrá los siguientes elementos: Si hay disposiciones o voluntades anticipadas o solicitud de eutanasia o suicidio asistido, la edad del paciente, la enfermedad o patología grave e incurable, además que la misma le produce un sufrimiento al paciente, las razones por las que la enfermedad del paciente ha sido calificada como no mejorable y sin perspectiva de mejora futura, los elementos que permiten asegurarse de que la solicitud del paciente se ha realizado de forma voluntaria, reflexiva, reiterada y sin presiones exteriores, el procedimiento que ha seguido el médico, la cualificación del o de los médicos que han sido consultados, así como la fecha de las citadas consultas, la calificación personal de los expertos que ocasionalmente han sido consultados por el médico y las fechas de las consultas, y finalmente, las circunstancias en las que el médico que ha tratado al paciente ha aplicado la eutanasia o la asistencia al suicidio y los medios utilizados para ello ${ }^{107}$.

La Comisión examinará la documentación oficial completa que ha remitido el médico en el segundo ejemplar y verificará si las condiciones y el procedimiento ha sido respetado. En caso de duda, la Comisión puede decidir por mayoría simple de siete miembros que lo constituyen, al menos, de levantar el anonimato del primer ejemplar que hemos descrito anteriormente, pudiendo solicitar al médico que ha tratado al paciente

\footnotetext{
${ }^{106}$ Art. 6.1 y 2 LEAS.

${ }^{107}$ Art. 7 LEAS.
} 
que informe y remita todos los documentos del expediente médico relativo a la eutanasia o a la ayuda al suicidio, resolviendo en un plazo de dos meses.

Cuando la decisión se adopte por mayoría de los siete miembros que deben integrar la Comisión y resuelvan que no se han respetado las condiciones previstas en el párrafo $2^{\circ}$ del art. $2^{\circ}$, comunicarán su decisión al médico que ha tratado al paciente y el expediente íntegro, así como una copia de la decisión adoptada al Colegio de médicos. Este último deberá pronunciarse en el plazo de un mes. El Colegio de médicos decidirá por mayoría de sus miembros si procede iniciar un procedimiento disciplinario. En el caso de que no se respeten las condiciones previstas en el párrafo $1^{\circ}$ del artículo $2^{\circ}$ de la presente Ley, la Comisión remitirá el informe al Juzgado ${ }^{108}$.

La Comisión enviará a la Cámara de Diputados, por primera vez, una vez transcurridos dos años de la entrar en vigor la Ley, y a partir de ahí cada dos años:

a) Un informe estadístico de la información recibida en el segundo documento, señalado anteriormente, que los médicos han emitido tal y como se establece en el art. 8.

b) Un informe que contendrá la descripción y evaluación de la aplicación de la presente Ley.

c) Las recomendaciones relativas a la posible iniciativa legislativa y/o otras medidas relativas a la ejecución de la presente Ley.

La Comisión podrá recibir toda la información útil de distintas autoridades e instituciones para completar su función-misión. Los consejos que puede recibir la Comisión serán confidenciales. Ninguno de los documentos puede contener la identificación de personas que han sido consultadas y que constan en los informes que han sido enviados a la Comisión en el ejercicio del control que se ha realizado en base a lo que se establece en el art. 8 .

La Comisión puede decidir emitir informes estadísticos y técnicos, con exclusión de datos de carácter personal a los equipos de investigación, siempre que realicen solicitudes debidamente motivadas. La Comisión puede consultar a expertos ${ }^{109}$.

Con el fin de completar su función, la Comisión, puede recurrir al personal administrativo puesto a su disposición por parte de la administración gubernamental ${ }^{110}$, siendo los gastos de su funcionamiento a cargo del presupuesto del Estado ${ }^{111}$. Cualquier persona que haya participado en la aplicación de la presente Ley, en cualquiera de las cualidades-profesiones-desempeñas, deberá respetar la confidencialidad de los

\footnotetext{
${ }^{108}$ Art. 8 LEAS.

${ }^{109}$ Art. 9 LEAS.

${ }^{110}$ Art. 10 LEAS.

${ }^{111}$ Art. 11 LEAS.
} 
hechos de los que haya conocido o le hayan sido confiados en el ejercicio de la función que ha desempeñado ${ }^{112}$.

Transcurridos seis meses desde que la Comisión ha remitido sus Recomendaciones, las señaladas en el art. 9 a la Cámara de Diputados, éstos desarrollarán un debate sobre el tema. El plazo de los seis meses se suspenderá en el periodo de disolución de la Cámara de Diputados ${ }^{113}$.

Se procede a la modificación del art. 397-1 del Código Penal, en el que se introduce una nueva disposición: "No incurrirá en el ámbito de aplicación de este precepto el médico que responde a la solicitud de eutanasia o de asistencia al suicidio, siempre que respete las condiciones de fondo previstas en la Ley de 16 de marzo de 2009 sobre la eutanasia o de la asistencia al suicidio" ${ }^{14}$.

Dentro de las Disposiciones particulares se señala que: "Ningún médico puede abstenerse de practicar una eutanasia o asistencia al suicidio". "Ninguna otra persona puede participar en una eutanasia o suicidio asistido". "Si el médico que va a ser consultado rechaza practicar una eutanasia o suicidio asistido, debe informar al paciente, o la persona de confianza designado por éste, si es que existe, en un plazo de 24 horas y deberá señalar las razones que justifican el rechazo de su intervención”. El médico que rechaza la solicitud de eutanasia o de suicidio asistido de un paciente o de la persona de confianza que ha designado, deberá remitir el expediente médico del paciente al médico designado por éste último o la persona designada de confianza ${ }^{115}$.

El Ministro de la Salud competente puede proceder, a concretar dos agentes-funcionarios para cumplir con las necesidades que deriven de la aplicación de la presente Ley, remitiendo y ordenando que la presente Ley se incluya su Memoria para ser ejecutada y cumplida por todos aquellos a los que se refiere ${ }^{116}$.

\section{La Ley de 16 de marzo de 2009, Relativa a los cuidados paliativos, a las directrices-voluntades anticipadas y al acompañamiento al final de la vida}

En el Boletín Oficial del Gran Ducado de Luxemburgo se publicó la Ley de 16 de marzo de 2009 Relativa a los cuidados paliativos, a las directivas-voluntades anticipadas y al acompañamiento al final de la vida, que modificó el Código de la Seguridad Social, la Ley modificada de 16 de abril de 1979 que concreta el

\footnotetext{
${ }^{112}$ Art. 12 LEAS.

${ }^{113}$ Art. 13 LEAS.

${ }^{114}$ Capítulo VI, Disposiciones modificativas, Art. 14 LEAS.

${ }^{115}$ Capítulo VII, Disposiciones particulares, Art. 15 LEAS.

${ }^{116}$ Capítulo VIII, Disposición Transitoria, Art. 16 LEAS. El Ministro de la Salud y de la Seguridad Social, Mars Di Bartolomeo, Palacio de Luxemburgo, el 16 de marzo de 2009.
} 
estatuto general de los funcionarios del Estado, la Ley modificada de 24 de diciembre de 1985, que concreta el estatuto general de los funcionarios municipales y el Código de trabajo ${ }^{117}$.

La Ley consta de 4 Capítulos y 14 artículos en los que se contienen: El derecho a los cuidados paliativos, la decisión de la persona al final de su vida y las directivas-voluntades anticipadas, de las vacaciones para el acompañamiento de las personas al final de la vida, y disposiciones modificativas y finales de distintos preceptos de la legislación sobre Seguridad Social, del Estatuto de los funcionarios del Estado y de los funcionarios municipales.

Se señala que toda persona que se encuentra en la fase terminal o avanzada de su enfermedad tiene derecho a los cuidados paliativos. Seguidamente se delimita el concepto de cuidados paliativos en los siguientes términos: "Los cuidados paliativos son cuidados activos, continuos y coordinados, practicados por un equipo multidisciplinar respetando en todo momento la dignidad de la persona. Deben cubrir todas las necesidades físicas, psíquicas y espirituales de la persona y su entorno, comprendiendo el tratamiento del dolor y el sufrimiento psíquico".

Estos cuidados pueden prestarse en los centros sanitarios, en los establecimientos que establecen las compañías aseguradoras de enfermedad o en el propio domicilio del paciente, siendo al Estado a quien corresponde formar adecuadamente al personal médico y al equipo que atiende al paciente. Un Reglamento del Gran Ducado concretaría el organismo encargado de formar al personal médico especialista en cuidados paliativos y al resto de profesionales que intervendrá en la prestación de esta asistencia ${ }^{118}$.

Se reconoce el derecho a rechazar los tratamientos de obstinación terapéutica y se hace referencia a los efectos secundarios de los tratamientos que se aplican al paciente en relación con el dolor ${ }^{119}$.

También se recoge el derecho del paciente a proponer sus deseos en relación con los tratamientos que quiere o no recibir en el proceso final de su vida y del contenido y forma en la que debe realizarse las directivas-voluntades anticipadas ${ }^{120}$.

Mención especial merece destacar por nuestra parte a la modificación del Código de trabajo en el que se contendrá el derecho a vacaciones que tienen los acompañantes de los pacientes en fase terminal ${ }^{121}$.

Finalmente se dispone en los artículos 10 a 14 las modificaciones de la legislación vigente para adaptar la presente legislación a las necesidades que derivan de la aplicación de la Ley.

\footnotetext{
${ }^{117}$ Memorial Journal Officiel du Grand-Duché de Luxembourg, Recueil de Legislation, A- no 46, de 16 mars 2009, pp. 610-614. Tras la Decisión adoptada por parte de la Cámara de Diputados de 18 de diciembre de 2008 y la del Consejo de Estado de 19 de diciembre de 2008, no hubo segunda votación en relación con el texto e la presente Ley.

${ }^{118}$ Art. 1 de la Ley de Cuidados Paliativos, Directivas-Voluntades Anticipadas y el acompañamiento al final de la vida. En adelante, LCPVAAFV.

${ }^{119}$ Art. 2 y 3 LCPVAAFV.

${ }^{120}$ Art. 4 a 8 LCPVAAFV.

${ }^{121}$ Art. 9 LCPVAAFV.
} 


\section{PROPOSICIONES DE LEY SOBRE LA ASISTENCIA AL SUICIDIO EN FRANCIA QUE NO HAN PROSPERADO}

La eutanasia y el suicidio médicamente asistido son temas recurrentes en Francia que con el caso Chantal Sébire (2008) han vuelto a ponerse de actualidad abriéndose un debate social, jurídico y político sobre la eutanasia y el suicidio asistido. Chantal, aquejada de una enfermedad incurable que le ocasionaba fuertes sufrimientos y una merma considerable de su calidad de vida, decidió poner fin a su penosa existencia mediante alguna modalidad de suicidio medicamente asistido, tras haber sido denegada por parte de los Tribunales su solicitud de acogerse a la eutanasia voluntaria. El argumento que justificó la citad denegación fue que la legislación francesa no permitía autorizar ningún tipo de suicidio asistido, ni de eutanasia. Destacar que la Ley Leonetti de 22 de abril de 2005, que reconoce a los enfermos terminales el derecho a rechazar un tratamiento y aliviar su sufrimiento no era la vía a través de la que se podía resolver el problema que tenía Chantal.

Otro caso que se produjo en Francia, también el año 2008, tras el suicidio del joven Rémy Salvat, aquejado de una enfermedad grave degenerativa desde los seis años, en ese momento tenía 23 años, volvió a abrir nuevamente el debate sobre el cambio que exigía la legislación francesa en relación con el suicidio asistido.

En Francia se han sometido a debate en la Asamblea Nacional distintas Proposiciones de Ley en relación con "Los derechos a asegurar a los pacientes el derecho a morir con dignidad"122, y la que "Instituye el Derecho a morir en dignidad y a garantizar a los médicos el ejercicio del derecho a su libertad de conciencia"123.

En la primera de las Proposiciones (2009) que no prosperó, queremos destacar algunas de las cuestiones que consideramos más significativas:

Se dispone en su Exposición de Motivos que "En el Código penal francés no existe distinción alguna entre la muerte que se provoca a una persona por compasión y la que se produce con premeditación y se califica como asesinato, en éste último supuesto, existe una pena de prisión a perpetuidad. Señala también que, en el Código deontológico se establece que el médico no tiene derecho a provocar la muerte de forma deliberada de un paciente enfermo".

Es Francia un país desarrollado en el que todavía no se ha legislado en relación con la práctica del ejercicio al derecho fundamental que tiene cada persona a decidir sobre su propia vida.

\footnotetext{
122 "Proposición de Ley n 1140, Asamblea General, en relación a asegurar a los pacientes al final de su vida el derecho a morir en dignidad”, Registrado en la Asamblea Nacional el 13 de junio de 2013

123 "Proposición de Ley no 1498, Asamblea General, en relación a la Institución del derecho a morir en dignidad y a garantizar a los médicos el derecho a su conciencia”, Registrado en la Asamblea Nacional el día 4 de marzo de 208.
} 
Esta ausencia de legislación está en total contradicción con los deseos de un gran número de ciudadanos que en distintas ocasiones se han pronunciado a favor de la eutanasia. Esta legislación es considerada en muchas ocasiones como anacrónica, inadecuada e injusta, al no dar una respuesta eficaz a la despenalización de la ayuda al paciente en fase terminal de morir. En los sondeos realizados el año 2001, hace ya muchos años, el $88 \%$ de los encuestados estaban a favor de dicha despenalización. Destacar que los sondeos más recientes, del año 2007, mostraban el deseo de los franceses en un $86 \%$ de proceder a la despenalización de la asistencia que podían prestar los médicos a morir con dignidad.

Teniendo en consideración todas estas circunstancias, se presentó la Proposición de Ley en la que: en principio se procedía a definir los casos en los que se podía ayudar a la persona a morir con dignidad, si asílo solicitaba. Seguidamente, se concretaban el procedimiento a través del que el paciente podía solicitar al médico que le ayudara a morir, la necesidad de consultar algún otro especialista y los tiempos de espera obligatorios para aplicarse la eutanasia, reconociéndose el derecho al paciente de poder revocar su solicitud en cualquier momento.

Así también se desarrolló en la Ley las condiciones que debían concurrir en los supuestos en los que el paciente estaba incapacitado para presentar la demanda, los medios de defensa con los que contaba el médico en los supuestos en los que el caso llegara a la vía judicial, el derecho que ostentaban los médicos que poder alegar la cláusula de conciencia, y por lo tanto, no proceder a la aplicación de la ayuda a morir del paciente, a concretar por parte del Gobierno las medidas necesarias para preservar los derechos de los pacientes que estaban hospitalizados, a la creación de la Comisión Nacional de Control de las prácticas en materia de ayuda activa a la muerte, y las Comisiones Regionales que estarían presididas por el Prefecto de la Región, la determinación de considerar muerte natural, la muerte de la persona que ha fallecido tras aplicarse la ayuda a la muerte en el tema de los contratos que tuviera vigentes y las consecuencias de la despenalización de la eutanasia en distintos preceptos del Código de la salud pública ${ }^{124}$.

Se manifestaba que "Una persona puede solicitar que se ponga fin a su vida, a través de un medio indoloro, siempre que se verifique que su estado de salud, la calidad y dignidad de su vida así lo requieren". Como consecuencia de lo cual, el Código penal deberá ser redactado, en su art. L. 110-2, en los siguientes términos: "El enfermo tiene derecho a que se respeta su libertad y su dignidad. Puede beneficiarse en las condiciones previstas en el presente Código, de una ayuda activa a morir" ${ }^{125}$.

El Código de la salud pública se completará, en su artículo L.1110-9, con la siguiente redacción: "Toda persona, en fase avanzada o terminal de su enfermedad, que se considera grave e incurable, o pasa a estar

\footnotetext{
${ }^{124}$ Exposición de Motivos de la Proposición de Ley 2009.

${ }^{125}$ Art. 1 de la Proposición de Ley de 2009.
} 
en un estado de dependencia que se considera incompatible con su dignidad, puede solicitar, en las condiciones previstas en la Ley, la asistencia médica para que se provoque su muerte. Después de que la persona rechace un tratamiento médico, el médico debe informarle, reservando su derecho a poder invocar el ejercicio de su derecho a la cláusula de conciencia ${ }^{126}$.

Se crea un nuevo apartado en el art. 1111-10-1 del Código de la Salud pública con la siguiente redacción:

"Después de que una persona, en fase avanzada o terminal de una enfermedad grave incurable, o su estado de salud ha pasado a estar en un grado de dependencia que se considera incompatible con su dignidad, puede solicitar a su médico la ayuda activa parar morir. El médico deberá consultar con otro colega, con el fin de asegurarse la situación real en la que se encuentra el paciente.

El médico responsable del paciente tiene la facultad de llamar a otro miembro del cuerpo médico. Ambos verificaran el carácter libre, consciente y reflexivo de la solicitud presentado, y se le ofrecerá al paciente en una entrevista la información relativa a los cuidados paliativos y al acompañamiento al final de la que le corresponden.

Los médicos deberán tener las conclusiones sobre el estado de salud del paciente en un tiempo máximo de 8 días. Una vez que los médicos han decidido que el paciente se encuentra en una situación terminal, y que la solicitud que ha presentado es clara, reflexiva y consciente, y el paciente persiste en su solicitud, que deberá realizarla por escrito, y si no lo puede, estará presente la persona designada por el paciente de su confianza, el médico que le atiende respetará la manifestación del paciente.

La ayuda activa a morir no podrá practicarse antes de que transcurran 15 días de la confirmación de la solicitud del paciente, pudiendo el paciente revocar en cualquier momento su petición. Este plazo puede reducirse en los casos, siempre que así lo solicite el paciente, en los que el médico entienda que con ello se protege la dignidad del paciente".

Las conclusiones a las que han llegado los médicos y la confirmación de la solicitud del paciente se incluirán en el expediente médico. En el plazo de 4 días laborables contados a partir del día del fallecimiento, el médico que ha participado en la ayuda activa a morir, deberá remitir a la Comisión Regional de Control que señala el art. L.1111-14 un informe explicando las condiciones en las que se produjo la muerte. En el Informe se incluirán los anexos y documentos que se contienen en el expediente médico y que prescribe la presente Ley ${ }^{127}$.

\footnotetext{
${ }^{126}$ Art. 2 de la Proposición de Ley de 2009.

${ }^{127}$ Art. 3 de la Proposición de Ley de 2009.
} 
En los siguientes artículos se hace referencia a las directivas-voluntades anticipadas ${ }^{128}$, a que las directivas-voluntades anticipadas pueden recogerse en el testamento que realiza la persona para el final de su vida $^{129}$, la incapacidad del paciente para manifestar su voluntad y el procedimiento que debe seguirse en estos $\operatorname{casos}^{130}$, la obligatoriedad de que intervenga en todos los casos un médico para proceder a la ayuda directa a la muerte $^{131}$, a la cláusula de conciencia del médico por la que, puede negarse a aplicar la ayuda directa a la muerte de un paciente ${ }^{132}$, a las iniciativas legislativas que el Gobierno deberá poner en marcha para que pueda aplicarse la Ley ${ }^{133}$, a la creación de la Comisión Nacional de Control de las prácticas de ayuda activa a la muerte ${ }^{134}$, a la consideración de muerte natural en relación a los contratos que tenga suscritos el paciente que fallece como consecuencia de la ayuda directa a la muerte ${ }^{135}$, a la modificación del art. 221-1 del Código penal ${ }^{136}$, y finalmente, a que el coste que derive de la aplicación de la ayuda directa a la muerte se pagará a través de la creación de un impuesto por parte del Estado sobre los impuestos al tabaco que se contiene en el Código penal de impuestos ${ }^{137}$.

La "Proposición de Ley relativa a los pacientes en la fase final de su vida y el derecho a morir en dignidad" de 2013 dispone, en su Exposición de Motivos que: "La Ley de 22 de abril de 2005 relativa a los derechos de los enfermos al final de la vida ha marcado en Francia una etapa importante en el acompañamiento del paciente al final de su vida. Ha permitido el desarrollo de los cuidados paliativos y la reducción considerable de la obstinación terapéutica en Francia. De todas formas, se considera que esta Ley es insuficiente. La no aplicación de tratamientos o la interrupción de su aplicación permiten la interrupción de la hidratación y la alimentación artificial. A pesar de todo, las condiciones en las que mueren los pacientes no son hoy día las más deseables.

De todo ello se concluye que, la muerte en Francia hoy día, tal y como señala MAHO ${ }^{138}$, no se desarrolla en las condiciones que serían deseables. La solución al tema sería que se autorizara la ayuda directa para morir, que se encuentra todavía prohibida. Más del 90\% de los ciudadanos franceses están a favor de legislar sobre la ayuda directa y activa a la muerte del paciente en fase terminal de su enfermedad.

\footnotetext{
${ }^{128}$ Art. 4 de la Proposición de Ley de 2009.

${ }^{129}$ Art. 5 de la Proposición de Ley de 2009.

${ }^{130}$ Art. 6 de la Proposición de Ley de 2009.

${ }^{131}$ Art. 7 de la Proposición de Ley de 2009.

${ }^{132}$ Art. 8 de la Proposición de Ley de 2009.

${ }^{133}$ Art. 9 de la Proposición de Ley de 2009.

${ }^{134}$ Art. 10 de la Proposición de Ley de 2009.

${ }^{135}$ Art. 11. de la Proposición de Ley de 2009.

${ }^{136}$ Art. 12 y 13 de la Proposición de Ley de 2009.

${ }^{137}$ Art. 14. de la Proposición de Ley de 2009.

${ }^{138}$ MAHO, en Mort à I'hôpital, 2008. En el que se afirma que sólo el 35\% de las muertes en los hospitales se realizan en condiciones aceptables.
} 
Se dispone además que, la eutanasia se practica de forma clandestina para atender a las situaciones de la fase terminal de vida del paciente. Por ello, sería conveniente que esta práctica se realizará de forma legal y se evitaran los riesgos en los que pueden incurrir los médicos que aplican este tratamiento.

La Proposición de Ley trata de asegurar a los pacientes el derecho morir dignamente en la fase final de su vida. Este derecho se concreta con la puesta en práctica de la eutanasia, el suicidio médico asistido y por la intensificación de los cuidados paliativos. La Ley debe asegurar la solución más conveniente entre las que acabamos de señalar, a cada paciente que se encuentre en la fase final de su vida.

Destacar que no existe una única solución posible, cada paciente es diferente, con aspiraciones diferentes y convicciones diferentes, lo que supone que sus necesidades son distintas y hay que cumplir con todas ellas.

Es por ello que, la legislación debe reconocer a cada ciudadano que se encuentre en la fase final de su vida cumplir con su voluntad, con ello podrá cumplirse con la elección del tipo de muerte que requiere cada paciente, este es el objetivo que se propone la Ley ${ }^{139}$.

Esta Proposición de Ley es más breve que la de 2009 y consta de 10 artículos en los que se propone la modificación en la redacción o la inclusión de algún nuevo apartado de la Ley de la Salud Pública.

El Código de la Salud Pública, dentro de los Derechos de los pacientes ${ }^{140}$, art. 1110-2, dispone que: "El enfermo tiene el derecho a que se respete su dignidad", se propone una nueva redacción en el que debería incluirse los términos, "su" y "libertad y dignidad", quedando el precepto con la siguiente redacción: "El enfermo tiene derecho a que se respete - su libertad y dignidad"141.

Las condiciones para que pueda aplicarse la eutanasia o el suicidio asistido serían: "Toda persona mayor de edad y con capacidad suficiente, en fase avanzada o terminal, incluso si no existe diagnóstico de muerte en un plazo breve de tiempo, o que padece una afección accidental o patología severa, grave, incurable y/o que le invalide de forma grave, infringiéndole sufrimientos físicos y psíquicos constantes y que no pueden reducirse, juzgando el propio paciente que esta situación es insoportable, puede solicitar, en las condiciones que taxativamente están previstas en éste Título, la ayuda activa a morir o el suicidio médico asistido" ${ }^{142}$.

\footnotetext{
${ }^{139}$ Exposición de Motivos de la Proposición de Ley de 2013.

${ }^{140}$ Código de la Salud Pública, Versión consolidada el día 2 de septiembre de 2013, Dentro de la Primera parte, "Protección General de la Salud", Libro primero, "La protección de las personas en el ámbito sanitario", Título primero, "Los Derechos de los enfermos y los usuarios del sistema sanitario", Capítulo preliminar, "Derechos de las personas", se contiene el art. 1110-2 que a partir de la modificación propuesta por el Proyecto de Ley de 2013 quedaría redactado en la forma establecida supra. Ver:

http://www.legifrance.gouv.fr/affichCode.do?cidTexte=LEGITEXT000006072665\&dateTexte=20130911. Consultado el 12-08-2013.

${ }^{141}$ Art. 1 Proposición de Ley de 2013. Deberá modificarse el art. del Código de la salud pública L. 1110-2.

${ }^{142}$ Art. 2 Proposición de Ley de 2013. Deberá modificarse el art. del Código de la Salud pública L.1110-9.
} vol.07, nº. 02, Rio de Janeiro, 2014.pp. 892-1009 
Se considera como muerte natural, en relación con los contratos que tiene suscritos la persona que solicita este tipo de actuación en la fase final de su vida, la persona cuya muerte derive de la ayuda activa a morir o del suicidio médico asistido que se ha realizado en base a las condiciones y procedimientos establecidos en este Código, considerándose que, cualquier cláusula que el paciente haya suscrito en el sentido se tendrá por no puesta ${ }^{143}$.

En relación con el procedimiento previsto, se señala en la Proposición que: "Cuando una persona mayor de edad y plenamente capaz, se encuentra en la fase terminal o avanzada de su enfermedad, incluso si no existe diagnóstico en relación a que morirá en un breve plazo de tiempo, sufre un accidente o una enfermedad severa, grave, incurable y/o que le produce una gran incapacidad y es incurable, padeciendo sufrimientos físicos o psíquicos constantes y que no pueden reducirse, o que el propio paciente considera insoportables, puede solicitar a su médico la ayuda activa a morir o el suicidio médico asistido, debiendo éste (el médico) asegurarse de la realidad de la situación en la que se encuentra el paciente"144.

Tras el examen del paciente, se estudie el expediente, y si existe equipo, consultado el equipo que le atiende sus afecciones, el médico deberá consultar con otro médico de su misma especialidad, en un plazo máximo de 48 horas.

Los médicos deben verificar el carácter libre, reflexivo, voluntario y persistente de la solicitud del paciente, y tras una entrevista con el mismo, deberán informarle sobre las distintas posibilidades terapéuticas que existen y las soluciones alternativas en el ámbito del acompañamiento al final de la vida. Si los médicos lo consideran oportuno, tendrán otra entrevista con el paciente en las 48 horas siguientes.

Los médicos presentaran sus conclusiones en relación con el estado de salud del paciente en un plazo máximo de 4 días, contados a partir de la solicitud presentada por parte del paciente inicialmente.

Una vez de que los médicos han llegado a la convicción de que se está ante una afección accidental o patología calificada como "grave, incurable y/o que es invalidante e incurable, infringiendo al paciente graves y constantes padecimientos físicos o psíquicos, y que no existe tratamiento que pueda reducir o eliminar, no existiendo tratamientos para subsanarlo", cuando se encuentra en estas circunstancias el paciente y ha emitido su voluntad de forma libre, reflexiva y reiterada, confirmando su voluntad, si la situación del paciente así lo permite" delante de las persona o personas de confianza que ha designado, los médicos deberán respetar la voluntad del paciente.

La actuación médica con la que se ayuda a la muerte, ejecutada con control médico, por el mismo médico en los supuestos de suicidio médico asistido, si el paciente así lo desea y tiene capacidad para ello, en el

\footnotetext{
${ }^{143}$ Art. 3 Proposición de Ley de 2013. Deberá modificarse el art. del Código de la Salud pública L. 11 10-9-1

${ }^{144}$ Art. 4 Proposición de Ley de 2013. Deberá incluirse en el art. del Código de la Salud pública un nuevo apartado, el L. 111010 , que a su vez tendrá distintos subapartados, en el presente caso, el 1.
} 
centro hospitalario en el que se encuentra, o en los centros creados específicamente para estos casos, no podrá realizarse si no ha transcurrido el plazo de 2 días, contados desde el día en el que se procedió a la conformación de la solicitud realizada por el paciente. Este plazo puede reducirse a solicitud del enfermo, siempre que el médico considere que con ello se protege la dignidad del paciente.

El paciente puede revocar su solicitud en cualquier momento.

Las decisiones médicas y la confirmación de la solicitud presentada por parte del paciente se incluirán en el informe médico del paciente. En el plazo de 8 días acaecida la muerte, el médico que ha participado en la ayuda activa en provocar la muerte del paciente o al suicidio asistido, remitirá un informe a la Comisión Regional de control previsto en la presente Ley, en el que expondrá las condiciones en las que se ha producido la muerte. En el informe se incluirán como anexos, todos los documentos que se contienen en el expediente del paciente. La Comisión de control verificará la validez de los mismos. En los supuestos en los que no se hayan respetado las condiciones previstas en la presente Ley, se remitirá la documentación al Juez competente $^{145}$.

Se solicita la modificación del art. L. 1111-1 del Código de la Salud pública en el que se contienen las directivas o voluntades anticipadas ${ }^{146}$.

También se señala el procedimiento previsto para los supuestos en los que el enfermo, en el que concurren todas las circunstancias que señala le Ley, se encuentre incapacitado. Para ello, se propone la inclusión de tres nuevos apartados en el art. L. 1111-13 del Código de la Salud pública ${ }^{147}$, y la creación de un organismo, denominado Comisión Nacional de Control en el ámbito de la ayuda activa a morir.

Se reconoce al médico el derecho a no participar en la ayuda directa a la muerte o al suicidio médico asistido. En estos casos, deberá asegurarse que otro médico va a ayudar al paciente a morir, deberá remitirle el expediente del enfermo, y todo ello tendrá que realizarlo en el plazo máximo de 2 días ${ }^{148}$

Toda persona que se encuentre en la fase final de su vida puede exigir y solicitar su derecho universal a los cuidados paliativos y al acompañamiento. Cada Departamento de Francia y de Ultramar deberá tener unidades de cuidados paliativos en la cantidad necesaria al número de habitante que tenga ${ }^{149}$.

Finalmente señala que, el coste que suponga para los organismos sociales la aplicación de la Ley, serán sufragados a través de la creación de un impuesto adicional previsto en los artículos 420bi, 428 y 520 A del Código General de impuestos ${ }^{150}$.

\footnotetext{
${ }^{145}$ Art. 4 Proposición de Ley de 2013. Deberá incluirse en el art. del Código de la Salud pública un nuevo apartado, el L. 111010, que a su vez tendrá distintos subapartados, en el presente caso, el 2 a 11.

${ }^{146}$ Art. 5, apartados 1 a 7 Proposición de Ley de 2013.

${ }^{147}$ Art. 6 Proposición de Ley de 2013, propone la inclusión de tres nuevos apartados al art. L. 1111, los apartados 1, 2 y 3.

${ }^{148}$ Art. 8 de la Proposición de Ley de 2013.

${ }^{149}$ Art. 9 de la Proposición de Ley de 2013.
} 


\section{La posición del Consejo de Europa sobre la dignidad de la persona con enfermedad terminal e incurable}

La dignidad de la persona en la fase terminal de su vida y los cuidados paliativos que son necesarios se constituyen en un reto importante para todos los países integrantes del Consejo de Europa. Si bien los cuidados paliativos se iniciaron en el año 1967 en Londres en el Hospital Christopher's Hospice, a partir de ese momento, se han ido extendiendo en todos los países. Es necesario destacar que en muchos países todavía se cuenta con escasos recursos económicos destinados a estos cuidados. Es por ello que, desde el año 1980, momento en el que se publica el Informe del Comité Europeo de Sanidad sobre los "Problemas relacionados con la muerte: cuidados para el moribundo", el Consejo de Europa se ha ocupado de formalizar distintas Recomendaciones para proteger la calidad de vida de los ciudadanos que se encuentran en la fase final de su vida y de los cuidados paliativos que deben ser aplicados en estas circunstancias, con el fin de mejorar la calidad de vida del paciente terminal.

\section{LA RECOMENDACIÓN 1418 ADOPTADA POR EL CONSEJO DE EUROPA EN EL AÑO 1999 SOBRE LOS DERECHOS DEL HOMBRE Y LA DIGNIDAD DE LA PERSONA CON ENFERMEDAD INCURABLE}

\section{Consideraciones Generales}

El Consejo de Europa tiene como fin proteger la dignidad del ser humano y sus derechos en aquellas personas que sufren enfermedades incurables. Por ello, elabora en su Asamblea General celebrada el día 25 de junio de 1999, del Consejo de Europa la Recomendación que trata de proteger los derechos del hombre y la dignidad de las personas que tienen una enfermedad incurable.

La dignidad de la persona es invocada frecuentemente por parte de aquellas personas que muestran su posición hostil a algunas formas de eutanasia, cuando estamos en presencia de personas que padecen una enfermedad incurable y que quieren poner fin a su vida.

El Comité de Ministros ha mostrado una posición inequívoca en relación con éste tema. Han señalado que: "los Estados miembro del Consejo de Europa deben proteger la dignidad del enfermo que padece una enfermedad incurable y que van a morir, prohibiendo de forma absoluta poner fin a la vida de éstos pacientes, a pesar de que la voluntad del paciente, en la fase final de su vida, haya sido manifestada, ésta no puede en ningún caso constituirse como justificación o fundamento jurídico para que se proceda a provocarle la muerte de forma directa y querida por una tercera persona”.

\footnotetext{
${ }^{150}$ Art. 10 de la Proposición de Ley de 2013.
} 
El Comité de Ministros se posicionó en relación con la Recomendación 1418 en dos momentos. En primer lugar, el día 30 de octubre de 2000, señalando o destacando la complejidad de la cuestión que se planteaba, y señalaron que "se consideraba totalmente prohibido el provocar intencionadamente la muerte a un paciente que tuviera o padeciera una enfermedad terminal e incurable". Todo ello, a pesar de que eran conscientes de que existía en la legislación de algunos Estados miembro, normar contradictorias a la posición que estaban adoptando, ellos se posicionaban, en todo momento, en contra de ciertos tratamientos y de la eutanasia. En la segunda de sus resoluciones, concretamente la adoptada el día 26 de marzo de 2002, nuevamente el Comité de Ministros, y tras solicitar algunos informes, concretamente al Comité director para los Derechos del Hombre (CDDH), volvieron a señalar que: "se posicionaban en contra de poner fin a la vida de un paciente incurable y con una enfermedad terminal", volviendo a afirmar que, "todo ello, a pesar de que el paciente terminal se hubiera posicionado o mostrado su interés de morir, lo que no justificaría en ningún momento que se ejecutaran o pusieran en marcha acciones dirigidas a causarle la muerte de forma directa”.

Siendo conscientes los miembros del Comité de Ministros de que algunos Estados ya habían adoptado la posición de promulgar algunas normas que favorecían la muerte anticipada de un enfermo terminal, señalaron que, "eran conscientes de que algunos Estados miembros de la Convención Europea de Derechos del Hombre disponían de un amplio margen de apreciación, y de adoptar algunas medidas, como había sido el caso en relación con el tema objeto a debate”.

El Comité consideró que efectivamente los derechos reconocidos en la Convención en relación con los enfermos incurables y moribundo, reflejaban una serie de problemas que debían ser interpretados, interpretación que consideraban que era efectivamente compleja, ya que debía resolverse la adopción de medidas en relación con los derechos que se recogían en la Convención y las libertades.

Indicaron además que, la Corte de Estrasburgo, Corte Europea de Derechos del Hombre, no se había posicionado prácticamente en relación con el tema de la eutanasia, lo que suponía que dejaba en una posición todavía más complicada al Comité de Ministros.

El Tribunal Europeo de Estrasburgo si adoptó una posición parcial al tema objeto de la presente Recomendación como consecuencia de una consulta elevada por parte de los Ministros. Se refiere expresamente en determinar si el derecho a la vida que se contiene en el art. 2 de la Convención, si dentro de éste derecho puede señalarse que también se contiene un derecho negativo. Este tema sí fue resuelto por parte del Tribunal en el Caso de Diane Pretty, enferma incurable que solicitó su muerte y recurrió al Tribunal de Estrasburgo para que se cumpliera su deseo.

Los Jueces del TEDH no accedieron a la solicitud de la Sra. Pretty y establecieron que: "El art. 2 de la Convención no podía interpretarse, sin proceder a distorsionar el texto, como derecho en el que pudiera 
incluirse el derecho solicitado por la paciente, es decir, del derecho a morir. El derecho a la autodeterminación que puede incluir la dicción literal del precepto no puede entenderse que incluya el derecho individual a elegir la muerte por parte de una persona. Concluya así el Tribunal señalando que, no puede realizarse una interpretación del art. 2 de la Convención en el que se indique que en el mismo sí se incluye el derecho a morir, bien sea por parte de una tercera persona o por parte de una autoridad pública”.

De lo que concluye el Comité que, el Tribunal no se ha posicionado directamente, ni en la presente resolución judicial ni en otro momento en relación con la compatibilidad o no de que el derecho a la muerte se recoja o contenga en el art. 2 de la Convención.

La Recomendación 1418 y quienes se posicionan en todo momento en contra de que la eutanasia tiene su fundamento en el art. 2 de la Convención, al señalar que, en ningún momento y bajo ninguna circunstancia éste precepto puede justificar la eutanasia. Han destacado así también que, son conscientes de que, tanto el legislador belga como el holandés se han posicionado, tras un duro y largo debate a favor de la eutanasia y/o el suicidio asistido, posición que está en directa confrontación con la que se mantiene por parte de la Recomendación 1418 y del Comité de Ministros.

Reconoce la Recomendación 1418 que el progreso tecnológico en el ámbito de la medicina, supone planearse los límites de la muerte y que, consecuentemente, las condiciones de la vida de un paciente terminal y su voluntad pueden pasar a ser relegados a una segunda posición. Además, entienden que, efectivamente el tema de la eutanasia se presenta, por todo ello, como un tema en el que hay que adoptar medidas en relación con la evolución o avances de la medicina y a los recursos terapéuticos con los que se cuenta hoy en día. Estos nuevos medios que están al alcance de la medicina, no pueden favorecer al plantearse el momento natural en el que va a producirse la muerte y en pocas ocasiones pueden favorecer a mejorar la calidad de vida del paciente terminal. Son conscientes de que efectivamente la obstinación terapéutica no tiene como fin principal, mejorar la calidad de vida del paciente terminal.

Por ello, ya en la Recomendación adoptada el año 1976, la Recomendación de la Asamblea Parlamentaria nº 779, se destacó que: "La prolongación de la vida no puede tener como único y último límite la práctica médica, que debe tener en consideración, sobre todo, reducir el sufrimiento del paciente”.

El año 1999 se posicionó el Comité de Ministros de forma más clara y denunció que "prolongar artificialmente el proceso de la muerte del paciente, se consideraba como una amenaza a la dignidad del ser humano y destacó que, la obligación de respetar y proteger la dignidad del enfermo incurable, moribundo, que era considerado como una consecuencia derivada de la dignidad inviolable que era inherente a toda persona en todos los momentos de su vida". 
Así también, la Asamblea General, el año 1999, señaló que "estaba injustificado que existiera en los Estados Miembros de la Convención un acceso insuficiente a los cuidados paliativos y a los tratamientos que redujeran el dolor, así como, su incomprensión en relación con la posición que adoptaban algunos Estados en relación con los cuidados a los que tenía derecho en enfermo en la fase final de su vida. Señalaron que, todos estos cuidados y medidas debían ser adoptados de forma obligatoria por parte de todos los Estados, a no ser que fuesen rechazados por el propio paciente, incluso si los citados tratamientos tenían como efecto secundario y no deseado la anticipación del fallecimiento del enfermo.

El Comité de Ministros, en la Resolución adoptada el día 26 de marzo de 2002 examinó el tema de garantizar la dignidad del paciente que derivaba del art. 3 de la Convención, señalando que el Tribunal ya se había posicionado en relación con éste tema y que había señalado que: "la medida adoptada como consecuencia de una necesidad terapéutica, no podía ser considerada ni como inhumana ni degradante", y también se posicionó en relación a que "una medida terapéutica no podía ser, generalmente, ser considerada como inhumana o degradante". En el presente supuestos, señaló que, en relación con la duración del tratamiento y los efectos psicológicos y mentales, dependiente de la edad, sexo, estado de salud de la víctima, en el Caso Irlanda c. Reino Unido, en el caso resuelto el 18 de enero de 1978. Así también, en el Caso A. c. Reino Unido de 23 de septiembre de 1998, señaló el Tribunal la "la obligación que impone a los Estados de adoptar medidas legislativas o de otro tipo con el fin de que las persona más vulnerables, dentro de las que podemos entender incluidas a aquellas personas que padecen enfermedades incurables y en la fase final de su vida, no sean sometidas a tratamientos inhumanos o degradantes. Una vez más, los Ministros destacaron que: "el doble objetivo de prolongar el sufrimiento del paciente sin proceder a la violación de la Convención puede llevar a adoptar medidas dentro de los países muy diversas", cuestión que consideramos difícil de lograr por nuestra parte.

El Comité de Ministros no se olvida de que la Asamblea no se ha pronunciado en relación a dar una definición de "cuidados paliativos", bien porque no existe dicha definición, o por entender que era difícil dar un concepto tan extenso y que fuera unitario a nivel europeo. Es entonces cuando los Ministros recuerdan que el Comité Europeo de la Salud recogió en su estudio sobre la situación de cuidados paliativos en numerosos países europeos, destacando la posición adoptada en una Recomendación de ECEPT (Europa del Este y Central en relación con los cuidados paliativos). Tras lo cual, se adoptó una Recomendación sobre la organización de los cuidados paliativos por parte de la Comisión de Ministros el mes de noviembre de $2003^{151}$.

\footnotetext{
${ }^{151}$ Para más información ver: http://www.msssi.gob.es/organizacion/sns/planCalidadSNS/pdf/excelencia/cuidadospaliativosdiabetes/CUIDADOS_PALIATIVOS/opsc_est6.pdf.pdf. (Consultado el 27-08-2014). 
La Recomendación 1418 trató de evitar en todo momento recurrir al término "eutanasia”. La muerte no se contiene en ningún párrafo del texto. Se indica que "la solicitud de eutanasia o del auxilio asistido se constituyen en peticiones ilegítimas de los profesionales de la salud que no deben ser tenidas en consideración, ya que a través del ejercicio de este comportamiento se está violando los códigos de conducta que deben respetar estos profesionales y que tienen su fundamento en la ética”.

La Asamblea adoptó así una posición en la que rechaza la eutanasia, otorgando gran importancia a los cuidados paliativos y al acompañamiento de la persona en la fase final de su vida. Indican además que todo paciente en la fase final de su vida tiene derecho a: a- tener toda la asistencia necesaria para asegurar la calidad de vida, la mejor posible. Cierto es que, la Recomendación se posiciona claramente a favor del derecho del enfermo terminal e incurable a su autodeterminación. b- se reconoce, también, el derecho del enfermo terminal a estar informado y de no ser informado, a rechazar un tratamiento y de que no esté influenciado por parte de terceras personas a adoptar determinadas decisiones. c- también se le reconoce el derecho a realizar voluntades anticipadas, voluntades en las que se concretaran las decisiones que adopta en relación con los tratamientos que quiere y no quiere recibir, todas ellas deberán ser respetadas, incluso cuando el paciente deje de estar consciente y no pueda señalar su voluntad de forma expresa, siempre que su voluntad se haya recogido expresamente y de forma clara, sin influencias externas, y que se refieran a cuestiones que guarden relación con la situación médica en la que se encuentra. Todas estas disposiciones de autodeterminación tienen evidentemente, límites.

Como ya señaló la Asamblea General, "los deseos de los enfermos terminales e incurables que van a morir, no se constituirán en justificación válida para proceder a poner fin a la vida del mismo”. La voluntad de rechazar determinados tratamientos, no se constituye en un derecho ilimitado. La decisión de rechazar un tratamiento no se tendrá en consideración, ya que ello no supone atentar a la dignidad de la persona, y todo ello, no puede exonerar de responsabilidad al médico.

En la Declaración de Madrid de 1987 de la Asociación Médica mundial se afirmó que: "poner fin o acabar con la vida de un paciente terminal e incurable, incluso si se realiza a petición del propio paciente, es considerada contraria a la ética médica. Ello no permite que los médicos dejen de lado el proceso natural o el curso natural de la muerte de un enfermo terminal e incurable".

La Asamblea se posicionó de forma manifiestamente hostil a cualquier tipo de eutanasia. Pero ello no supone que no se permitan tratamientos que reduzcan el dolor y que como efecto indirecto y no querido reduzcan la vida del paciente en fase terminal.

Por su parte, el Comité de Ministros es consciente de que la Recomendación 1418 no ha logrado que se constituya una doctrina unitaria en este tema tan difícil y delicado. Además, son conscientes de que en 
Holanda y Bélgica han adoptado recientemente una legislación que se desmarca de los principios adoptados por parte de la Asamblea. El Comité de Ministros reconoce que, de forma habitual, tanto los pacientes en fase terminal como los médicos se enfrentan al tema de la eutanasia. Todo ello les lleva a posicionarse a favor de que existen razones suficientes que justifican abrir nuevamente en la Asamblea del Parlamento Europeo un nuevo debate, a pesar de que, tras el nuevo debate. Entienden que, la nueva posición adoptada por parte de Holanda y Bélgica no puede ni debe debatirse nuevamente sobre el tema, de forma seria. Por ello, hay Estados que están a la espera de que se vuelva a debatir y a adoptar las medidas oportunas, implicando a través de la presente Recomendación 1418 tanto a la Asamblea como al Comité de Ministros.

El debate sobre el tema de la eutanasia también se está valorando y negociando en otros Estados, como por ejemplo en Suiza, en el que se está discutiendo sobre la asistencia pública al suicidio asistido.

La Recomendación 1418 ha tratado de evaluar las distintas culturales, actitudes y valores. A pesar de lo cual, se ha posicionado claramente a favor de la prohibición absoluta de la muerte, principio recogido en todas las religiones monoteístas, siendo conscientes de que algunas iglesias protestantes se han pronunciado a favor de la despenalización de la eutanasia activa directa, como se ha posicionado la iglesia de Holanda. En Francia, por su parte, tras un fuerte debate, el Comité Consultivo Nacional de Ética ha recomendado, en su Decisión 63 de 27 de enero de $2000^{152}$, la legitimidad ética, de forma excepcional, de la vulneración de la prohibición de provocar la muerte.

Es por todo ello que, es recomendable proceder a la revisión de la Recomendación 1418, a pesar de que no exista un cambio de posición claro a la posición adoptada inicialmente. El tema es delicado, se entremezclan en el mismo, posiciones claramente emocionales y controvertidas. En este sentido, incluso en Francia, la Ley 15 de mayo de 2003 presentado por 24 Diputados socialistas que solicitaban que se reconociera el derecho a provocar la muerte junto con el derecho legítimo a disponer de la vida.

Señalar que, hay autores que consideraban que este nuevo debate sobre la despenalización de la eutanasia era "inútil, impracticable, e incluso peligroso". Era "inútil" ya que los que se posicionan a favor de la misma eran prácticamente inexistentes, según se desprende de los informes recabados. Era "Impracticable" ya que era difícil definir en una norma que haga referencia a una situación que es excepcional y que se encuentra recogida en el ámbito médico y ético, a través de leyes deontológicas. Y finalmente, es "peligrosa”, ya que se constituiría en una excepción formal y contiene una prohibición de matar, con el riesgo que de ello puede derivar.

Por otra parte, posicionarse a favor de una solución exclusivamente ética tampoco resuelve el tema. No se puede legislar ni a favor de su permisión ni de su penalización. La autorización de realizar el acto

${ }^{152}$ Les Cahiers du Comité Consultatif National d'étique, abril 2000, pp. 3-33. 
eugenésico puede constituirse en un actor moralmente permitido, pero nunca puede ser aceptado jurídicamente.

Todo ello nos lleva a cuestionarnos, ¿Es posible obtener finalmente una posición del Consejo de Europa sobre la eutanasia? Estamos en presencia de un derecho que está en cuestión, pero, evitar plantearse y debatir sobre el tema no es una solución ${ }^{153}$.

El día 25 de octubre de 2002 se realizaron distintas Audiciones de la Asamblea Parlamentaria del Consejo de Europa sobre la eutanasia en París a distintos Profesores que son miembros del Comité Consultivo Nacional de Ética de Francia.

La cuestión planteada entre otras fue: "La práctica de la eutanasia es una realidad médica”, es la pregunta que se realizó por parte del Comité Consultivo Nacional de Ética de Francia en su Informe no 58 titulada "Consentimiento informado a las personas que se someten a determinados cuidados o a tratamientos experimentales".

A las personas que fueron consultadas se les preguntó "si se posicionaban a favor de una discusióndebate público y sereno sobre el acompañamiento del paciente en la fase final de la vida".

En el Informe n ${ }^{\circ} 63$ se posicionaron a favor de las siguientes cuestiones:

1. Que se producía una cierta confusión en relación al tema de la eutanasia. Era evidente que hoy día en Francia y en otros países del mundo occidental, el progreso científico favorecen la reivindicación del "bien morir". Esta "utopía" de la buena muerte está cada vez más presente en nuestra sociedad, en la que casi el $70 \%$ de los pacientes mueren en los hospitales o en una institución dedicada a atender a los pacientes en la fase final de su vida.

2. La muerte se muestra en nuestra sociedad como dolorosa y difícil, y no queda más remedio que atender. Ciertos tratamientos y actitudes que realizan los médicos en la fase final de la vida del paciente han sido objeto, hoy día, de un amplio consenso. La medicina debe cuidad, acompañar... cuando ya no es posible aplicar alguna de las técnicas que mejoren el estado de salud del paciente. Es en esta fase final cuando, sobre todo, debe respetarse la autonomía y dignidad del paciente.

3. En Francia, la legislación trata de garantizar el derecho a los cuidados paliativos, estos derechos se contienen en la Ley de 9 de junio de 1999. Así también, en aplicación de la Ley de 4 de marzo de 2002 relativa a los derechos de los enfermos, se procedió a incorporar un nuevo precepto en el Código de la salud pública, concretamente, el art. L. 110-5 que dispone que: "toda persona tiene derecho a recibir los tratamientos y cuidados para reducir el dolor. En todo momento, el hecho de

\footnotetext{
${ }^{153}$ DICK MARTY, "Recommandation 1418- La position du Conseil de l'Europe, en L 'euthanasie, Volumen II. Perspectives,
} Nationales et européennes, 2004, pp. 133 y ss. 
que el paciente llegue a esta situación debe ser prevista y evaluada, así como tratada. Los profesionales de la salud deberán adoptar todas las medidas que tiene a su disposición, con el fin de asegurar a cada paciente una vida digna hasta el momento en el que llegue su muerte".

4. Cuando el "encarnizamiento terapéutico", entendido como, una obstinación no razonable, es rechazada como consecuencia de que el paciente está abocado a la muerte, por padecer una enfermedad incurable, la aplicación de cualquier técnica médica que suponga esta obstinación es rechazada, incluso por parte de instancias religiosas, éticas y deontológica.

5. Se van a destacar algunas cuestiones que consideramos duras, del Informe que fue emitido por parte del Comité de ética:

a) Rechazar determinados tratamientos, obstinación terapéutica, evidentemente puede en algunos casos precipitar el momento de la muerte del paciente, pero ello no implica la aceptación de la anticipación de la muerte.

b) El aplicar un tratamiento para reducir el dolor, en ocasiones puede anticipar la muerte del paciente, pero en este caso, no sólo no estamos ante un crimen, sino ante un deber que deriva de los cuidados que hay que facilitar a todo enfermo terminal.

c) En ocasiones, los tratamientos aplicados para reducir el dolor y sufrimiento del enfermo terminal, no suponen que el médico busque su muerte, si la muerte sobreviene con el paciente en estado indoloro, esto supone que es la hora que él ha elegido.

d) Cuando se eliminan todas las técnicas que facilitan la respiración del paciente o su reanimación, supone que se está, por parte de los médicos que le atienden al paciente, ante la convicción de que la muerte es inminente. Todo ello puede suponer que, se está respetando al paciente. Seguir con esas técnicas sería inútil en la fase final de la vida, a esa convicción han llegado los médicos que le tratan y por ello dejan de lado esas técnicas.

e) En algunos casos, la decisión adoptada por parte del personal médico de no reiniciar la reanimación, de no prolongarla o se aplica una sedación profunda, es evidente que puede adelantar el momento de la muerte del paciente.

f) No estamos ante supuestos en los que se concluye de forma deliberada con la vida del paciente, ya que la muerte que sobreviene es consecuencia de la enfermedad y no de la actuación médica.

6. Como consecuencia de todas estas posiciones, el Comité de Ética rechaza entrar en el debate semántico de la eutanasia pasiva. Rechazar el encarnizamiento terapéutico, los cuidados paliativos, el acompañamiento del paciente, integran todas estas técnicas, consecuencia de la vida misma, es decir, respetar al paciente hasta sus últimos instantes de vida. Es necesario que cada paciente tome la 
decisión que considere oportuna en relación a su muerte. Esta es una responsabilidad del paciente, mientras que la obligación de los responsables políticos es la de facilitar la ayuda financiera necesaria para que pueda ejercitarse este derecho de forma efectiva.

7. Los cuidados paliativos y el acompañamiento del paciente en la fase final de la vida supondrá que se reduzca el número de solicitudes que piden que se les aplique la eutanasia.

\section{La Recomendación 1418 adoptada por el Consejo de Europa en el año 1999 sobre los derechos del hombrey la dignidad de la persona con enfermedad incurable y moribunda}

Establece la citada Recomendación en la que se protegen los derechos del hombre y la dignidad de la persona incurable y moribunda que:

1. El fin del Consejo de Europa es la de proteger la dignidad del ser humano y los derecho que de ello derivan.

2. El desarrollo de la medicina, ha supuesto que hoy día, numerosas afecciones, incluso las que son incurables o fatales, el perfeccionamiento de las técnicas médicas y el desarrollo de la reanimación, que permite mantener de forma prolongada la vida del paciente terminal que, puede reducir o limitar el número de muertes. Las condiciones de vida de éstos pacientes que van a morir, pasan a un segundo plano, así como los derechos de sus familiares y cuidadores.

3. El año 1976 en la Resolución 613 de la Asamblea se declaró que "teniendo en consideración que los enfermos moribundos tienen antes que cualquier otro derecho, el derecho a morir en paz y dignidad, siendo acompañados por su familia y de sus amigos”, si le unimos la Recomendación 779 de 1976 en la que se indicaba que "la prolongación de la vida no debía tener como único fin la aplicación de una técnica médica, sino que debía ir dirigida, sobre todo, a reducir o eliminar el dolor y sufrimiento".

4. Tras la Convención para la protección de los derechos del hombre y de la dignidad de la persona a la igualdad en la aplicación de la biología y la medicina, ha establecido principios fundamentales, aun sin realizar una mención expresa y explícita de las condiciones que se tendrán en consideración en relación con los enfermos que padecen enfermedades incurables y moribundos.

5. La obligación de respetar y proteger la dignidad del enfermo incurable o moribundo es la consecuencia natural de la dignidad inviolable e inherente de la persona humana que debe respetarse en todos los momentos de la vida. Este respeto y protección se traducen en la creación de un entorno apropiado que permite a la persona morir con dignidad.

6. Es preciso velar por los cuidados de aquellas personas que se consideran especialmente vulnerables por parte de la sociedad, como lo han mostrado las innombrables experiencias pasada y presentes de 
sufrimientos padecidos. El ser humano, que inicia su vida en un estado de dependencia, necesita de protección en el momento en el que se está enfrentando a la muerte.

7. Distintos factores hacen que suponga una amenaza sobre los derechos fundamentales que tiene todo paciente incurable y que toda persona que va a morir necesita que se le preserve su dignidad. Entre estas destacan las siguientes:

a) El acceso insuficiente a los cuidados paliativos y a los tratamientos contra el dolor,

b) La ausencia en ocasiones de tratamientos que reducen los padecimientos psicológicos y la toma en consideración de las necesidades psicológicas, sociales y espirituales.

c) La prolongación artificial del proceso de la muerte, bien por la utilización por parte de los médicos de medios que no son proporcionales a los padecimientos que sufre el paciente, o por la aplicación de tratamientos sin tener en consideración las consecuencias que van a derivar de ellos.

d) La ausencia de formación permanente y de las necesidades psicológicas que tienen los profesionales de la salud que intervienen en la aplicación de cuidados paliativos.

e) La atención y cuidados insuficientes que se concede a los familiares y amigos del enfermo incurable.

f) El miedo que muestran los pacientes terminales de perder su autonomía y de suponer una carga para sus familiares y amigos, pasando a estar totalmente dependiendo de ellos.

g) La ausencia de un entorno social o institucional en el que el paciente puede dejar a sus familiares y amigos en paz.

h) La insuficiencia de fondos o recursos destinados a los cuidados que debe tener un enfermo incurable y moribundo.

i) La discriminación social que sufre la persona que está en la fase de agonía y de la muerte.

8. La Asamblea invita a los Estados miembros a desarrollar en su legislación interna las disposiciones que aseguren a los pacientes incurables y moribundos la protección jurídica y social necesaria contra los peligros con los que se puede encontrar en el ámbito de sus derechos, y en particular:

a) El riego de padecer síntomas insoportables en la fase previa a la muerte, (dolor, problemas respiratorios...).

b) El riesgo de ver que se prolonga su vida en contra de su voluntad.

c) El riesgo de morir aislado y abandonado.

d) El riesgo de ver limitados los medios artificiales para seguir viviendo como consecuencia de cuestiones de índole económico.

e) El riesgo de acabar sus días con la conciencia de que es una carga para la sociedad. 
f) La insuficiencia de medios económicos y de recursos destinados a su asistencia y al cuidado de los pacientes incurables y moribundos.

9. Por ello, la Asamblea recomienda al Comité de Ministros que anime a los Estados miembros del Consejo de Europa a respetar y proteger la dignidad de las personas con enfermedades incurables y moribundos, sobre todo a:

a) Proteger los derechos de los enfermos incurables y moribundos a todo un conjunto de cuidados paliativos completos, tomando las medidas necesarias para:

10. Que los cuidados paliativos sean parte de los derechos individuales reconocidos por la Ley en todos los Estados miembros.

11. Asegurar un acceso equitativo a los cuidados paliativos apropiados a cada enfermedad incurable y a toda persona moribunda.

12. Animar a los parientes y amigos a acompañar al enfermo incurable y moribundo, así como para asegurar cuidados profesionales. Después de que la familia y/o los organismos privados consideren que los cuidados que reciben son insuficientes, su intervención deberá sustituirse o completase por otras formas de cuidados médicos profesionales.

13. Disponer de equipos y recursos especializados, de forma que los cuidados paliativos puedan ser dispensados a los enfermos incurables y moribundos en su domicilio, cuando el tratamiento ambulatorio sea posible.

14. Que se proceda a cooperar entre todas las personas que son llamadas a procurar cuidados a los enfermos terminales.

15. Que desarrollen y pongan en vigor normativas destinadas a asegurar la calidad de los cuidados dispensados a los enfermos terminales.

16. Que los profesionales en el cuidado de éstos pacientes terminales sean formados de forma que, puedan atender a todos los pacientes terminales, se tenga en consideración los cuidados que deben ofrecerse a los médicos, enfermeras y psicólogos integrados en un equipo, en función de las normas que tengan en consideración todas éstas cuestiones.

17. Que, salvo en los supuestos en los que sea rechazado por parte de la persona interesada, los enfermos incurables reciban tratamiento anti dolor y los cuidados paliativos adecuados, incluso cuando el tratamiento aplicado tenga como efecto secundario el de reducir la vida de la persona a la que se le aplica.

18. Crear centros y desarrollar investigaciones, de formación y formadores en el ámbito de la medicina y de los cuidados paliativos, así como en tanatología interdisciplinar. 
19. Que en las unidades especializadas en cuidados paliativos y en los servicios para los enfermos que se encuentran en la fase final de su vida, se creen unidades especiales, al menos en los grandes hospitales, de forma que la medicina y los cuidados paliativos sean parte integrante de todos los tratamientos médicos.

20. Tomar conciencia en los ciudadanos de que la generalización de la medicina y de los cuidados paliativos son un objetivo principal de la medicina.

a) Proteger el derecho de los enfermos incurables y moribundos a su autodeterminación, y en adoptar las medidas necesarias para:

21. Hacer efectivo el derecho de las personas con enfermedades incurables y moribundas a una información verdadera y completa, comunicada con compasión, sobre el estado de su salud, respetando la decisión que tiene la persona de no ser informado.

22. Que el enfermo terminal e incurable pueda tener una segunda opinión diferente de la del médico que le atiende habitualmente.

23. Que el enfermo terminal e incurable no reciba un tratamiento que sea contrario a la voluntad que ha manifestado, siempre que en dicha decisión no haya intervenido presión de una tercera persona. Hay que tener en cuenta que, la decisión del enfermo no haya sido adoptada como consecuencia de presiones económicas.

24. Respetar las instrucciones y declaraciones de voluntad anticipadas que ha realizado el paciente, sobre los tratamientos médicos que quiere o no recibir, incluso en el momento en el que no sea capaz de manifestar sus deseos. Se deberán respetar las instrucciones que de forma anticipada había señalado. Si ha indicado en sus instrucciones previas la existencia de un representante legal y los poderes que le confiere. También se tendrá en consideración que el representante legal no adopte, en nombre del representado, decisiones que tienen como base en las decisiones presuntamente adoptadas por parte del paciente terminal, incluso si manifiesta algunas posiciones que no se evidencie que el enfermo ha mostrado anticipadamente en su declaración, o en base a las circunstancias de la enfermedad que padece el enfermo.

25. Que, sin prejuzgar la responsabilidad última del médico, la voluntad expresada por un enfermo incurable, en lo que se refiere a un tratamiento concreto se tendrán en consideración, ya que el propio paciente, al no estar consciente, no puede dar indicaciones para que se respete su dignidad.

26. Que la ausencia de instrucciones previas o de una declaración formal del paciente no pueda ni deba atentar al derecho a la vida del paciente. Es necesario señalar la lista de tratamientos que en ningún caso pueden ser rechazados o interrumpidos. 
a) En mantener la prohibición absoluta de poner fin intencionadamente a la vida del enfermo terminal y moribundo.

27. Visto que el derecho a la vida, sobre todo en lo que concierne a los enfermos terminales y moribundo, está garantizado por parte de los Estados miembros en base a lo que se establece en el art. 2 de la Convención Europea de Derechos del Hombre, que señala que "la muerte no puede provocarse a nadie de forma intencionada".

28. Visto que el deseo de morir expresado por parte de un enfermo en la fase final de su vida no puede constituirse, jamás, en fundamento jurídico para que la muerte se provoque por parte de una tercera persona.

29. Visto que el deseo de morir expresado por un enfermo incurable o moribundo no puede en sí mismo, servir de justificación legal al ejercicio de una acción destinada a provocar la muerte.

Todas estas cuestiones fueron sometidas nuevamente a la evaluación del Comité de Ministros del Consejo de Europa, que adoptaron distintas resoluciones. La primera de ellas, fue adoptada el día 30 de octubre de 2000, en la reunión no 728 de Delegados de los Ministros; la segunda, fue adoptada el día 26 de marzo de 2002, en la reunión no 790 de los Delegados de los Ministros.

\section{La Recomendación Rec (2003) 24, del Comité de Ministros del Consejo de Europa de los Estados Miembros sobre la organización de los cuidados paliativos}

Introducción

La Recomendación Rec (2003) 24 fue adoptada por parte del Comité de Ministros el día 12 de noviembre de 2003 en su Sesión 860 de los delegados de los Ministros. Así el Comité de Ministros, en virtud del art. 15.b) del Estatuto del Consejo de Europa, señala que:

1. Considerando que el fin del Consejo de Europa es lograr una unión más fuerte entre los Estados Miembros, y que dicho fin puede lograrse, entre otras, a través de la adopción de acciones comunes en el ámbito de la salud pública.

2. Teniendo en consideración el art. 11 de la Carta Social Europea relativa al derecho a la protección de la salud, y el art. 3 de la Convención de los derechos del hombre y de la biomedicina, que solicitó a los Estados Parte un acceso equitativo a los cuidados de la salud de calidad, que el art. 4 de esta misma Convención exige que toda intervención en el ámbito de la salud, que incluye la investigación, debe realizarse respetando las normas y obligaciones profesionales, y el art. 10 que dispone que toda persona tiene derecho a conocer toda la información necesaria en relación con su salud. 
3. Recordando en ese sentido la Recomendación del Comité de Ministros de los Estados Miembros, Recomendación no R (2003) 5 relativa al desarrollo de estructuras permanentes con la participación de las personas y los pacientes, en el proceso relativo a los cuidados de la salud.

4. Con la convicción de que el respeto y la protección de la dignidad del paciente enfermo de una enfermedad incurable o de un moribundo, supone que haya recibido todos los cuidados apropiados en un entorno apropiado, para que puede morir respetándose su dignidad.

5. Teniendo en consideración en éste sentido la Recomendación 1418 (1999) de la Asamblea Parlamentaria en relación a la protección de los derechos del hombre y la dignidad de los pacientes con enfermedades incurables y moribundos.

6. Teniendo en cuenta, también, la Recomendación n R (89) 13 del Comité de Ministros, en relación con la organización de cuidados multidisciplinares a las personas que padecen cáncer.

Se reconoce la "necesidad de desarrollar los cuidados paliativos en los distintos Estados Miembro".

7. Teniendo en consideración la Declaración de Poznan de 1998 sobre los cuidados paliativos en la Europa Oriental.

8. Reconociendo que el derecho a los cuidados de la salud, que tratan de lograr la mejor calidad de la situación del paciente que es capaz de ofrecerle la medicina, con independencia de su edad, de la raza a la que pertenece, de la condición económica o social, y de la naturaleza de su enfermedad o de la enfermedad que padece.

9. Considerando que cada vez más personas tendrán necesidad de recibir cuidados paliativos.

10. Considerando que la disparidad y disponibilidad, así como la calidad de los cuidados paliativos en los Países de la Unión necesitan de una cooperación en los distintos países,

11. Conscientes de que los cuidados paliativos deben ser adoptados en relación con todos los pacientes que tienen una enfermedad en fase avanzada, que deben aplicarse técnicas para reducir el dolor y otros síntomas, y que debe ofrecer soluciones para los problemas psicológicos, sociales y espirituales.

12. Siendo conscientes de que el objetivo de los cuidados paliativos es asegurar la mejor calidad de vida posible a los pacientes y a sus familias.

13. Considerando que los cuidados paliativos se constituyen en una demanda que favorece la vida, que supone que se asume la muerte como un proceso normal, y que no se constituye en una guía para la desesperanza ni para el fatalismo.

14. Considerando que los cuidados paliativos se constituyen en parte integrante del sistema de salud y se constituyen en elemento inalienable del derecho de los ciudadanos a los cuidados a los que tienen 
derechos, y que corresponde a los Gobiernos garantizar que los cuidados paliativos sean accesibles a todas las personas que lo necesitan.

15. Considerando que es necesario proceder al desarrollo de los cuidados paliativos de calidad, que se realicen de forma humanitaria, con el fin de que se constituya en un elemento esencial de los cuidados que se reconocen a toda persona en la fase final de su vida.

16. Reconociendo que toda persona en la fase final de la vida quiere ser tratada como persona íntegra por parte de los profesionales de la salud, profesionales que tienen que preservar la dignidad del paciente, favorecer su independencia, cuidar de los síntomas y garantizar el mayor confort posible.

17. Reconociendo que los cuidados paliativos se conviertan, al igual que el resto de tratamientos médicos, concretándose todos ellos en función de la situación de cada paciente, orientándose a sus necesidades, y teniendo en cuenta los valores y preferencias del paciente, así como su dignidad y autonomía, constituyéndose todos ellos en preocupaciones esenciales de los pacientes que necesitan cuidados paliativos.

Recomiendan a los Gobiernos de los Estados Parte:

1. Adoptar las políticas y medidas legislativas y de otro tipo necesarias para establecer un sistema coherente y completo a nivel nacional en el ámbito de los cuidados paliativos.

2. Dedicar a este fin, siempre que sea posible, las medidas presentadas en el apéndice de esta Recomendación, teniendo en cuenta sus circunstancias nacionales respectivas.

3. Promover el trabajo de grupo internacional entre organizaciones, institutos de investigación y otras agencias activas en el campo de los cuidados paliativos.

4. Dar soporte a una activa y orientada difusión de esta Recomendación y de su Memorándum explicativo, acompañada por su traducción donde sea pertinente.

\section{Consideraciones generales}

Dentro de las "Consideraciones Generales" se señala que:

1. A pesar de que en algunos países la mayor parte del presupuesto de asistencia sanitaria se destina a las personas en sus años finales de vida, no siempre reciben los cuidados más adaptados a sus necesidades.

2. Los cuidados paliativos no se dirigen a una enfermedad específica y abarcan el período desde el diagnóstico de enfermedad avanzada hasta el fin del duelo; su duración puede variar desde semanas a años, o (raramente) días. No es sinónimo de los cuidados a los enfermos terminales, pero los incluyen. 
3. Es crucial la creación, en los Estados miembros, de un clima en el que se reconozca la importancia de los cuidados paliativos.

4. Es necesario informar al público, especialmente a los pacientes y a sus familias, de la importancia de los cuidados paliativos y de las posibilidades que en ellos se ofrecen.

5. Varios estudios recientes, que proveen datos de un total de treinta y cinco países de Europa, señalan diferencias entre los países en relación a los cuidados paliativos, entre los cuales hay variaciones en el reintegro de gastos (cuando es aplicable), en la organización del sistema de asistencia sanitaria, y en la posición en éste de los cuidados paliativos; factores éticos y culturales diferentes; el papel de las organizaciones nacionales, y la colaboración internacional para el desarrollo de los cuidados paliativos, la disponibilidad de opiáceos; y cuestiones sobre formación y gestión del personal.

\section{Principios fundamentales}

\section{Se dispone que son "Principios Fundamentales":}

1. La política de cuidados paliativos debe basarse en los valores propuestos por el Consejo de Europa: Derechos Humanos y derechos de los pacientes, dignidad humana, cohesión social, democracia, equidad, solidaridad, igualdad de oportunidades para ambos sexos, participación y libertad de elección.

a) Los cuidados paliativos tienen las siguientes dimensiones fundamentales:

b) control de síntomas;

c) apoyo psicológico, espiritual y emocional;

d) apoyo a la familia;

e) apoyo al duelo.

Se afirma que los siguientes Principios dan soporte a la Recomendación:

2. Los cuidados paliativos son una parte vital e integral de los servicios de salud. Deben ser incorporadas previsiones para su desarrollo e integración funcional en las estrategias nacionales de salud.

3. Toda persona que necesite cuidados paliativos debe tener acceso a ellos sin retraso indebido, en su lugar de residencia o tan cerca como sea razonablemente posible, de acuerdo con sus necesidades y preferencias.

4. Los cuidados paliativos tienen como objetivo la consecución y mantenimiento de la mayor calidad de vida para los pacientes. 
5. Los cuidados paliativos persiguen abordar las cuestiones físicas, psíquicas y espirituales asociadas a la enfermedad avanzada. Por tanto, se requiere un acceso coordinado a un equipo altamente cualificado, adecuadamente provisto, interdisciplinar y multiprofesional.

6. Los problemas agudos intermedios deberán ser tratados si el paciente lo desea, pero deberán permanecer sin tratamiento, mientras los mejores cuidados paliativos continúan prestándose, si el paciente lo prefiere.

7. El acceso a los cuidados paliativos se basará en la necesidad, y no debe ser influido por el tipo de enfermedad, la localización geográfica, el estatus socioeconómico u otros factores semejantes.

8. Serán incorporados programas de educación en cuidados paliativos en la formación de todos los profesionales de la salud implicados.

9. Se emprenderá investigación dirigida a la mejora de la calidad asistencial. Todas las intervenciones en cuidados paliativos se apoyarán tanto como sea posible sobre informaciones científicas relevantes

10. Los cuidados paliativos recibirán un adecuado y equitativo nivel de dotación.

11. Como en todos los sectores de la atención médica, los proveedores de cuidados de salud implicados en los cuidados paliativos serán absolutamente respetuosos con los derechos de los pacientes, cumplirán las obligaciones profesionales y los estándares, y, en cada contexto, actuarán en el mejor interés de los pacientes.

\section{Estructura y servicios}

En cuanta a la "Estructura y Servicios", se señala que:

1. Los cuidados paliativos son una actividad interdisciplinar y multiprofesional que se ocupa de las necesidades del paciente, teniendo en cuenta a los cuidadores informales, como los miembros de la familia.

2. Los servicios y las políticas de cuidados paliativos deben ofrecer una amplia gama de recursos, incluyendo atención a domicilio, ingreso en unidades específicas o convencionales, hospital de día y consulta externa, atención a llamadas de emergencia y facilidades para el descanso del cuidador. Deberán ser integrales y apropiados al sistema asistencial y a la cultura, y estarán enfocados a las necesidades cambiantes y a los deseos de los pacientes.

3. Los cuidadores informales serán apoyados en su labor, y deberán evitarse las grandes repercusiones sociales, incluyendo la pérdida del trabajo, como consecuencia de sus cuidados. Un derecho formal al "permiso para cuidados" puede ser deseable. 
4. Todos los profesionales involucrados en los cuidados de pacientes con enfermedad avanzada y progresiva deberán tener fácil acceso a la consulta con expertos cuando y como lo necesiten.

5. Los especialistas en cuidados paliativos deberán estar disponibles para todos los pacientes cuando lo necesiten, en cualquier momento y en cualquier situación.

6. Se garantizará que existe liderazgo en los cuidados paliativos a nivel nacional y adecuada coordinación de los servicios, con clara localización de las responsabilidades. La formación de grupos de trabajo regionales se recomienda como un buen medio para lograr esta meta.

7. Los pacientes deberán tener acceso garantizado a los cuidados paliativos, sin indebidas barreras económicas. Deben tomarse medidas, especialmente financieras, de forma que la continuidad en los cuidados paliativos esté garantizada, y se adapte a las necesidades del paciente.

8. Deberán existir suficientes facilidades para el descanso del cuidador, para ofrecer relevo cuando los cuidadores en el domicilio se hallen desbordados.

\section{Politica asistencia y Organización}

Por lo que hace referencia a la "Política Asistencial y Organización", se afirma que:

1. Los cuidados paliativos deben ser parte integral del sistema de cuidados de salud de los países, y como tal debe ser un elemento de los planes de salud generales, y de los programas específicos relativos, por ejemplo, al cáncer, sida o la geriatría.

2. Los Gobiernos deben llevar a cabo un estudio de evaluación de necesidades que oriente las necesidades por servicios, por personal de los distintos niveles de especialización, y por formación de las diferentes profesiones (incluyendo voluntariado).

3. A los Gobiernos nacionales y regionales corresponde, sobre la base de la evaluación de las necesidades, diseñar y poner en práctica estrategias globales y racionales en cuidados paliativos, en estrecha colaboración tanto con los representantes de las profesiones médicas como de los pacientes y de las familias.

4. En el marco de estas estrategias, los Gobiernos deben identificar las barreras legales, sociales, económicas, culturales administrativas y/o físicas para el acceso a los servicios de cuidados paliativos. Deben ser puestos en práctica iniciativas y programas para reducir tales barreras, que a menudo refuerzan las desigualdades.

5. La legislación debe hacer accesibles para el uso médico los opioides y otras drogas en un surtido de formulaciones y dosificaciones. El temor al abuso no deberá limitar el acceso a la necesaria y efectiva 
medicación. Los países pueden considerar si esto requiere nueva legislación o una modificación de la ya existente.

6. Se recomienda que, tanto a nivel nacional, regional como local, se constituyan grupos focales interdisciplinares o consejos dedicados a los cuidados paliativos, que incluyan pacientes, familias y otros, para mantener la atención política y social. Preferiblemente, tales grupos cooperarán con los Gobiernos y otros cuerpos para poner en práctica las necesarias políticas.

7. Para facilitar la monitorización de la calidad de los cuidados paliativos es necesaria la constitución de un "conjunto mínimo de datos" (CMD) uniforme, al menos a nivel nacional.

8. Debido a la importancia de la equidad, debe prestarse especial atención a los cuidados paliativos prestados a los grupos desfavorecidos (por ejemplo, presos con dificultades de aprendizaje, personas sin hogar, refugiados) y a las diferencias culturales y étnicas en relación con las necesidades de los pacientes. Con la misma importancia, deberá prestarse especial atención a los cuidados paliativos para la infancia.

9. Los cuidadores profesionales tienen derecho a una adecuada remuneración, y al reconocimiento por su trabajo y por su competencia.

10. Será publicado un informe nacional anual sobre la organización y el funcionamiento de los cuidados paliativos.

\section{Mejora de calidad e investigación}

Por lo que se refiere a la "Mejora de la calidad e investigación", se dispone que:

1. Debe ser estimulada la definición y adopción de indicadores de buenos cuidados paliativos valorando todas las dimensiones de los cuidados desde la perspectiva del paciente.

2. Deben desarrollarse de forma sistemática guías de práctica clínica para los cuidados paliativos, basadas en las mejores evidencias disponibles, con la participación de los pacientes.

3. Una realimentación continua sobre las prácticas, en forma de audit, es esencial para el control de calidad.

4. Aunque la investigación científica en cuidados paliativos pueda plantear problemas éticos especialmente acuciantes, los servicios asistenciales y las intervenciones médicas deben ser evaluados usando métodos científicos probados, tanto de naturaleza cuantitativa como cualitativa. El enfoque de todos los estudios debe ser orientado al paciente.

5. Debe ser estimulada la investigación colaborativa, tanto a nivel nacional como europeo. 
6. Debe establecerse un observatorio a nivel nacional y regional para recoger, procesar y difundir información de confianza sobre los progresos y la calidad de los cuidados paliativos.

\section{Educación y Fomento}

En cuanto a la "Educación y Fomento" se señala que:

1. Tanto para la investigación como para la educación es crucial el reconocimiento académico de la importancia de los cuidados paliativos.

2. Los cuidados paliativos deben ser incluidos en toda formación de pregrado de los médicos y enfermeras. Debe establecerse un currículum estándar también para los estudios y formación de posgrado, y deberá haber programas de formación para expertos en cuidados paliativos.

3. Se debe promover la cooperación internacional en educación, por ejemplo, estableciendo un directorio de unidades de cuidados paliativos interesadas en participar en programas conjuntos.

4. Todos los profesionales y no profesionales implicados en los cuidados paliativos deben ser formados adecuadamente para su tarea, y deben recibir en todos los niveles formativos una instrucción concreta, perceptiva y culturalmente sensible.

5. La educación en cuidados paliativos debe ser tanto mono disciplinar como interdisciplinar.

6. La educación en cuidados paliativos debe ser revisada con regularidad, por ejemplo en forma de supervisión.

7. Serán establecidos centros de referencia en cada país, para la enseñanza y formación en cuidados paliativos.

8. Idealmente, habrá tres niveles en la formación (continuada) para los profesionales: formación básica, intermedia y avanzada.

9. Se recomienda que los países dediquen atención específica a la educación de la población general sobre todos los aspectos relevantes de los cuidados paliativos.

10. Las imágenes negativas injustificadas sobre los opiácidos entre los pacientes, familias, los profesionales y la población deben ser corregidas, recalcando las diferencias fundamentales entre las aplicaciones clínicas y el potencial de abuso, tanto en campañas públicas como en la educación de los profesionales.

\section{La familia}

Por lo que concierne a la asistencia a la "familia" se afirma que: 
El objetivo y el principio en la ayuda a los allegados de los pacientes (principalmente miembros de la familia) es poner en práctica y desarrollar su capacidad para prestar soporte emocional y práctico a los pacientes, adaptar al proceso y afrontar el duelo y la ausencia. Debe prestarse particular atención a la prevención y tratamiento de la depresión por agotamiento.

\section{La Comunicación con los familiares y parientes}

En cuanto a la "Comunicación con los familiares y los parientes", se indica que:

1. Los cuidados paliativos requieren un clima, una actitud y una relación cuidador-paciente que promocione la franqueza en la información a los pacientes y familias.

2. Los profesionales deben tener en cuenta la extensión con que los pacientes desean ser informados sobre su situación; en este sentido, debe prestarse atención a las diferencias culturales.

3. Los profesionales deben adaptar el modo en que informan a los pacientes a las barreras emocionales o cognitivas que se asocian a menudo con padecer una enfermedad avanzada y progresiva.

4. Cuando haya niños implicados, tanto por su propia enfermedad como por la enfermedad de un progenitor, la comunicación se debe adaptar a sus necesidades.

\section{Los Equipos, trabajos en equipo y planteamiento de los cuidados}

En relación a los "Equipos, trabajos en equipo y planteamiento de los cuidados", se dispone que:

1. Los cuidados paliativos interdisciplinares y multiprofesionales, y la mayor parte de las veces involucran a un médico y a una enfermera, y a otros trabajadores sanitarios que disponen de los conocimientos necesarios para responder a las necesidades físicas, psicológicas y espirituales del paciente y la familia. Debe facilitarse el funcionamiento de tales equipos.

2. La toma de decisiones, especialmente la elaboración, monitorización y revisión regular de los planes individuales de cuidados anticipatorios, debe ser compartida entre el paciente, la familia y el equipo, cuando sea apropiado, y cumplir los deseos de los pacientes. Debe asegurarse una comunicación apropiada entre los servicios implicados (curativos y paliativos).

3. Los voluntarios pueden ser una parte importante del equipo. No reemplazan el trabajo de los profesionales, pero tienen su propia contribución y conocimientos. Debe facilitarse el establecimiento de los servicios de voluntariado, así como el acceso al papel de voluntario.

4. Todos los miembros de los equipos deben ser competentes en sus funciones, y darse cuenta de las posibilidades y limitaciones del papel propio y del de los otros miembros. 
5. Recibir mensajes coherentes de los diferentes proveedores de cuidados es crucial para el paciente y la familia. Por lo tanto, los flujos de información óptimos son esenciales para evitar malentendidos o discrepancias. Es aconsejable establecer un coordinador principal, preferiblemente el médico que trata al paciente, dependiendo de las circunstancias.

6. Toda comunicación entre profesionales que se refiera a los pacientes y familias está sujeta al secreto profesional, respetando el derecho del paciente al secreto médico como el derecho de la familia a la privacidad.

7. Los cuidados paliativos son generalmente muy gratificantes, pero igualmente pueden ser muy exigentes. Por tanto, el cuidado del cuidador es una parte esencial de los cuidados paliativos, y la salud laboral de quienes trabajan en cuidados paliativos debe ser el centro de las políticas.

ElDuelo

Por lo que se refiere al "Duelo", se dispone que:

1. Deben ofrecerse servicios de cuidado al duelo a todos aquellos que necesiten ayuda.

2. Todos los trabajadores profesionales en cuidados paliativos deben estar atentos a los signos de duelo complicado o patológico.

\section{LA EUTANASIA, EL SUICIDIO MÉDICAMENTE ASISTIDO Y LOS "CUIDADOS PALIATIVOS” EN ESPAÑA}

\section{Consideraciones generales}

En España la eutanasia y el suicidio médicamente asistido están penalizados en el Código penal. Destacar que, tanto la definición de la eutanasia como del suicidio médicamente asistidos ${ }^{154}$ se desprenden del propio artículo del Código penal ${ }^{155}$.

El art. 143.4 del Código penal dispone: "El que causare o cooperare activamente con actos necesarios y directos a la muerte de otro, por la petición expresa, serie e inequívoca de éste, en el caso de que la víctima sufriera una enfermedad grave que conduciría necesariamente a su muerte, o que produjera graves

\footnotetext{
${ }^{154}$ En adelante, SMA.

${ }^{155}$ ROYES, A. "La eutanasia y el suicidio ...”, ob. cit. p. 325. Para más información, ver: GARCÍA-MANRIQUE R. MILLION DOLlA B. "La eutanasia como compromiso", en Revista de Bioética y Derecho, 2005, 3, pp. 11 y ss. http://www.bioeticayderecho.ub.es/revista, (Consultado 15-08-2014). GARCÍA-MANRIQUE R. "Mar adentro: la eutanasia para todos los públicos”, en Revista de Bioética y Derecho, 2005-2, pp. 11 y ss. http://www.bioeticayderecho.ub.es/revista. (Consultado 15-08-2014).
} 
padecimientos permanentes y dificiles de soportar, será castigado con la pena inferior en uno o dos grados a las que señalan los apartados 2 y 3 del citado artículo".

Se trata de una excelente definición de eutanasia y SMA, ya que señalan directamente todos los requisitos necesarios para que se proceda a aplicar la atenuante que distingue las citadas conductas del homicidio ${ }^{156}$, entre los que queremos destacar:

1. Causar o cooperar activamente con actos necesarios y directos a la muerte de otro;

2. Petición voluntaria; expresa; serie e inequívoca del paciente;

3. Carácter incurable y grave de la enfermedad con consecuencia de muerte, o el que aunque no se condujera a la muerte del paciente en un plazo breve, le ocasione un sufrimiento permanente e insoportable para el mismo.

Destacar que, el término "padecimiento permanente y difícil de soportar" debe entenderse, en opinión de ROYES, que incluye tanto el posible sufrimiento físico como mental (es decir, el ocasionado por la propia presencia de la enfermada y la merma de calidad de vida o de dignidad que aquella provoque). Que el padecimiento sea o no "difícil de soportar" es, obviamente, algo subjetivo, depende de cada persona enferma, por lo que sólo ésta puede establecer si su situación clínica es o no "insoportable", con lo que el paciente se convierte así en el único que puede manifestar con claridad si cumple o no de modo suficiente con esta condición $^{157}$.

El requisito de la "voluntariedad" exige que el paciente se encuentre en condiciones de tomar decisiones por si mismo y en su beneficio, lo cual parecería que excluye a aquellos pacientes que tengan mermada dicha capacidad o que sufran alguna patología psiquiátrica que les incapacite para tomar este tipo de decisiones. Sin embargo, es discutible que el hecho de padecer alguna enfermedad mental constituya sistemáticamente y en todos los casos motivo de exclusión para que el paciente solicite la eutanasia o el SMA. En el presente caso, suele exigirse un informe psicológico o psiquiátrico del paciente antes de tramitar su petición, pero no se prejuzga el resultado de este informe, es decir, que no se considera un motivo de exclusión por si mismo la mera existencia de antecedentes de patología psiquiátrica o la presencia de trastorno mental ${ }^{158}$.

Con el fin de cumplir con los compromisos asumidos en España de las Recomendaciones remitidas a todos los Estados Miembros del Consejo de Europa en relación con los cuidados paliativos, se procedió a desarrollar toda la normativa necesaria para dar por cumplido dichos compromisos.

En la reunión celebrada el mes de mayo de 1991 en Estocolmo en la que participaron once países europeos, se procedió a establecer la "definición" del término "cuidados paliativos" afirmando que:

\footnotetext{
${ }^{156}$ ROYES, A. “La eutanasia y el suicidio ... ”, ob. cit. p. 325.

${ }^{157}$ ROYES, A. “La eutanasia y el suicidio ... ”, ob. cit. p. 325.

${ }^{158}$ ROYES, A. “La eutanasia y el suicidio ...", ob. cit. p. 325.
} 
Es un programa de asistencia Total, Activa y Continuada de los pacientes y sus familias por un equipo interdisciplinar, cuyo objetivo es dar calidad de vida, sin intentar alargar la supervivencia. Contempla las necesidades físicas, psicológicas y sociales del enfermo y sus familiares. Si es necesario incluye el apoyo del proceso de duelo.

Por su parte, la Organización Mundial de la Salud ${ }^{159}$ define los "cuidados paliativos" el año 1990 afirmando que es:

El cuidado global y activo de aquellos pacientes cuya enfermedad no responde a un tratamiento curativo, en los que es esencial el control del dolor y otros síntomas, la atención a los problemas psicológicos, sociales y espirituales, y el conseguir la mejor calidad de vida para ellos y sus familias. Los cuidados paliativos afirman la vida y consideran el morir como un proceso natural, no prolongan ni aceleran la muerte, ofrecen un sistema de apoyo para ayudar a los pacientes a vivir tan activamente como sea posible hasta su muerte y a sus familiares para afrontar la enfermedad, la pérdida y el duelo. Por tanto los cuidados paliativos tienen como objetivo promover el confort y mejorar la calidad de vida del paciente en el final de la vida, recuperando, desde una perspectiva humanística, el acercamiento a una muerte tranquila, sin estorbos terapéuticos innecesarios, donde la familia vuelva a cobrar su papel principal cerca del paciente.

Posteriormente la OMS ha ampliado la definición de cuidados paliativos señalando que se constituyen en un:

Enfoque que mejora la calidad de vida de pacientes y familias que se enfrentan a los problemas asociados con enfermedades amenazantes para la vida, a través de la prevención y alivio del sufrimiento por medio de la identificación temprana e impecable evaluación y tratamiento del dolor y otros problemas, fisicos, psicológicos y espirituales.

La definición se completa con los siguientes principios sobre los cuidados paliativos: a- Proporcionan alivio del dolor y otros síntomas. b- Afirman la vida y consideran la muerte como un proceso normal. c- No intentan ni acelerar ni retrasar la muerte. d- Integran los aspectos espirituales y psicológicos del cuidado de los pacientes. e- Ofrecen un sistema de soporte para ayudar a los pacientes a vivir tan activamente como sea posible hasta la muerte. $\mathrm{f}$ - Ofrecen un sistema de soporte para ayudar a las familias a adaptarse durante la enfermedad de los pacientes y en el duelo. g- Utilizan una aproximación de equipo para responder a las necesidades de los pacientes y sus familias, incluyendo soporte emocional en el duelo, cuando esté indicado. hMejoran la calidad de vida y pueden también influenciar positivamente en el curso de la enfermedad. i- Son aplicables de forma precoz en el curso de la enfermedad, en conjunción con otros tratamientos que pueden prolongar la vida, tales como quimioterapia o radioterapia e incluyen aquellas investigaciones necesarias para comprender mejor y manejar situaciones clínicas complejas.

Será a partir del año 1990 cuando se comienzan a inaugurar en los distintos hospitales españoles las "Unidades de Cuidados Paliativos".

\footnotetext{
${ }^{159}$ En adelante OMS.
} 


\section{Guía de cuidados paliativos}

El Ministerio de Sanidad pública promulgó, el mes de noviembre de 1993, la primera "Guía de Cuidados Paliativos de la Sociedad Española de Cuidados Paliativos", (SECPAL) ${ }^{160}$.

Se dispone en la misma que: Se entiende por "Enfermedad terminal" aquella situación en la que se encuentra el paciente en el que concurren una serie de características que son importantes no sólo para definirla, sino también para establecer adecuadamente la terapéutica.

Los elementos fundamentales para señalar que estamos en presencia de una enfermedad terminal son: 1.- Presencia de una enfermedad avanzada, progresiva, e incurable. 2.- Falta de posibilidades razonables de respuesta al tratamiento específico. 3.- Presencia de numerosos problemas o síntomas intensos, múltiples, multifactoriales y cambiantes. 4.- Gran impacto emocional en el paciente, familia y equipo terapéutico, muy relacionado con la presencia, explicita o no de la muerte. 5.- Pronóstico de vida inferior a seis meses. Esta situación compleja produce una demanda importante de atención y de soporte, a los que debemos responder adecuadamente, señala la Sociedad Española de Cuidados Paliativos.

Afirma la SECPAL que los tratamientos curativos y paliativos no son excluyentes, sino que son una cuestión de énfasis. Así se aplican gradualmente un mayor número y proporción de medidas paliativas cuando avanza la enfermedad y el paciente deja de responder al tratamiento específico. En el momento en el que se agota el tratamiento específico, una vez agotados de forma razonable aquellos métodos de los que se dispone, entran la enfermedad en situación progresiva, dirigiéndose los objetivos terapéuticos a la promoción del control del enfermo y su familia.

Dispone la SECPAL que las bases terapéuticas en los pacientes terminales serán:

1. La atención integral, que tendrá en cuenta los aspectos físicos, emocionales, sociales y espirituales. Forzosamente se trata de una atención individualizada y continuada.

2. El enfermo y su familia son una unidad a tratar. La familia es el núcleo fundamental del apoyo del enfermo, adquiriendo una relevancia especial en la atención domiciliaria. La familia requiere medidas específicas de ayuda y educación.

3. La promoción de la autonomía y la dignidad del enfermo tienen que dirigir todas las decisiones terapéuticas que se vayan adoptando. Este principio sólo será posible si se elaboran con el enfermo los objetivos terapéuticos.

${ }^{160}$ Ver texto íntegro en: http:/ / www.secpal.com/guiacp/guiacp.pdf. Sociedad Española de Cuidados Paliativos. vol.07, nº. 02, Rio de Janeiro, 2014.pp. 892-1009 
4. Se adopta una concepción terapéutica activa, incorporando una actitud rehabilitadora y activa que nos lleve a superar el "no hay nada más que hacer". Nada más lejos de la realidad y que demuestra un desconocimiento y actitud negativa ante esta situación.

5. Es importante el "ambiente". Una "atmósfera" de respeto, confort, soporte y comunicación influyen de forma decisiva en el control de síntomas. La creación de este ambiente depende de las actitudes de los profesionales y de la familia, así como de medidas organizativas que den seguridad y promocionen la comodidad al enfermo.

Señala como "Instrumentos básicos" la SECPAL que: La calidad de vida y confort de los pacientes antes de su muerte pueden ser mejoradas considerablemente mediante la aplicación de los conocimientos actuales de los cuidados paliativos, cuyos instrumentos básicos son:

1. Control de los síntomas: Hay que saber conocer, evaluar y tratar adecuadamente los numerosos síntomas que aparecen y que inciden directamente sobre el bienestar de los pacientes. Mientras algunos se podrán controlar (dolor, disnea... ), en otros será preciso promocionar la adaptación del enfermo a los mismos (debilidad, anorexia ... ).

2. Apoyo emocional y comunicación con el enfermo, la familia y el equipo terapéutico, estableciendo una relación sincera y honesta.

3. Algunos cambios en la organización, que permitan el trabajo interdisciplinar y una adaptación flexible a los objetivos cambiantes que padece el enfermo.

4. Equipos interdisciplinares, ya que es muy difícil plantear los cuidados paliativos son un trabajo en equipo que disponga de espacios y tiempos específicos para ello, con formación específica y apoyo adicional.

Para llevar adelante todos estos instrumentos es importante disponer de conocimientos y habilidades concretas en cada momento, que se constituyen en verdaderas disciplinas científicas. Se considera para ello determinante e imprescindible adoptar una actitud adecuada ante esta situación, a menudo límite para el apoyo del enfermo, la familia y el equipo terapéutico que le atiende:

a) Evitar antes de tratar, en el sentido de evitar los síntomas sólo al hecho de tener una enfermedad terminal y preguntarse el mecanismo fisiopatológico concreto. Además de la causa, debemos evitar la intensidad, el impacto físico y emocional y los factores que provocan o aumentan los síntomas que padece el paciente.

b) Explicar las causas de estos síntomas en términos que el paciente pueda comprender, así como las medidas terapéuticas a aplicar. No debemos olvidar que el enfermo está preocupado y quiere saber por qué tiene los síntomas. Explicar, así mismo, la etiología de los síntomas y las estrategias a la familia. 
c) La estrategia terapéutica a ampliar siempre será mixta, general de la situación de enfermedad terminal y específica para cada síntoma que comprende a su vez medidas farmacológicas y no farmacológicas. Además deben fijarse los plazos para conseguir los objetivos y contemplar la prevención de nuevos síntomas o situaciones que puedan aparecer.

d) Monitorización de los síntomas mediante el uso de instrumentos de medida estandarizada (escala de puntuación o análogas) y esquemas de registro adecuados (esquema corporal del dolor, tablas de síntomas...). La correcta monitorización nos ayudará a clarificar los objetivos, sistematizar el seguimiento, y mejorar nuestro trabajo al poder comparar nuestros resultados. Requerirá la validación previa por el equipo del instrumento de medida que debe aplicarse.

e) Atención a los detalles para optimizar el grado de control de los síntomas y minimizar los efectos secundarios adversos de las medidas terapéuticas que se aplican. Actitudes y conductas adecuadas por pare del equipo (escuchar, terapia emocional, contacto físico ...), contribuyendo no sólo a disminuir la sensación de abandono e impotencia del paciente, sino que además elevan el umbral de percepción del dolor por parte del enfermo.

Se concluye afirmando que, la rigurosidad y minuciosidad de la actuación del cuadro médico que atiende al paciente tendrá una traducción clínica evidente en los pacientes sobre su nivel de confort, siendo necesario conjuntar una gran experiencia clínica en el manejo de estos pacientes con un alto nivel de sentido común a la hora de tomar algunas decisiones, evitando aquellas medidas de diagnóstico que no vayan a alterar las estrategias necesarias de forma notable, así como no retrasando el tratamiento por el hecho de no disponer del mismo.

Es imprescindible que el equipo terapéutico completo elabore, asuma, practique y evalúe los objetivos terapéuticos en cada síntoma y en especial en el caso del dolor.

Señalan algunos autores que la situación de "enfermedad terminal" se determina siguiendo los siguientes criterios:

1. Presencia de enfermedad avanzada, incurable, progresiva.

2. Ausencia de posibilidades razonables de respuesta a tratamientos específicos o alternativos.

3. Insuficiencia de órganos (mono o múltiple).

4. Presencia de numerosos síntomas/ problemas intensos multifactoriales y cambiantes.

5. Gran impacto emocional en el paciente, familia y equipo terapéutico muy relacionado con la presencia, explícita o no, de la muerte.

6. Pronóstico de vida limitado (generalmente inferior a 6 meses). 
7. Periodo que genera una gran demanda asistencial por parte del paciente y su familia ${ }^{161}$.

A esta fase terminal de la enfermedad no sólo se llega desde las enfermedades oncológicas, también se alcanza en el proceso evolutivo de enfermedades crónicas progresivas de larga duración. En esta etapa de la vida se deberá atender de forma individualizada y continuada al paciente y su familia, como una unidad objeto de atención, incluyendo a todas aquellas personas que participan activamente en los cuidados del enfermo y que requieren medidas especiales de apoyo y educación.

Elemento fundamental de esta atención es el respeto de la autonomía y la dignidad de la persona enferma; cualquier actuación deberá acompañarse de la información que permita el proceso de deliberación y toma de decisiones. Será preciso adoptar una concepción activa y positiva de la terapéutica que supere la sensación de impotencia, fracaso y frustración relacionada con las medidas de tipo curativo previamente aplicadas y sin efecto. Creando, de esta forma, el clima necesario para facilitar la expresión de preocupaciones, miedos y sentimientos de pacientes y familiares en un ambiente de respeto a la intimidad.

Los Instrumentos básicos sobre los que se sustenta la práctica diaria de los cuidados paliativos son:

1. El control de síntomas: reconocer, evaluar y tratar adecuadamente los numerosos síntomas que alteran el bienestar de los pacientes.

2. El apoyo emocional y la comunicación con el enfermo, su familia y el equipo terapéutico, estableciendo una relación franca y honesta.

3. Las modificaciones precisas en la organización que permitan el trabajo interdisciplinar y una adaptación flexible a las necesidades cambiantes de los pacientes.

4. El equipo interdisciplinar con formación específica que permita el abordaje de los múltiples problemas y necesidades que se plantean en una situación de enorme complejidad como es la del paciente al final de la vida ${ }^{162}$.

Se establece un "Plan de Estrategias de Cuidados paliativos en el Sistema Nacional de Salud español", para los años 2010-2014, en el que se señalan algunos compromisos que deben asumir también, por parte de las Comunidades Autónomas, con el fin de contribuir a la homologación y mejora de los cuidados paliativos.

\footnotetext{
${ }^{161}$ PASCUAL A. Medicina Paliativa: Una nueva filosofia. Sociedad Española Dolor. 1995; pp. 5-10. NÚÑEZ OLARTE, JM. "Una elección básica: tratamiento paliativo o tratamiento curativo", en. Ética en cuidados paliativos. COUREIRO, A. Editorial Triacastela. Madrid 2004:pp. 109-125. ESPINAR CID, v. "Los cuidados paliativos: acompañando a las personas en el final de la vida”, en Cuadernos de Bioética, XXIII, 2012/1.

${ }^{162}$ GÓMEZ SANCHO, M. "Necesidades humanas, control de síntomas: Principios generales", en: GÓMEZ SANCHO, M (ed): Cuidados Paliativos: Atención integral a enfermos terminales, Las Palmas de Gran Canarias; ICCEPS. 1998, pp. 285292. CALLAHAN, D. "Death and the research imperative", en The New England Journal of Medicine, 2000; pp. 654-656. CASSEL, E. J. (2004). The nature of suffering and the goals of medicine ( $2^{a}$ ed.) Nueva York: Oxford University Press.
} 
En el citado Plan se establecen como "Valores" fundamentales: 1- El Derecho al alivio del sufrimiento. 2- El Valor intrínseco de cada persona como individuo autónomo y único. 3.- La Calidad de vida definida por cada paciente. 4- Las Expectativas del enfermo y su familia sobre la respuesta del sistema sanitario a sus necesidades en el final de la vida. 5.- La Solidaridad ante el sufrimiento.

Se consideran "Principios" determinantes del citado Plan los siguientes: 1- Acompañamiento a los pacientes y sus familias basado en sus necesidades. 2- Atención integral, accesible y equitativa. 3- Continuidad de la atención y coordinación de niveles asistenciales. 4- Comunicación abierta y honesta. 5- Reflexión ética y participación de los pacientes y sus familiares en la toma de decisiones. 6- Competencia y desarrollo profesional continuado para responder adecuadamente a las necesidades de los pacientes y familiares. 7Trabajo en equipo interdisciplinar. 8- Actuaciones terapéuticas basadas en las mejores evidencias disponibles. 9- No discriminación en función de la edad, sexo, ni de ninguna otra característica.

El año 2009, una reciente Resolución adoptada el 29 de Enero de 2009 por la Asamblea Parlamentaria del Consejo de Europa considera los cuidados paliativos como un componente esencial de una atención sanitaria basada en un concepto humano de dignidad, autonomía, derechos humanos, derechos de los pacientes y una percepción generalmente reconocida de solidaridad y cohesión social. Además recomienda los cuidados paliativos como un modelo de políticas sociales y de salud innovadoras ${ }^{163}$.

Teniendo en consideración que en España las Comunidades Autónomas tienen competencias en el ámbito sanitario, vamos a desarrollar algunas cuestiones que tienen que ver con los cuidados paliativos en el País Vasco.

El Plan de cuidados paliativos de la Comunidad Autónoma Vasca en relación con los pacientes en la fase final de la vida ha sido desarrollado a partir del año 1993. Se dispone en la Guía de Cuidados paliativos que: "Los avances tecnológicos, junto con la investigación y desarrollo de nuevos fármacos posibilitan, actualmente, la curación de un gran número de enfermedades. Sin embargo, también es cierto que su aplicación, en determinadas situaciones, prolonga el tiempo de morir de muchas personas enfermas, hasta el punto de que la fase final de la vida de algunas de ellas se acompaña de un sufrimiento innecesario. No resulta extraño que sean cada vez más las voces, de toda índole, que se pronuncien por el derecho a una muerte digna”.

Los cuidados paliativos son programas de tratamiento dirigidos a pacientes con enfermedades progresivas e irreversibles que no responden a los tratamientos curativos. Entre sus objetivos destacan el control de síntomas clínicos como el dolor, y la atención de los problemas psicológicos, sociales y espirituales, orientados a conseguir el alivio del sufrimiento de la persona enferma y su familia. Para lograr estos objetivos es

\footnotetext{
${ }^{163}$ Palliative care: a model for innovative health and social policies. Doc. 117584 November 2008. Parlamentary Assembly. Council of Europe.
} 
importante reafirmar la importancia de la vida considerando la muerte como un hecho natural, establecer un proceso que no acelere su llegada, ni la posponga, proporcionar alivio del dolor y otros síntomas, y ofrecer un sistema de apoyo a la unidad de tratamiento formada por paciente y familia: a las personas enfermas, para ayudarles a llevar una vida lo más activa posible hasta el momento de morir, y a sus familiares para que puedan afrontar la enfermedad y sobrellevar el periodo de duelo.

Los tratamientos paliativos incluyen intervenciones médicas, como la radioterapia y quimioterapia, o quirúrgicas, siempre que puedan establecerse con claridad los beneficios sobre los riesgos. La Organización Mundial de la Salud (OMS) ya recomendaba en 1990 que los procedimientos paliativos fueran considerados como parte integrante del tratamiento del cáncer. En el año 2002, en su publicación sobre el desarrollo de programas de cáncer, añade a los tres ya clásicos niveles de atención (prevención primaria, secundaria, y diagnóstico y tratamiento), un cuarto nivel para el alivio del dolor y los cuidados paliativos. Insiste en que los cuidados paliativos deben aplicarse de manera precoz en el curso de estas enfermedades.

El Sistema Sanitario Vasco ha avanzado durante los últimos años en el área de los cuidados paliativos. Se ha organizado un modelo de asistencia integral de recursos que se materializo en tres fases:

1. La impregnación y sensibilización, que tuvo como fin principal la formación continúa de los profesionales, con el objetivo de sensibilizar y proporcionar conocimientos básicos en el área de los cuidados paliativos.

2. La asignación de recursos específicos, para lo que se crearon unidades de cuidados paliativos en hospitales de media y larga duración, desarrollando también la asistencia domiciliaria del paciente.

3. El Plan para consolidar el desarrollo de los Cuidados paliativos en la Comunidad Autónoma del País Vasco. Esta consolidación se desarrollo entre los año 1998 y 2002 y tenía dos objetivos principales, el primero, consistía en la mejora en la atención de los enfermos al final de la vida, la segundo, era sensibilizar y capacitar a los profesionales sanitarios para el abordaje terapéutico a este tipo de pacientes.

Una de las alternativas que se proponen en el País Vasco es la hospitalización domiciliaria como alternativa a la hospitalización convencional para determinados tipos de pacientes que requieren cuidados continuos, por lo peculiar de su proceso patológico. Se considera que con un equipo multidisciplinar, bien estructurado y organizado, y con el soporte tecnológico hospitalario adecuado, los cuidados se desarrollan mejor en el propio domicilio. Éste actúa como principio terapéutico, debido a que la persona enferma se encuentra en su medio natural, con la familia, y por ello psicológicamente en un mejor restablecimiento. Al mismo tiempo se evitan factores de riesgo intrínseco a todo ingreso hospitalario, como pueden ser, las infecciones nosocomiales. 
En el País Vasco existes cinco servicios de Hospitalización a domicilio: Txagorritxu-Santiago, Basurto, Cruces, Galdakano y Donostia, de lo que se deduce que de este servicio se beneficia, principalmente, la población urbana.

Con el fin de mejorar el servicio que se presta a los pacientes en la fase final de la vida, se han propuesto cumplir con determinados “ Objetivos generales”, entre los que podemos destacar:

1. Mejorar la calidad de la atención a las personas en el final de la vida mediante la provisión de servicios sanitarios que aseguren la continuidad de los cuidados, la coordinación entre los distintos niveles asistenciales y la colaboración con los servicios sociales.

Se han señalado, también, algunos objetivos específicos, entre los que se destacan: a- Diseñar un Plan de Asistencia en cada Territorio Histórico. b- Regular la oferte de atención al paciente en la fase final de su vida. c- Integrar la atención a los pacientes en la fase final de la vida dentro del catálogo de servicios para la atención socio-sanitaria.

2. Adecuar los dispositivos asistenciales a las personas que requieren atención en la fase final de la vida, garantizándoles el inicio de los cuidados paliativos en el tiempo adecuado, la asistencia domiciliaria, la asistencia institucional y el soporte emocional.

Para ello, se han concretado los siguientes "Objetivos específicos": a.- Establecer mecanismos para la introducción de los cuidados paliativos de forma temprana en el curso de la enfermedad terminal. b- Lograr que el mayor número de personas en la fase terminal de la vida sean atendidas en su entorno familiar. cOfertar un grado de especialización adecuado a cada nivel de asistencia institucionalizada. d- Garantizar un soporte emocional adecuado a la situación de los pacientes y extenderlo a sus familiares.

3. Incorporar al Sistema sanitario público elementos facilitadores de la labor asistencial a través de la formación, investigación y evaluación.

Para ello, se han propuesto los siguientes objetivos específicos: a- Mejorar la formación del personal asistencial de las organizaciones de Osakidetza (Servicio de salud vasco) en relación a los cuidados paliativos. b- Fomentar líneas de investigación para la mejora de la calidad de la atención a través de los cuidados paliativos. c- Evaluar las actuaciones sanitarias sobre los pacientes en la fase final de la vida. d- Conocer el grado de satisfacción de los pacientes y sus familiares.

4. Promover la participación ciudadana, facilitando que todas las personas puedan expresar sus voluntades anticipadas para llegar a una muerte digna, y favoreciendo la labor de las asociaciones de voluntariado. 
Con el fin de lograr éste objetivo, se han propuesto algunos objetivos específicos, entre los que destacamos: a- Extender entre la ciudadanía el conocimiento de su derecho a expresar sus voluntades anticipadas. b- Integrar al voluntariado dentro del sistema de atención a los pacientes terminales.

La normativa estatal señala que es necesario, "Fomentar la aplicación de los Principios bioéticos y la participación de los pacientes en su proceso de acuerdo con los principios, valores y contenidos de la "Ley de Autonomía del paciente" y de la legislación vigente en las distintas Comunidades Autónomas ${ }^{164 "}$. La inclusión de medidas generales sobre atención al final de la vida en los servicios sanitarios y el acceso a equipos de cuidados paliativos para enfermos y familias en situación de complejidad es un derecho de pacientes y familias.

Señala que, dentro de los "Objetivos especificos" se pueden destacar los siguientes:

1. Informar a los pacientes sobre su estado y sobre los objetivos terapéuticos, de acuerdo con sus necesidades y preferencias. Recomendaciones:

a) En la historia clínica de los pacientes deberá existir un apartado específico donde se hará constar el proceso de información a pacientes así como sus deseos expresados en relación con el cuidado, lugar de preferencia de muerte y aquellos otros relacionados con los objetivos específicos perseguidos.

b) La información será respetuosa con los sistemas de creencias, preferencias y valores de los pacientes y familias.

c) El proceso de información se realizará de forma progresiva, en un lugar adecuado, cuidando los aspectos psicológicos, emocionales y existenciales.

d) El proceso será asesorado o supervisado por un profesional con experiencia.

e) La información será progresiva, adaptada al proceso de afrontamiento de la situación.

f) Se respetará el derecho expresado por algunos pacientes a no ser informados.

g) Se registrará tanto la información inicial, como los cambios evolutivos

h) En el caso de los población infantil y adolescentes, la información se adaptará a su edad y teniendo en cuenta sus deseos y necesidades.

2. Fomentar la participación activa de los pacientes, o personas en quienes deleguen, en la toma de decisiones sobre su proceso y el lugar de su muerte, de lo que quedará constancia en la historia clínica. Señala además que:

a) Cada paciente podrá designar un representante, que actuará como interlocutor con el equipo médico, en el supuesto de que no desee participar de forma activa en la toma de decisiones. Si no puede manifestar su voluntad, la participación en la toma de decisiones se llevará a cabo a través de la

\footnotetext{
${ }^{164}$ En adelante: CCAA.
} 
familia, salvo que el paciente hubiera designado un representante interlocutor en las instrucciones previas o voluntades anticipadas, en cuyo caso la participación se llevará a cabo con éste último.

b) Los profesionales del equipo multidisciplinar que intervienen en el proceso de atención están implicados en la participación de los pacientes en la toma de decisiones y deberán aportar información de forma clara y suficiente, permitiéndole expresar dudas y temores, resolviendo sus preguntas y facilitándole el tiempo necesario para que reflexione.

3. Facilitar la toma de decisiones ante dilemas éticos al final de la vida (limitación del esfuerzo terapéutico, alimentación e hidratación, sedación, etc.) teniendo en cuenta los valores de cada paciente, los protocolos y/o las recomendaciones éticas y guías de práctica clínica de acuerdo a estándares de calidad éticos al final de la vida”.

El proceso de decisión se registrará en la historia clínica, señalándose que es recomendable que:

a) Se promoverán protocolos de ética clínica adaptados a situaciones de enfermedad avanzada y terminal.

b) Se dispondrá de recomendaciones sobre el proceso de toma de decisiones, su registro en la historia y aspectos técnicos de la sedación.

c) Las CCAA impulsarán la creación de Comités de Ética Asistencial tanto a nivel de atención primaria como de especializada.

4. Difundir en las CCAA la normativa sobre voluntades anticipadas que regula el Registro de las mismas y el acceso de los profesionales a dicha información. Por ello, considera recomendable que:

a) El Ministerio de Sanidad, Política Social e Igualdad (MSPI) y las CCAA realizarán campañas de información a la población y a los profesionales, sobre la posibilidad de redactar instrucciones previas o voluntades anticipadas conforme a las distintas legislaciones autonómicas vigentes.

b) Las CCAA informarán a los profesionales sobre la forma y los requisitos de acceso al registro de instrucciones previas.

c- Los profesionales asesorarán a cada paciente y a su familia sobre la normativa y la posibilidad de realizar una declaración de instrucciones previas o voluntades anticipadas, dejando constancia en la historia clínica de este asesoramiento.

5. Realizar acciones de sensibilización e información a la población general sobre los objetivos, los principios y los recursos de los cuidados paliativos. Para lograr éste objetivo, señala que:

a) Las CCAA y el MSPSI realizarán campañas de información y folletos explicativos sobre los principios básicos, objetivos y contenidos de la Estrategia de Cuidados Paliativos. 
b) Se promocionará la formación de los profesionales en aspectos éticos y de información y comunicación con enfermos y familias.

c) Favorecer el debate y la participación ciudadana en los cuidados paliativos en los órganos que, para ello se designen.

Finalmente se hace referencia a la delimitación de algunos términos que se utilizan de forma habitual y en ocasiones impropia en el ámbito de los cuidados paliativos. Se señala que entiende por:

1. Complejidad: conjunto de factores de mayor dificultad o intensidad de necesidades que requieren habitualmente la intervención de un equipo de cuidados paliativos. Depende tanto de las características de cada paciente, como de problemas de difícil control, de la necesidad de determinadas acciones diagnósticas o terapéuticas y de dificultades de adaptación familiar.

2. Crisis de necesidad: situación aguda caracterizada por la aparición de una o varias necesidades concretas, físicas, psicológicas, sociales o espirituales que disminuyen el confort y la calidad de vida del enfermo, y que altera la adaptación y estabilidad emocional de la familia y requiere de una intervención específica para su resolución.

3. Cuidados paliativos: enfoque que mejora la calidad de vida de pacientes y familias que se enfrentan a los problemas asociados con enfermedades amenazantes para la vida, a través de la prevención y alivio del sufrimiento por medio de la identificación temprana e impecable evaluación y tratamiento del dolor y otros problemas, físicos, psicológicos y espirituales.

4. Equipo de cuidados paliativos: su actividad central se limita a los cuidados paliativos. Se dedican por lo común a la atención de pacientes con necesidades asistenciales más complejas e intensivas y por tanto requieren un mayor nivel de formación, de personal y de medios. Están compuestos por profesionales de medicina y enfermería, con la cooperación necesaria de profesionales de la psicología y trabajo social y la colaboración de otros profesionales. La composición de los equipos estará en función de las características demográficas y geográficas y de los niveles de necesidad de las estructuras territoriales sanitarias de referencia. Realizan también funciones docentes e investigadoras en distintos grados.

5. Equipo de soporte domiciliario: equipo de cuidados paliativos que interviene en el domicilio del paciente tras interconsulta de los profesionales responsables. Puede realizar tareas de asesoramiento o intervención directa.

6. Equipo de soporte hospitalario: equipo de cuidados paliativos que interviene en el hospital, tras interconsulta de los profesionales responsables. Puede realizar tareas de asesoramiento o intervención directa. 
7. Niveles de cuidados paliativos: El nivel de cuidados paliativos básicos, primarios, generales o enfoque paliativo hace referencia a los cuidados que deben proporcionarse a todos los pacientes que lo precisen, tanto en atención primaria, como especializada. El nivel de cuidados paliativos específicos, secundarios, especializados o avanzados contempla diversos tipos de intervenciones de los equipos de cuidados paliativos ante situaciones de complejidad. Algunos autores denominan tercer nivel a la atención hospitalaria en Unidades de Cuidados Paliativos.

8. Genograma: Es una representación gráfica de las relaciones personales, biológicas y legales de, al menos, tres generaciones de una familia. Su principal utilidad es analizar si los problemas de uno de sus miembros puede o no estar relacionado con el contexto familiar y sus cambios y evoluciones temporales.

9. Situación de enfermedad avanzada-terminal: los criterios propuestos para la definición de los pacientes con enfermedad en fase avanzada / terminal han sido:

a) Enfermedad incurable, avanzada y progresiva.

b) Pronóstico de vida limitado.

c) Escasa posibilidad de respuesta a tratamientos específicos.

d) Evolución de carácter oscilante y frecuentes crisis de necesidades.

e) Intenso impacto emocional y familiar.

f) Repercusiones sobre la estructura cuidadora.

g) Alta demanda y uso de recursos.

10. Unidad de cuidados paliativos: se trata de unidades de hospitalización específicas de cuidados paliativos, atendidas por un equipo interdisciplinar. Pueden ubicarse en hospitales de agudos o de tipo socio sanitario. Con frecuencia las unidades realizan también labores de equipo de soporte hospitalario y consulta externa.

\section{CONCLUSIONES}

I. Durante los últimos años se han producido numerosos debates públicos en nuestro país y en otros muchos, sobre la forma en la que se debe tratar a los enfermos terminales o personas con procesos degenerativos irreversibles que pedían morir para evitar el sufrimiento o para no tener que vivir la fase final de la enfermedad. Estos debates han puesto de manifiesto las distintas posiciones que existen entre la voluntad de los enfermos terminales e irreversibles y las disposiciones legales.

En las sociedades que han despenalizado la práctica de la eutanasia y el Suicidio Médicamente Asistido (SMA) existen importantes diferencias en cuanto a las condiciones que debe reunir el paciente para 
que la eutanasia y el SMA no sean legalmente punibles. La disposición de la propia vida en determinados supuestos sigue siendo objeto de debates en las sociedades europeas. Todo ello es consecuencia de que las discusiones se centran en cuestiones o conceptos nucleares en la forma en la que debe atenderse al paciente en la fase final de su vida, como son, la dignidad humana, el papel de la medicina, la autodeterminación del paciente con enfermedad grave e incurable.

En las sociedades en las que el pluralismo es un valor importante, cada vez es más frecuente la opinión y la actitud de las personas para las que la disposición de la propia vida es entendida como un ejercicio de la libertad y de la dignidad personal, ejercicio de un derecho en el que los poderes públicos, es decir, el legislador, no debería inmiscuirse salvo, para proteger la libertad y la dignidad. Es por ello que, parte de la sociedad entiende que es abusiva la intervención de los poderes públicos que, en un trasnochado ejercicio de paternalismo, pretenden impedir que los ciudadanos que lo deseen, y que reúnan determinados de salud y de capacidad para el ejercicio de su autonomía personal, pongan fin a una vida que no desean y para lo cual solicitan la ayuda de otros.

Quienes mantienen posiciones contrarias a la despenalización de la eutanasia y el SMA señalan que la permisividad acarrearía inevitablemente consecuencias devastadoras para las personas enfermas en general y para la atención sanitaria en particular. Consideran que se produciría un incremento importante de actuaciones calificadas como eutanasias no voluntarias o involuntarias, en las que en ocasiones existiría también la complicidad de los poderes públicos, puesto que, tanto la eutanasia como el SMA se constituirín en alternativas más económicas que los cuidados paliativos.

Destacar que, los países que han reconocido la posibilidad de practicarse la eutanasia o el SMA han señalado límites y requisitos en su legislación, aunque es evidente que, ninguna norma jurídica puede evitar que se produzcan abusos en su aplicación

En por ello que, viendo que en nuestro país no está regulada la eutanasia ni el SMA, hemos procedido a revisar la situación legal de la eutanasia y del suicidio asistido en algunos países de nuestro entorno europeo.

En Holanda se aprobó la Ley de finalización de la vida y del auxilio al suicidio, que entró en vigor el 1 de abril de 2002. La ley considera eutanasia toda intervención directa y eficaz del médico para causar la muerte del paciente que sufre una enfermedad irreversible o que se encuentra en fase terminal y con padecimiento insoportable, a petición expresa de este.

Se establece en su articulado una serie de requisitos de diligencia que si se cumplen, no hacen punible la práctica de la eutanasia. Entre estos requisitos destaca los siguientes:

1. Que la persona objeto de la eutanasia o auxilio al suicidio sea residente en Holanda. 
2. Que el médico esté convencido de que la petición es voluntaria, está bien meditada y expresa los deseos del enfermo, o sea, que es plenamente capaz y se ha reiterado en su voluntad. Esta puede haber sido manifestada en un documento de voluntades anticipadas.

3. Que se constate un padecimiento insoportable y sin esperanzas de mejora.

4. Que se haya informado al paciente de su situación y de las perspectivas de futuro.

5. Que se haya consultado a otro facultativo y que este haya corroborado el cumplimiento de los requisitos. En caso de sufrimiento psicológico se tienen que consultar a dos médicos. Los médicos consultores tienen que ver al enfermo y elaborar un informe por escrito sobre la situación concreta en la que se encuentra el paciente.

6. Que la realización de la eutanasia o auxilio al suicidio se haga con el máximo cuidado y profesionalidad.

En Holanda sigue estando tipificado como delito la eutanasia y el auxilio al suicidio a excepción de los casos en que se cumplan los requisitos que se han establecido legalmente para poder practicarlos. Por tanto, cuando el médico practique la eutanasia o el auxilio al suicidio cumpliendo con todos los requisitos establecidos, no será perseguido por los Tribunales. Cualquier otra conducta que tenga por resultado la muerte del paciente como consecuencia de la actuación médica a petición de este, pero sin cumplir el resto de los requisitos establecidos en la legislación, será castigada penalmente.

En Bélgica se aprobó el 28 de mayo de 2002 una Ley relativa a la eutanasia que entró en vigor el 20 de septiembre del mismo año. En este caso, a diferencia de la legislación holandesa, se despenaliza la eutanasia pero no se menciona el suicidio asistido. La razón de este hecho es que, a diferencia de Holanda u otros muchos países europeos en los que los Códigos penales castigan el auxilio al suicidio a todos los efectos, el Código Penal belga no lo castiga y por este motivo no se incluyó en la Ley. Entendieron que, una conducta no típica, ni punible no es preciso que sea recogida en una despenalización. Lo que podría querer decir que la actuación de una persona que presta auxilio al suicidio en un contexto eutanásico (padecimiento insoportable, enfermedad irreversible o terminal a petición del propio paciente) no podría ser castigada por los Tribunales.

Los requisitos que la Ley belga establece para poder practicarse la eutanasia legalmente son:

1. Que el paciente sea mayor de edad o menor emancipado, capaz y consciente de su petición.

2. Que la petición sea voluntaria, reiterada sin pretensiones exteriores, pudiendo haberla manifestado en un documento de voluntades anticipadas y que tenga una vigencia inferior a cinco años. La posibilidad de solicitar la eutanasia mediante un documento de voluntades anticipadas está regulado a través del Decreto de 2 de abril de 2003. 
3. Que haya padecimiento físico o psíquico constante e insuperable ocasionado por una condición patológica grave e incurable.

Se destacan como requisitos que debe cumplir necesariamente el médico que atiende al paciente:

1. Informar al paciente sobre la existencia de cuidados paliativos.

2. Reiterar el diálogo en los plazos de tiempo razonables.

3. Consultar a otro médico independiente que tiene que visitar el paciente y redactar un informe que esté de acuerdo o en desacuerdo con las primeras valoraciones.

4. Recopilar información del equipo cuidador si es que existe.

5. Procurar que el enfermo consulte con otras personas de su entorno.

6. Dejar pasar un mes entre la petición y la realización de la eutanasia.

Después de practicada la eutanasia, el médico tiene que cumplir con las prescripciones que establece la Ley.

En Bélgica, paralelamente a la aprobación de la Ley relativa a la eutanasia, de mayo de 2002, se introdujo toda una regulación relativa a los cuidados paliativos que establece que todos los belgas deben tener acceso a este tipo de asistencia en condiciones adecuadas.

Se establece en la Ley que se entenderá por eutanasia: El acto practicado por parte de una tercera persona, que pone intencionadamente fin a la vida de una persona a solicitud de ésta última”.

Se autoriza la eutanasia cuando concurren los tres siguientes requisitos:

1. Que exista plena y libre voluntad del paciente de que se practique.

2. Que tenemos que estar en presencia de un enfermo terminal e incurable, que padece sufrimientos insoportables e incurables. La enfermedad debe ser terminal o debe estar en situación irreversible. También cuando estamos en presencia de un enfermo que tiene grave sufrimiento psicológico, con pérdida de autonomía, escasa calidad de vida, sentimiento de ser una carga para sus allegados, etc.

3. Que el enfermo padece dolores insoportables.

A pesar de que se cumplen todos los requisitos señalados anteriormente, es necesario que se cumplan las condiciones establecidas en la Ley, para lo que será necesario que: el médico, antes de aplicar la eutanasia, tenga en consideración determinadas cuestiones y cumplir con los siguientes requisitos:

1. Debe informar al paciente de su estado de salud y de su esperanza de vida, plantear las posibilidades terapéuticas que pueden existir, así como ofrecer los cuidados paliativos que tiene a su disposición.

2. Tras cumplir con los requisitos señalados anteriormente, médico y paciente tienen que llegar a la convicción de que la eutanasia es la única solución razonable en su situación médica y que la petición de eutanasia del paciente es completamente voluntaria. 
3. La petición deberá realizarse por escrito, y puede haber sido redactada y autentificada antes, en previsión de condiciones futuras de incompatibilidad. Si el paciente se encuentra en una fase en la que no puede realizarlo por sí mismo, la solicitud se realizará por parte de una persona mayor de edad a su elección que no tendrá interés en la muerte del paciente. En la solicitud, ésta última persona deberá hacer constar que el paciente no puede formular personalmente la solicitud de eutanasia y deberá indicar las razones de su imposibilidad. En éste caso, la solicitud deberá realizarse por escrito y será presentada al médico, señalando el nombre del médico concreto. Este documento se conservará en el informe médico del paciente. El paciente puede revocar su solicitud en cualquier momento, en este caso, la solicitud será retirada del dossier del paciente y se le entregará personalmente a él.

4. La Ley prevé además que se consulte con otro médico, independiente y con competencia en la enfermedad del paciente, así como a todo el equipo sanitario que atiende al enfermo, si existe el citado equipo.

Además, si el médico pronostica que la muerte no ocurrirá en un periodo de tiempo breve, ha de consultar a un segundo médico, psiquiatra o especialista de la patología en cuestión, y deberá transcurrir al menos un mes de reflexión entre el momento de la petición de la eutanasia y su ejecución efectiva.

Seguidamente la Ley recoge la Declaración anticipada de voluntad que puede realizar toda persona mayor de edad o menor emancipada y capacitada para ello, por escrito, señalando su voluntad de que el médico le practique la eutanasia en determinados supuestos:

1. Que tenga un accidente o patología grave e incurable.

2. Que no esté consciente.

Esta declaración puede designar a una o varias personas de confianza, mayores de edad y señaladas por orden de preferencia, con los que el médico debe consultar para determinar la voluntad del paciente.

En Suiza la eutanasia está penalizada pero no el auxilio al suicidio, aunque a diferencia de Holanda no se tiene que contar necesariamente con la asistencia del médico. Esta sólo se exigirá en el caso de que sea necesaria para asegurar el control correcto de la prescripción, y no porque se considere que la ayuda al suicido sea una función de la medicina.

La Ley Suiza sobre "Directivas de aplicación de la Ley de la salud pública y de asistencia al suicidio en centro sanitarios de interés público", que entró en vigor en enero de 2013, Ley del Cantón de Vaud tuvo su origen en el art. 27-d) de la Ley de la salud pública.

El art. 27.d) de la Ley de la Salud pública, base legal de la Ley de Asistencia al Suicidio, según se señala en el apartado $1^{\circ}$, dispone, en relación con la asistencia al suicido en establecimientos sanitarios reconocidos como de interés público que: 
1. Los establecimientos sanitarios reconocidos de interés público no pueden rechazar la asistencia al suicidio cuando sea solicitado por un paciente o un residente, siempre que se cumplan las siguientes condiciones:

a) El médico responsable del tratamiento o del establecimiento médico, en concurrencia con el equipo que aplica los cuidados, el médico que atiende y los familiares o personas próximas al paciente o residente, verifiquen que:

i. $\quad$ es capaz de discernir su decisión de suicidarse y que persiste con su intenciónvoluntad de suicidarse.

ii. padece una enfermedad o secuelas graves e incurables.

b) Las alternativas, en particular las que hacen referencia a los cuidados paliativos, han sido evaluados con el paciente o con el residente.

2. Tras verificar las condiciones establecidas en el apartado a), párrafo $1^{\circ}$, el médico responsable puede solicitar la opinión de otro médico autorizado a ejercer la medicina en el Cantón de Vaud o de una Comisión de evaluación interna del centro sanitario o establecimiento médico-social.

3. El médico responsable solicitará por escrito la asistencia al suicidio en un plazo de tiempo razonable.

4. Si el paciente dispone de una vivienda exterior y el establecimiento sanitario no dispone de una sección específica para este fin, el médico puede rechazar la asistencia al suicidio en el citado establecimiento, a pesar de que el regreso del paciente a su vivienda habitual sea razonablemente exigible.

5. El personal del establecimiento sanitario y el médico responsable que están implicados en la aplicación de la asistencia al suicidio, no pueden intervenir, a título profesional, en el proceso de asistencia al suicido.

6. Cuando la asistencia al suicidio se va a aplicar en el establecimiento sanitario, el médico responsable debe asegurarse que los medios empleados están en consonancia con las prescripciones médicas.

7. El Departamento concreta las condiciones en las que debe aplicarse este artículo, tras consultar con las personas implicadas en la misma.

Vigente el art. 27.d) de la Ley de la Salud Pública, el auxilio al suicidio se aplicaba en Suiza en las condiciones señaladas anteriormente. Destacar que, antes de entrar en vigor la Ley de asistencia al suicidio y como consecuencia de la aplicación del suicidio asistido que permitía la Ley de la Salud Pública a través de su art. 27.d), se emitieron dos Recomendaciones de la Comisión Nacional de ética para la medicina los años 2005 y 2006. La citada Comisión recomendó al legislador que los poderes públicos supervisaran las organizaciones de ayuda al suicidio que actuaban en Suiza al amparo del art. 115 del Código penal. Así también, la Recomendación 13/2006 consideró que la práctica del suicidio asistido debía regirse por un acuerdo de mínimos que garantizase, la protección de quienes se plantean inicialmente poner fin a la vida con la asistencia de estas organizaciones.

Esta Comisión considera que, desde la perspectiva ética, la asistencia al suicidio se fundamenta en dos ejes: a- el apoyo y la atención a las personas que se plantean el suicidio, y, b- el respeto a su derecho a la autodeterminación.

Un requisito ineludible del auxilio al suicidio en Suiza es que detrás de la actuación de quien ayuda a morir no exista ninguna motivación egoísta ni de tipo personal o económico. Si esto se llegase a acreditar, el responsable sería perseguido penalmente, de acuerdo con el artículo 115 del Código Penal. 
Suiza cuenta con tres organizaciones voluntarias que dan apoyo a las personas que solicitan la ayuda al suicidio: EXIT, que actúa en los Cantones de habla germánica e italiana; AMD, en los cantones franceses; y DIGNITAS, para las personas extranjeras que vayan a Suiza para recibir ayuda al suicidio.

En Luxemburgo se aprobaron el año 2009 dos Leyes: la a) la "Ley de 16 de marzo de 2009 sobre la eutanasia y la asistencia al suicidio", y, b) La "Ley de 16 de marzo de 2009 relativa a los cuidados paliativos, a la directiva-testamento anticipada y al acompañamiento al final de la vida”.

La Ley sobre la eutanasia y la asistencia al suicidio señala las condiciones y el procedimiento que debe seguirse para solicitar la eutanasia.

Señala el art. $2^{\circ}$ en sus distintos apartados que: No se sancionará penalmente y no puede dar lugar a una acción civil de daños y perjuicios contra un médico, cuando éste actúe en respuesta a una solicitud de eutanasia o de asistencia al suicidio, siempre que se cumplan las siguientes condiciones:

1. Informar al paciente de su estado de salud y su esperanza de vida, informar al paciente de las alternativas terapéuticas que tiene todavía, teniendo en consideración su estado de salud, así como, los cuidados paliativos que procedan y sus consecuencias.

El médico debe llegar a la convicción de que la solicitud del paciente es voluntaria, y que, desde el punto de vista del paciente no existe ninguna otra solución en su situación concreta.

La información se recogerá en el expediente médico del paciente en el que se indicará que se ha informado debidamente.

2. Debe asegurarse de la persistencia del sufrimiento físico o psicológico del paciente, y de la voluntad mostrada por éste de la persistencia de su solicitud. Para ello, mantendrá distintas conversaciones con el paciente en un tiempo prudente, teniendo en consideración la situación sanitaria concreta del paciente.

3. Deberá consultar con otro médico cuando, como consecuencia del estado grave e incurable en el que se encuentra el paciente así se requiera. El médico al que se consulta deberá informarse del estado del paciente, para ello, deberá ver el expediente médico del mismo, examinar al paciente, y asegurarse del carácter constante, insoportable y sin perspectivas de mejora del sufrimiento físico o psíquico.

Tras cumplir con todo ello, emitirá un informe en el que se contendrán todas las circunstancias descritas anteriormente y que se cumplen en el presente caso.

El médico consultado debe ser imparcial, tanto en relación con el paciente como con el médico que le trata, y ser experto en la enfermedad que tiene el paciente.

El médico que atiende al paciente informará a éste de las conclusiones a las que ha llegado el médico consultado. 
4. A no ser que el paciente se oponga, se mantendrá informado al equipo que le atiende, a los familiares de la solicitud del paciente.

5. Se mantendrá informado de la solicitud presentada por el paciente a las personas de su confianza (del paciente) que haya designado éste en su declaración de solicitud de eutanasia o de auxilio al suicidio, a no ser que el paciente se oponga.

6. Debe asegurarse que el paciente ha manifestado su solicitud a las personas que él quiere.

7. Informar a la Comisión Nacional de Control y Evaluación el nombre de la persona que ha muerto y su registro.

Se dispone en la Ley las condiciones en las que se va a desarrollar el procedimiento de la eutanasia o la asistencia al suicidio.

Comienza señalando que: "Toda persona mayor de edad y capacitada para ello, puede, en los casos en los que no pueda manifestar su voluntad, designar por escrito su solicitud de poner fin a su vida, las condiciones y circunstancias en las que desearía someterse a la eutanasia, siempre que el médico certifique la concurrencia de las siguientes circunstancias:

1. Que sufre una enfermedad o patología grave e incurable;

2. Que está inconsciente;

3. Que la situación en la que se encuentra es irreversible, teniendo en consideración el estado de la ciencia médica en ese momento.

Los médicos deberán, en todos los caso y antes de proceder a aplicar la eutanasia, respetar las condiciones formales y de procedimiento que señalaremos seguidamente:

1. Consultar a otro médico cuando la situación irreversible del paciente así lo requiera. El médico a quien se consulta deberá revisar el expediente médico y examinar al paciente. Redactará un informe de sus impresiones. Si hay designada una persona de confianza en las disposiciones-voluntades finales del paciente, el médico que atiende al paciente deberá informarle de la situación en la que se encuentra y del resultado de la consulta realizada a otro médico. El médico a quien se consulta debe ser imparcial en relación, tanto con el paciente como con el médico que atiende al enfermo, debiendo ser también, especialista en la patología que padece el paciente.

2. Si existe un equipo de cuidados que atiende al enfermo deberá continuar manteniendo el tratamiento con los equipos que traten al enfermo en la fase final de su vida.

3. Si las voluntades-disposiciones anticipadas de una persona señalan a una persona de confianza, se deberá mantener con la misma una relación fluida para que pueda expresar lo que hubiese sido la voluntad del paciente en esos momentos. 
4. Si las voluntades-disposiciones anticipadas señalaron a una persona de confianza, ésta participará a la hora de determinar la voluntad del paciente, junto con los familiares y allegados del paciente.

En el Boletín Oficial del Gran Ducado de Luxemburgo se publicó la Ley de 16 de marzo de 2009 Relativa a los cuidados paliativos, a las directivas-voluntades anticipadas y al acompañamiento al final de la vida.

Se señala en la Ley que toda persona que se encuentra en la fase terminal o avanzada de su enfermedad tiene derecho a los cuidados paliativos. Seguidamente se delimita el concepto de cuidados paliativos en los siguientes términos: "Los cuidados paliativos son cuidados activos, continuos y coordinados, practicados por un equipo multidisciplinar respetando en todo momento la dignidad de la persona. Deben cubrir todas las necesidades físicas, psíquicas y espirituales de la persona y su entorno, comprendiendo el tratamiento del dolor y el sufrimiento psíquico".

Estos cuidados pueden prestarse en los centros sanitarios, en los establecimientos que establecen las compañías aseguradoras de enfermedad o en el propio domicilio del paciente, siendo al Estado a quien corresponde formar adecuadamente al personal médico y al equipo que atiende al paciente.

En Francia la eutanasia continúa penalizada, si bien se distingue entre eutanasia activa y pasiva.

Se han sometido a debate en la Asamblea Nacional distintas Proposiciones de Ley. La Ley no 1140, en relación con "Los derechos a asegurar a los pacientes el derecho a morir con dignidad", de 2009, y la Ley no 1498 que "Instituye el Derecho a morir en dignidad y a garantizar a los médicos el ejercicio del derecho a su libertad de conciencia", de 2013.

Como consecuencia de lo cual, se proponía en la primera de las Leyes de 2009 que, modificación del Código penal, que deberá ser redactado, en su art. L. 110-2, en los siguientes términos: "El enfermo tiene derecho a que se respeta su libertad y su dignidad. Puede beneficiarse en las condiciones previstas en el presente Código, de una ayuda activa a morir".

Se establecía, también, que el Código de la salud pública se completará, en su artículo L.1110-9, con la siguiente redacción: "Toda persona, en fase avanzada o terminal de su enfermedad, que se considera grave e incurable, o pasa a estar en un estado de dependencia que se considera incompatible con su dignidad, puede solicitar, en las condiciones previstas en la Ley, la asistencia médica para que se provoque su muerte. Después de que la persona rechace un tratamiento médico, el médico debe informarle, reservando su derecho a poder invocar el ejercicio de su derecho a la cláusula de conciencia”.

Se crea un nuevo apartado en el art. 1111-10-1 del Código de la Salud pública con la siguiente redacción: 
"Después de que una persona, en fase avanzada o terminal de una enfermedad grave incurable, o su estado de salud ha pasado a estar en un grado de dependencia que se considera incompatible con su dignidad, puede solicitar a su médico la ayuda activa parar morir. El médico deberá consultar con otro colega, con el fin de asegurarse la situación real en la que se encuentra el paciente.

El médico responsable del paciente tiene la facultad de llamar a otro miembro del cuerpo médico. Ambos verificaran el carácter libre, consciente y reflexivo de la solicitud presentado, y se le ofrecerá al paciente en una entrevista la información relativa a los cuidados paliativos y al acompañamiento al final de la que le corresponden.

Los médicos deberán tener las conclusiones sobre el estado de salud del paciente en un tiempo máximo de 8 días. Una vez que los médicos han decidido que el paciente se encuentra en una situación terminal, y que la solicitud que ha presentado es clara, reflexiva y consciente, y el paciente persiste en su solicitud, que deberá realizarla por escrito, y si no lo puede, estará presente la persona designada por el paciente de su confianza, el médico que le atiende respetará la manifestación del paciente.

La ayuda activa a morir no podrá practicarse antes de que transcurran 15 días de la confirmación de la solicitud del paciente, pudiendo el paciente revocar en cualquier momento su petición. Este plazo puede reducirse en los casos, siempre que así lo solicite el paciente, en los que el médico entienda que con ello se protege la dignidad del paciente".

Por su parte, la "Proposición de Ley relativa a los pacientes en la fase final de su vida y el derecho a morir en dignidad" de 2013 disponía que: La Proposición de Ley trata de asegurar a los pacientes el derecho a morir dignamente en la fase final de su vida. Este derecho se concreta con la puesta en práctica de la eutanasia, el suicidio médico asistido y por la intensificación de los cuidados paliativos. La Ley debe asegurar la solución más conveniente entre las que acabamos de señalar, a cada paciente que se encuentre en la fase final de su vida.

II. El Consejo de Europa promulgó distintas Recomendaciones a partir del año 1999. La primera de ellas, la Recomendación 1418 sobre la dignidad de la persona con enfermedad incurable, que fue revisada posteriormente, y la segunda, la Recomendación Rec (2003) 24, del Comité de Ministros del Consejo de Europa sobre la organización de los cuidados paliativos.

En la Recomendación 1418 se señala que tiene como fin principal proteger la dignidad del ser humano y sus derechos en aquellas personas que sufren enfermedades incurables. Se afirma en la Recomendación 1418 que:

1. En ningún momento y bajo ninguna circunstancia puede justificarse la eutanasia 
2. El progreso de la tecnología en el ámbito de la medicina, supone plantearse los límites de la muerte y que, las condiciones de vida de un paciente terminal y la voluntad que ha manifestado pueden quedar relegados a un segundo plano, llegando a aplicarse lo que se denomina "obstinación terapéutica".

3. Con el fin de limitar la obstinación terapéutica y la prolongación de la vida del paciente no puede tener como único y último límite la práctica médica, que debe tener como fin principal reducir el sufrimiento del paciente y no prolongar de forma innecesaria su vida.

4. Prolongar artificialmente la vida del paciente se considera una amenaza a la dignidad del enfermo incurable.

5. Existe un acceso insuficiente a los cuidados paliativos y a los tratamientos que reducen el dolor en los Estados Miembros del Consejo de Europa.

6. El Comité de Ministros define los "cuidados paliativos".

7. La Recomendación trata en todo momento de evitar recurrir al término "eutanasia", otorgando importancia a los cuidados paliativos y al acompañamiento de la persona en la fase final de su vida.

8. Autorizar el acto eugenésico puede constituir un acto moralmente permitido, pero nunca puede ser aceptado jurídicamente.

9. El "encarnizamiento terapéutico", entendido como, una obstinación no razonable, es rechazada como consecuencia de que el paciente está abocado a la muerte, por padecer una enfermedad incurable, la aplicación de cualquier técnica médica que suponga esta obstinación es rechazada.

10. Hay distintos factores que suponen una amenaza a los derechos fundamentales que tiene todo paciente terminal y que toda persona que va a morir necesita que se le preserve su dignidad. Entre los factores que hemos señalado destacan: el acceso insuficiente a los cuidados paliativos y al tratamiento contra el dolor; la ausencia de tratamientos que reducen los padecimientos psicológicos; la prolongación artificial del proceso de la muerte y la ausencia de formación permanente de los profesionales de la salud

11. Los Estados Parte del Consejo de Europa deben asegurar a los pacientes terminales la protección jurídica y social necesaria contra los peligros con los que se pueden encontrar en el ámbito de sus derechos, animando a los Estados a respetar y proteger los derechos de los pacientes terminales. Por su parte, la Recomendación Rec (2003), sobre la organización de los cuidados paliativos dispone que:

1. Se reconoce la necesidad de desarrollar los cuidados paliativos en los distintos Estados Miembro.

2. El objetivo de los cuidados paliativos es asegurar la mejor calidad de vida posible a los pacientes terminales y sus familiares. 
3. Los cuidados paliativos se constituyen en parte integrante del sistema de salud de todos los Estados.

4. Recomienda a los Gobiernos de los Estados a adoptar políticas y medidas legislativas para establecer un sistema coherente y completo a nivel nacional en el ámbito de los cuidados paliativos y promover el trabajo en grupo en el campo de los cuidados paliativos a nivel nacional e internacional.

5. La finalidad de los cuidados paliativos son: el control de síntomas; el apoyo psicológico, espiritual y emocional; el apoyo a la familia, y el apoyo al duelo.

III. Con el fin de cumplir con los compromisos asumidos por España y que derivan de la Recomendaciones remitidas a todos los Estados Miembro por parte del Consejo de Europa en relación con los cuidados paliativos, se ha desarrollado toda la normativa necesaria, tanto a nivel estatal como autonómico.

El Ministerio de Sanidad promulgó el año 1993 la primera Guía de Cuidados paliativos de la Sociedad Española de Cuidados Paliativos, destacando que los cuidados paliativos y curativos no son excluyentes, sino que son una cuestión de énfasis

Se señala que los enfermos terminales necesitan de una atención integral; que el enfermo terminal y su familia son una unidad a tratar; que debe promocionarse la autonomía y la dignidad del enfermo; que debe adoptarse una concepción terapéutica activa en relación con el paciente; que la calidad de vida del enfermo y su confort deben ser determinantes a la hora de aplicar cualquier tratamiento; que deben controlarse los síntomas; así como apoyar emocionalmente al enfermo y su familia y que los pacientes deberán ser tratados por equipos interdisciplinares

Dispone que se entiende por enfermedad terminal "aquella en la que concurren alguno de los siguientes criterios: presencia de enfermedad terminal, incurable y progresiva; ausencia de posibilidades razonadas de respuesta a tratamientos; insuficiencia de órganos; presencia de numerosos síntomas y pronóstico de vida limitado".

Se constituye en elemento fundamental de la atención al paciente terminal el respeto de su autonomía y dignidad

Los instrumentos básicos en los que se sustentan los cuidados paliativos son: el control de síntomas; el apoyo emocional y la comunicación con el enfermo y su familia y la intervención de un equipo multidisciplinar que se adapte a las necesidades cambiantes del paciente.

En el País Vasco se ha desarrollado un Plan de cuidados paliativos el año 1993, organizándose un modelo asistencial integral de asistencia a los enfermos terminales.

Los objetivos fundamentales del Plan han sido: mejorar la calidad de la atención a las personas en la fase final de su vida; adecuar los dispositivos asistenciales a las personas que requieren atención en la fase final 
de su vida; incorporar al Sistema sanitario público elementos facilitadores de la labor asistencial a través de la formación, investigación y evaluación; promover la participación ciudadana; difundir en la Comunidad Autónoma la normativa sobre voluntades anticipadas; realizar acciones de sensibilización e información a la población sobre los objetivos, principios y recursos que se disponen a nivel de cuidados paliativos.

\title{
EUROPEAN MODELS OF EUTHANASIA AND THE SUICIDE REPRESENTED IN HOLLAND, BELGIUM, SWITZERLAND, LUXEMBOURG AND FRANCE
}

\begin{abstract}
:
Some European countries, they have recognized the euthanasia and / or the suicide represented. We proceed to make concrete the Laws that have been promulgated in Holland, Belgium, Switzerland and Luxembourg, as well as the Propositions that have not prospered in France. We will emphasize, also, the position that the Council of Europe has supported in relation with the protection of the dignity of the patient in the terminal phase and the treatment in Spain. We understand that we are in presence of a right that corresponds to every patient in the final phase of his life.
\end{abstract}

Keywords: Euthanasia, Assisted Suicide, Terminal Patients, European Models, Council of Europe.

\section{BIBLIOGRAFÍA}

ARMANDO S. y ANDRUET H. "Ley holandesa de terminación de la vida a petición propia, nuestra consideración acerca de la eutanasia”, en Derecho y Salud, 2001.

CALLAHAN, D. "Death and the research imperative", en The New England Journal of Medicine, 2000.

CASSEL, E. J. (2004). The nature of suffering and the goals of medicine (2a ed.) Nueva York: Oxford University Press.

DICK MARTY, "Recommandation 1418- La position du Conseil del'Europe, en $L$ 'euthanasie, Volumen II. Perspectives, Nationales et européennes, 2004.

ESPINAR CID, v. "Los cuidados paliativos: acompañando a las personas en el final de la vida", en Cuadernos de Bioética, XXIII, 2012/1.

FERNÁNDEZ CREHUET, J. "Eutanasia, atención a pacientes terminales y profesionales de la salud. Intervención en la Comisión del Senado sobre Eutanasia”, en Cuadernos de Bioética, n 44, 2001.

GARCÍA D. “Ética de los confines de la vida”, en Ética y Vida. Estudios de biología, Bogotá, 1998, Tomo III.

GARCÍA-MANRIQUE R. MILLION DOLLA B. “La eutanasia como compromiso", en Revista de Bioética y Derecho, 2005-3. http: www.bioeticayderecho.ub.es/revista, (Consultado 15-08-2014). 
GARCÍA-MANRIQUE R. "Mar adentro: la eutanasia para todos los públicos”, en Revista de Bioética y Derecho, 2005-2. http: www.bioeticayderecho.ub.es/revista. (Consultado 15-08-2014).

GÓMEZ SANCHO, M. "Necesidades humanas, control de síntomas: Principios generales", en: GÓMEZ SANCHO, M (ed.): Cuidados Paliativos: Atención integral a enfermos terminales, Las Palmas de Gran Canarias; ICCEPS. 1998.

JOCHENSEM, H. "Eutanasia: la situación en Holanda y una evaluación crítica", en Cuadernos de bioética, vol. 7, n² 27, 1996.

JÚDEZ GUTIÉRREZ, F. J. "Suicidio asistido y eutanasia: un debate clásico y trágico, con pronóstico reservado”, en Anales del Sistema sanitario de Navarra, vol. 30, no extr. 3, 2007.

MAHO, en Mortàl'hôpital, 2008.

MARCOS DEL CANO, A. M. "La eutanasia en el ordenamiento jurídico holandés", en Cuadernos de bioética, volumen 7, n² 27, 1996.

NÚÑEZ OLARTE, JM. "Una elección básica: tratamiento paliativo o tratamiento curativo", en Ética en cuidados paliativos. COUREIRO, A. Editorial Triacastela. Madrid 2004.

PASCUAL A. Medicina Paliativa: Una nueva filosofía. Sociedad Española Dolor. 1995.

ROYES Albert, "La eutanasia y el suicidio médicamente asistido", en Psicooncología, Volumen 5, n 2-3, 2008. SEZZATINI, E. "Aspectos biojurídicos sobre la legalización de la eutanasia", en Labor hospitalaria: organización y pastoral de la salud, no 291,2009.

STEVENS, J. "La eutanasia es un hecho una actividad impune en Holanda: declaraciones del Doctor J. Stevens, en Cuadernos de bioética, vol. 4, n 14, 1993.

TAK, P. “La nueva Ley sobre eutanasia en Holanda, y sus precedentes”, en Revista penal, nº 12, 2003.

VEGA GUTIÉRREZ J., "La práctica de la eutanasia en Bélgica y la Pendiente resbaladiza”, en Cuadernos de Bioética, XVIII, 2007/1.

Trabalho enviado em 25 de setembro de 2014.

Aprovado em 25 de setembro de 2014. 